

\section{Return on Investment Initiative for Unleashing American Innovation}

This publication is available free of charge from: https://doi.org/10.6028/NIST.SP.1234

April 2019

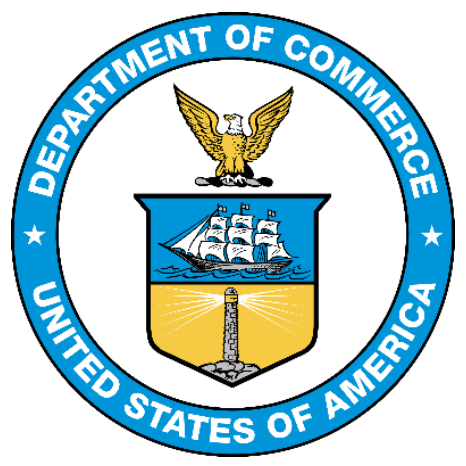

U.S. Department of Commerce

Wilbur L. Ross, Jr., Secretary

National Institute of Standards and Technology Walter Copan, NIST Director and Undersecretary of Commerce for Standards and Technology

\section{DISCLAIMER STATEMENT}

Any mention of companies or commercial products within this document is for information only. The contents of the Green Paper do not imply recommendation or endorsement by any part of the United States Government.

National Institute of Standards and Technology Special Publication 1234 Natl. Inst. Stand. Technol. Spec. Publ. 1234, 142 pages (April 2019) 


\section{PREFACE}

\section{MESSAGE FROM THE UNDER SECRETARY OF COMMERCE FOR STANDARDS AND TECHNOLOGY}

The Return on Investment (ROI) Initiative for Unleashing American Innovation is part of a national conversation that is designed to advance the Lab-to-Market cross agency priority (CAP) goal of the President's Management Agenda (PMA). ${ }^{1}$ The ROI Initiative's vision is to unleash American innovation into our economy. The objective of the Lab-to-Market CAP Goal is to maximize the transfer of Federal investments in science and technology into value for America in ways that will (a) meet current and future economic and national security needs in a rapidly shifting technology marketplace and enhance U.S. competitiveness globally, and (b) attract greater private sector investment to create innovative products, processes, and services, as well as new businesses and industries.

The PMA's Lab-to-Market CAP Goal is co-led by the U.S. Department of Commerce (DOC) via the National Institute of Standards and Technology (NIST) and the White House Office of Science and Technology Policy (OSTP). By statute, DOC is the lead Federal agency for technology transfer policy and practice. The Secretary of Commerce has delegated to NIST the stewardship for technology transfer policy, to promote and advance technology transfer, and to report on its progress to the Nation. Indeed, NIST's mission is to promote U.S. innovation and industrial competitiveness, serving also as the host organization for the Federal Laboratory Consortium for Technology Transfer (FLC) in convening America's Federal Laboratories. In these capacities, NIST is a partner with the Nation's research and development (R\&D) enterprise in seeking continued advancement of U.S. innovation.

As part of the ROI Initiative, NIST implemented an open, inclusive, and collaborative process to identify and assess options for supporting the ROI Initiative's overall goal and objectives. NIST's outreach efforts were designed to ensure that Federal R\&D, intellectual property, and technology transfer stakeholders had an opportunity to provide inputs to inform this Green Paper. NIST's outreach included a Request for Information (RFI) published in the Federal Register, four public meetings, a summit hosted by NIST, consultations with interagency working groups responsible for technology transfer issues, and multiple stakeholder engagement sessions. The Green Paper also integrates findings by NIST from an extensive review of prior reports and studies related to federally funded R\&D technology transfer policies and practices.

NIST released the draft of this Green Paper for public feedback in December 2018. This final version reflects feedback that NIST received on the draft paper as well as from the RFI and public meetings. Our long-term goal is to remove barriers to innovation, modernize partnering models, and create increased opportunities for returns to the American people from investment in R\&D.

1 President's Management Agenda (PMA). Modernizing the Federal Government for the 21st Century; released March 20, 2018. https://www.whitehouse.gov/wp-content/uploads/2018/o3/PresidentsManagement-Agenda.pdf 


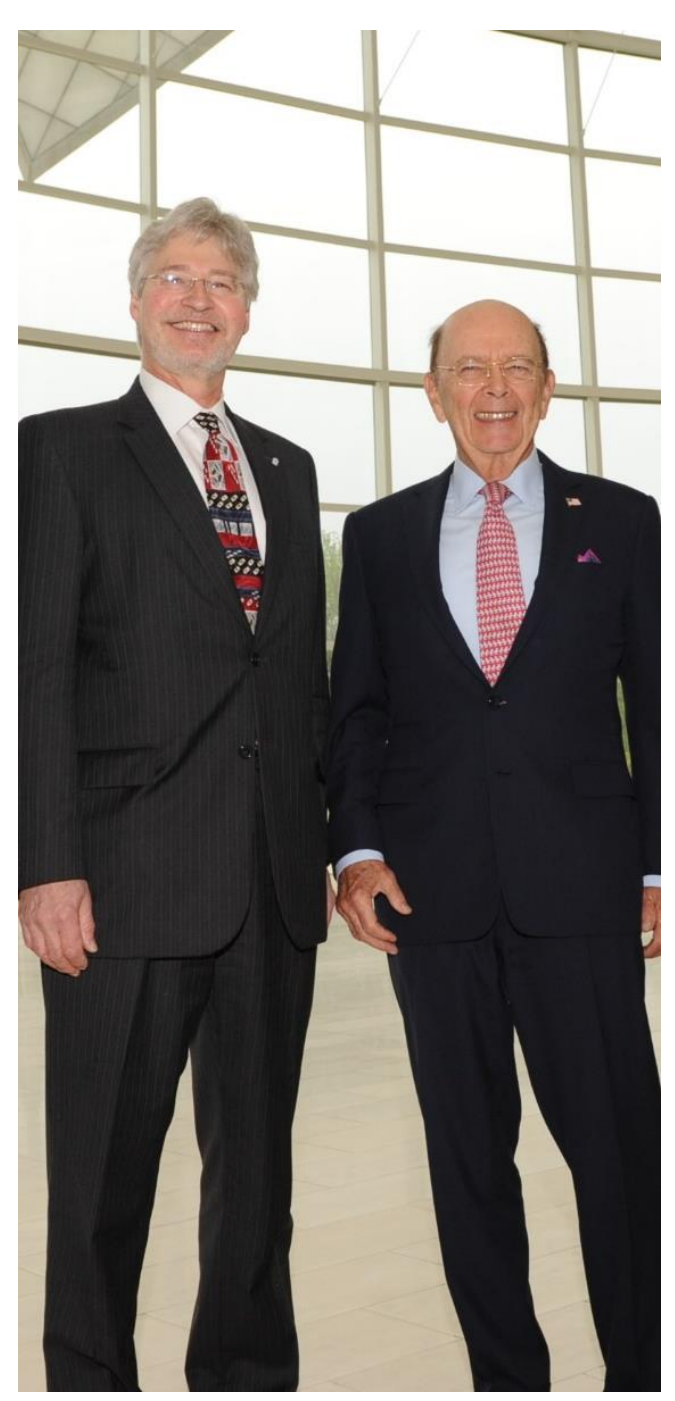

United States Secretary of Commerce Wilbur L. Ross (right) at the Unleashing American Innovation Symposium, held at U.S. Institute of Peace, Washington, D.C. on April 19, 2018 with Dr. Walter Copan.

The development of this Green Paper was a productive way to have a dialogue, and this Green Paper is a discussion document that is based on NIST's assessment of the feedback that NIST received from members of the U.S. stakeholder community on a wide range of topics, many of which fall within the primary or shared responsibilities of other agencies and departments (this Green Paper has not been reviewed and cleared through a formal interagency process, and thus the views and findings expressed in the Green Paper are those of NIST).

This Green Paper provides a summary of key stakeholder inputs and identifies findings by NIST that will help inform future deliberations, decision-making, and implementing actions by the relevant departments and agencies that could further enhance the U.S. innovation engine at the public-private interface. Moreover, the future deliberations, decision-making, and implementation of any of the topics discussed in the Green Paper would involve specific policy, legislative, and/or regulatory actions; such actions would need to be considered, decided upon, and implemented by the relevant departments and agencies via formal established government processes. These processes include appropriate interagency consultations, formal interagency review, and in many cases formal public comment.

I am grateful to all stakeholders, especially those who submitted oral and written comments to NIST in response to the RFI and at ROI public forums throughout 2018; to the outstanding, dedicated team at NIST and the Office of Science and Technology Policy; to all the U.S. Federal science and technology agencies represented in the National Science and Technology Council and its Lab-to-Market Subcommittee; and to the Science and Technology Policy Institute (STPI) for your many contributions thus far.

Thank you for your continuing engagement in helping to shape this critical national priority.

Sincerely,

Walter G. Copan, Ph.D.

Under Secretary of Commerce for Standards and Technology

Director, National Institute of Standards and Technology 


\section{EXECUTIVE SUMMARY}

The United States (U.S.) has led the world in innovation, research, and technology development since World War II, but that leadership is being challenged on a global scale. At risk is America's leadership in industries of the future such as artificial intelligence, quantum computing, and robotics. In combination with the rapid, foundational advances in technology, innovation has never been more critical to U.S. economic competitiveness and national security than it is today.

The President's Management Agenda (PMA), released March 20, 2018, lays out a long-term vision for modernizing the Federal Government for the 21st Century. ${ }^{2}$ The Return on Investment (ROI) Initiative directly supports the PMA and is designed to unleash American innovation. ROI refers here to the economic and national security return to the Nation based on the investment in Federal research and development (R\&D) by the American people.

The PMA's Lab-to-Market cross agency priority (CAP) Goal is co-led by the U.S. Department of Commerce (DOC) via the National Institute of Standards and Technology (NIST) and the White House Office of Science and Technology Policy (OSTP). By statute, DOC is the lead Federal agency for technology transfer policy and practice. The Secretary of Commerce has delegated to NIST the stewardship for technology transfer policy, to promote and advance technology transfer, and to report on its progress to the Nation. Indeed, NIST's mission is to promote U.S. innovation and industrial competitiveness, serving also as the host organization for the Federal Laboratory Consortium for Technology Transfer (FLC) in convening America's Federal Laboratories. In these capacities, NIST is a partner with the Nation's R\&D enterprise in seeking continued advancement of U.S. innovation.

The U.S. innovation system is substantially fueled by the discoveries and inventions arising from federally funded R\&D at the Nation's universities, research institutes, and Federal Laboratories. The Bayh-Dole and Stevenson-Wydler Acts3 were transformational for the U.S. when enacted in 1980, providing clarity of intellectual property ownership for the public good, and incentivizing the commercial development of inventions for U.S. economic impact. These landmark pieces of legislation, as well as their subsequent updates, have served America well.

The Bayh-Dole Act predominantly deals with ownership of inventions made with Federal funding. Specifically, it allows companies, nonprofits, and universities to retain title to federally funded R\&D inventions to facilitate their further development. Under the Stevenson-Wydler Act, each Federal agency that carries out and sponsors R\&D has been given the mandate, as part of its agency's mission, to form public-private collaborations, secure intellectual property rights, and to

2 Ibid.

335 U.S.C. § 200-209 and 15 U.S.C § 3710-3716, respectively 
contribute directly to U.S. innovation through technology transfer. Federal agencies are obligated to communicate the benefits of those inventions having potential economic value to the private sector, and to effectively transition them for use by American companies and entrepreneurs. With these legislative acts, the technology transfer profession was born-and the results for the U.S. economy have continued to grow ever since.

The competitive environment for the U.S. has changed dramatically since implementation of the Bayh-Dole and Stevenson-Wydler Acts and their amendments in subsequent technology transfer legislation. This legislative framework has been widely emulated around the world and further adapted. Technology transfer and its practices have advanced substantially as the pace of innovation continues to accelerate globally. Shorter product life cycles, disruptive business models, new partnering strategies, and globalized R\&D and supply chains are enabled by revolutionary advances in digital, communications, biological, materials, and quantum technologies.

As part of the ROI Initiative, this Green Paper summarizes stakeholder feedback that NIST received, expressing the critical need to modernize the U.S. system of technology transfer and innovation for the 21st Century. Although Federal technology transfer laws and activities have served the Nation well over nearly four decades and continue to support innovation, the U.S. is continuing to lose ground to competition.

The development of this Green Paper was a productive way to have a dialogue, and this Green Paper is a discussion document that is based on NIST's assessment of the feedback that NIST received from members of the U.S. stakeholder community on a wide range of topics, many of which fall within the primary or shared responsibilities of other agencies and departments (this Green Paper has not been reviewed and cleared through a formal interagency process, and thus the views and findings expressed in the Green Paper are those of NIST).

This Green Paper provides a summary of key stakeholder inputs and identifies findings by NIST that will help inform future deliberations, decision-making, and implementing actions by the relevant departments and agencies that could further enhance the U.S. innovation engine at the public-private interface. Moreover, the future deliberations, decision-making, and implementation of any of the topics discussed in the Green Paper would involve specific policy, legislative, and/or regulatory actions; such actions would need to be considered, decided upon, and implemented by the relevant departments and agencies via formal established government processes. These processes include appropriate interagency consultations, formal interagency review, and in many cases formal public comment.

U.S. economic competitiveness is strengthened by the ability of private sector companies to advance the new technologies resulting from basic R\&D, and to deliver the products and services that drive the Nation's economy forward. This ecosystem has allowed the U.S. to enjoy the economic benefits of advancing science and technology and has kept the Nation prosperous and strong. The partnership between Federal R\&D and the private sector has proven to be an effective 
model. In 2017 alone, the Federal Government invested approximately $\$ 150$ billion in R\&Dabout one-third at Federal Laboratories across the country and two-thirds at universities and private sector R\&D institutions. Federal R\&D funding represents about one-third of all U.S. R\&D spending.

Measures of technology transfer in the U.S. from 1996 to 2015 demonstrate over $\$ 1$ trillion in economic growth and millions of new jobs. Critical technologies such as life-saving drugs, vaccines, and medical devices, the internet, global positioning system or GPS, and countless other innovations underpinning every aspect of the American way of life are traceable to groundbreaking work at Federal Laboratories, universities receiving Federal funding, and private sector R\&D organizations. Removing impediments to effective technology transfer and collaboration will help accelerate economic value creation.

The PMA's Lab-to-Market (L2M) CAP Goal aims to improve the transfer of technology from federally funded R\&D to the private sector to promote U.S. economic growth and national security. The L2M CAP Goal is organized around the five strategies, which also serve as the organization for the chapters in this Green Paper. 4

1. Identify regulatory impediments and administrative improvements in Federal technology transfer policies and practices;

2. Increase engagement with private sector technology development experts and investors;

3. Build a more entrepreneurial R\&D workforce;

4. Support innovative tools and services for technology transfer; and

5. Improve understanding of global science and technology trends and benchmarks.

Each of the strategy chapters is organized to provide an introductory background, note the challenges, and explain the resulting findings from NIST based on the extensive stakeholder input process to streamline Federal technology transfer policies and practices and accelerate the transfer of technology to the private sector. The findings note the current barriers in policy, regulation, and statute that could be addressed through future legislative, regulatory, and/or policy changes to reduce government bureaucracy and cut red tape to accelerate innovation. A succinct summary of NIST's findings from the stakeholder engagement process is in the following table.

4 See CAP Goal 14 of the PMA, page 47-48, at https://www.whitehouse.gov/wpcontent/uploads/2018/03/Presidents-Management-Agenda.pdf 


\section{ROI Initiative - Summary of NIST's Findings Based on Input from Stakeholders5}

\begin{tabular}{|c|}
\hline $\begin{array}{l}\text { Strategy } 1 \\
\text { Identify regulatory impediments and administrative improvements in } \\
\text { Federal technology transfer policies and practices }\end{array}$ \\
\hline Government Use License: According to stakeholders, the scope of the "government use license" is not well defined \\
\hline $\begin{array}{l}\text { March-In Rights: According to stakeholders, the circumstances under which the government may appropriately exercise } \\
\text { march-in rights to license further development of an invention to achieve practical application are not clear }\end{array}$ \\
\hline $\begin{array}{l}\text { Preference for U.S. Manufacturing: According to stakeholders, existing statute supports the preference for U.S. } \\
\text { manufacturing but the process to obtain a waiver is confusing }\end{array}$ \\
\hline $\begin{array}{l}\text { Copyright of Software: According to stakeholders, the "Government Works" exception to copyright protection for software } \\
\text { products of Federal R\&D at Government-Owned, Government-Operated Laboratories constrains commercialization }\end{array}$ \\
\hline $\begin{array}{l}\text { Proprietary Information: According to stakeholders, an expanded protection period for proprietary information under a } \\
\text { Cooperative R\&D Agreement would encourage greater collaboration with Federal Laboratories }\end{array}$ \\
\hline $\begin{array}{l}\text { Strengthen Technology Transfer at Federal Laboratories: According to stakeholders, updates to policies and practices } \\
\text { under the Stevenson-Wydler Act could be simplified }\end{array}$ \\
\hline $\begin{array}{l}\text { Presumption of Government Rights to Employee Inventions: According to stakeholders, the process to determine a } \\
\text { present assignment of invention rights by Federal employees to the Federal Government is overly burdensome }\end{array}$ \\
\hline $\begin{array}{c}\text { Strategy } 2 \\
\text { Increase engagement with private sector technology development experts and investors }\end{array}$ \\
\hline $\begin{array}{l}\text { Streamlined Partnership Mechanisms: According to stakeholders, improved clarity and use of best practices government- } \\
\text { wide would streamline agreements and ensure greater transparency for R\&D partners }\end{array}$ \\
\hline $\begin{array}{l}\text { Expanded Partnership Mechanisms: According to stakeholders, private sector investment for translational R\&D and } \\
\text { technology maturation could be increased through expanded partnership agreements and nonprofit foundations }\end{array}$ \\
\hline $\begin{array}{l}\text { Technology Commercialization Incentives: According to stakeholders, recipients of Federal funding could benefit from a } \\
\text { limited use of R\&D funding awards to enable intellectual property protection }\end{array}$ \\
\hline
\end{tabular}

Technology Entrepreneurship Programs: According to stakeholders, expanding technology entrepreneurship programs at Federal R\&D agencies government-wide will help build a more entrepreneurial workforce

Managing Conflicts of Interest: According to stakeholders, current requirements for managing conflicts of interest pose challenges to build a more entrepreneurial R\&D workforce

\section{Strategy 4}

Support innovative tools and services for technology transfer

Federal IP Data Reporting System(s): According to stakeholders, a secure, modern platform is not available for reporting data on intellectual property resulting from Federal R\&D

Access to Federal Technologies, Knowledge, and Capabilities: According to stakeholders, a federated data portal is not available to easily access, use, and analyze information on federally funded technologies, knowledge, and capabilities that are available to the public

\section{Strategy 5}

Improve understanding of global science and technology trends and benchmarks

Benchmarking and Metrics: According to stakeholders, current metrics to capture, assess, and improve broad technology transfer outcomes and impacts based on federally funded R\&D and underpinning operational processes are inadequate

5 "Stakeholders" is defined as RFI respondents, participants in public forums and stakeholder events, interagency partners, those who provided feedback on the Draft Green Paper, and/or references to prior reports and studies listed in the Green Paper. See additional information on pages 19-20 under "Inputs to the Green Paper." Any use of "stakeholders" in the Green Paper is not intended to imply a consensus from all participants. 


\section{CONTENTS}

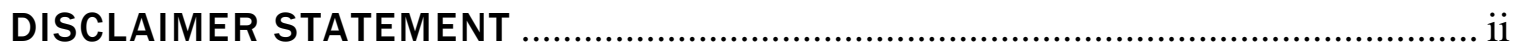

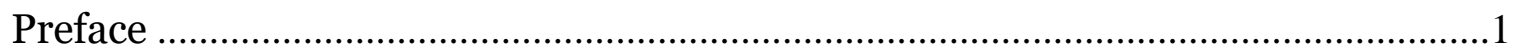

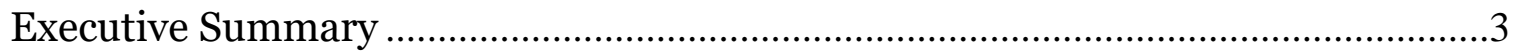

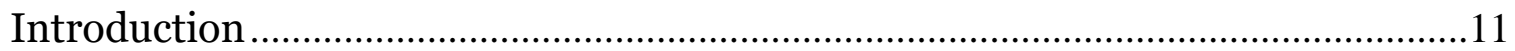

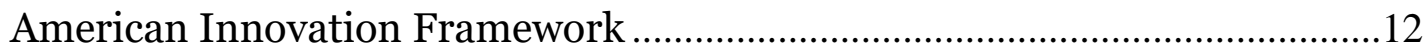

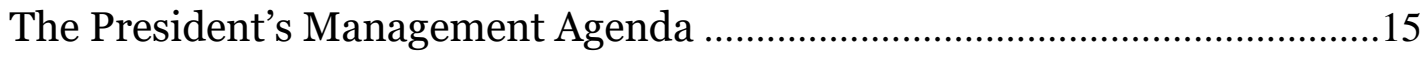

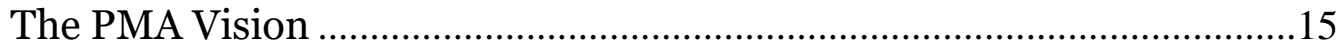

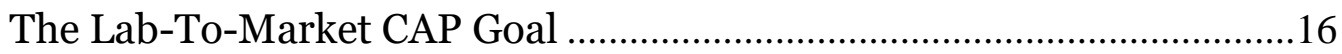

Return on Investment Initiative .................................................................

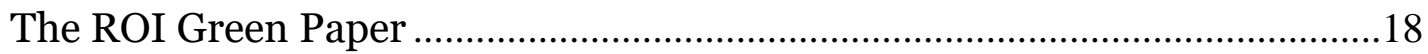

Inputs to the Green Paper ..........................................................................19

Definitions Used in the Green Paper ........................................................20

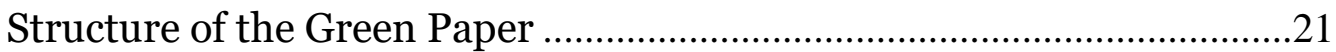

Next Steps from the Green Paper .............................................................22

Strategy 1. Identify Regulatory Impediments and Administrative Improvements in Federal Technology Transfer Policies and Practices ..........................................23

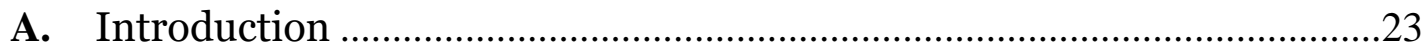

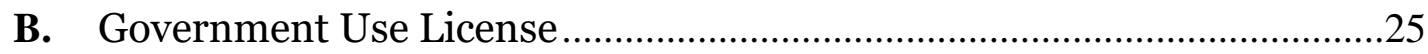

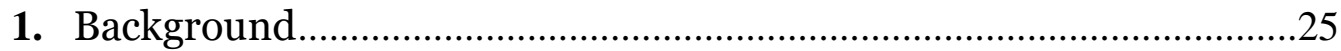

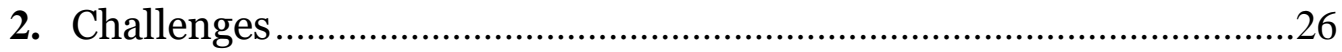

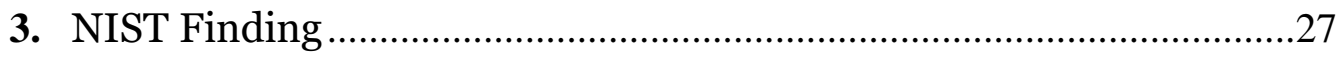

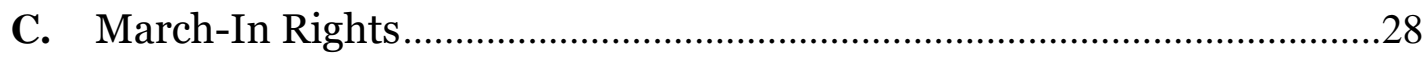

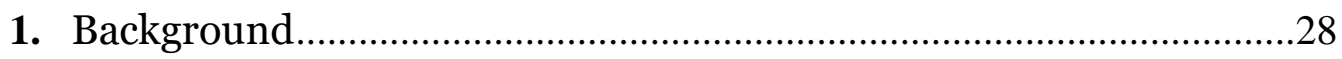

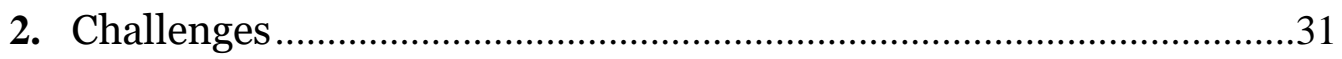

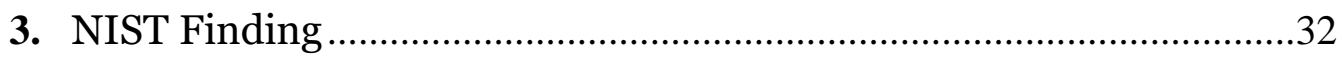

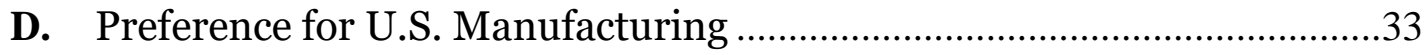

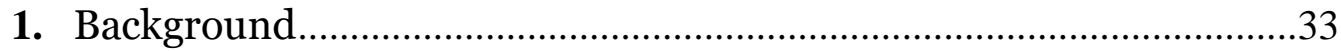

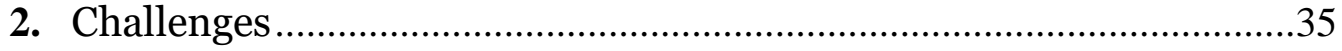

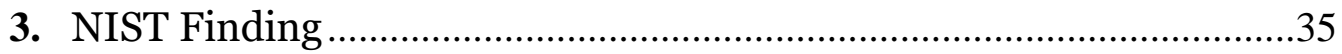

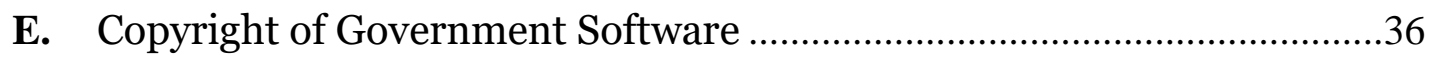

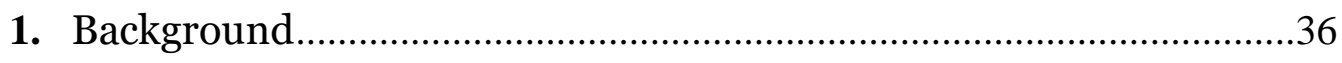

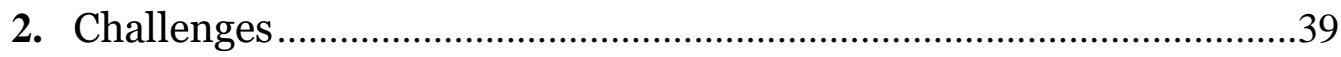

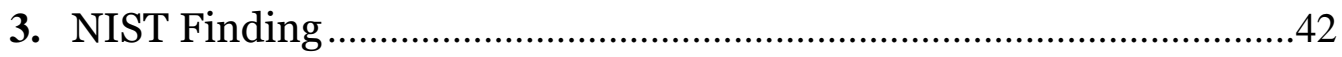

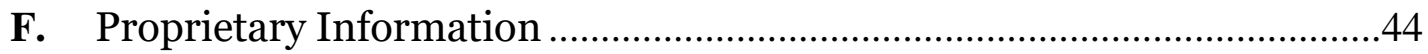

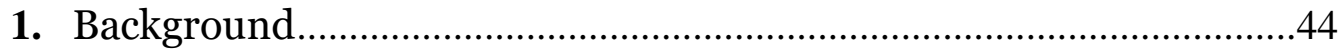




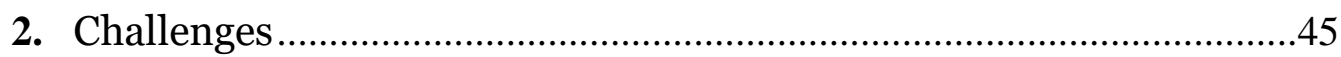

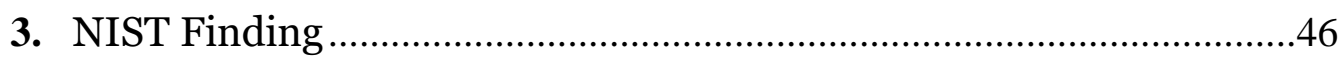

G. Strengthen Technology Transfer at Federal Laboratories ..........................47

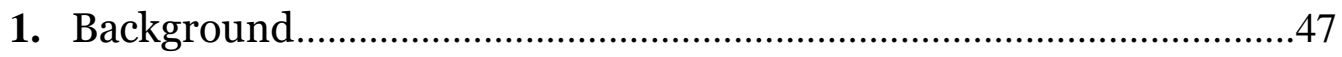

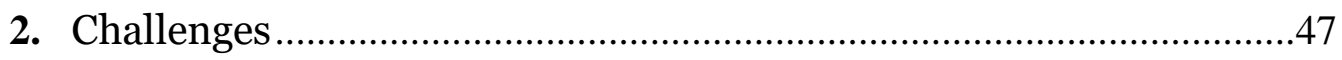

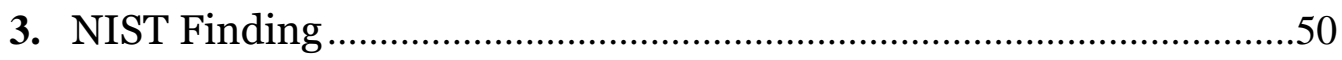

H. Presumption of Government Rights to Employee Inventions .................51

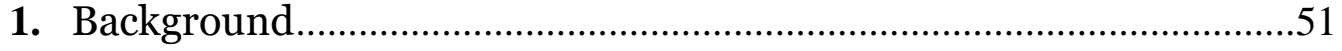

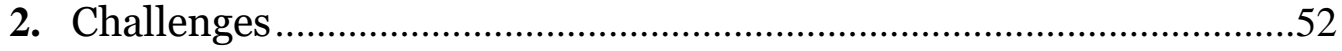

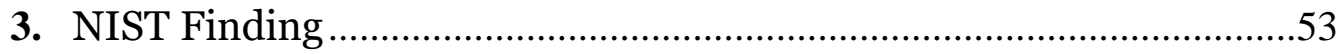

Strategy 2. Increase Engagement with Private Sector Technology Development Experts

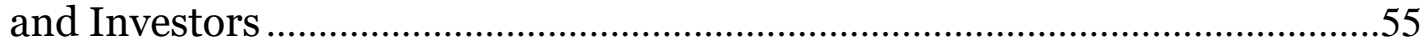

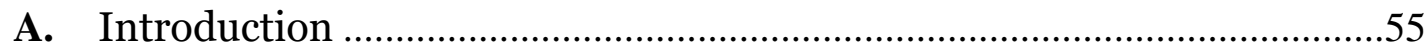

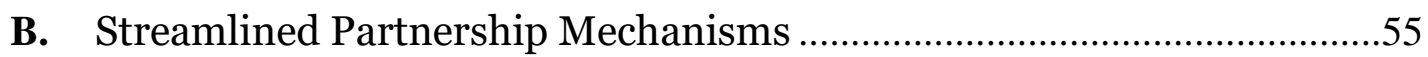

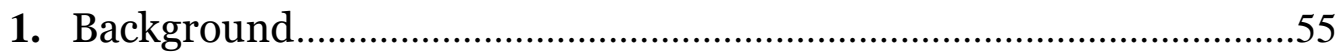

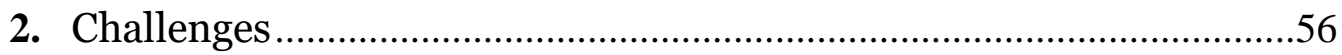

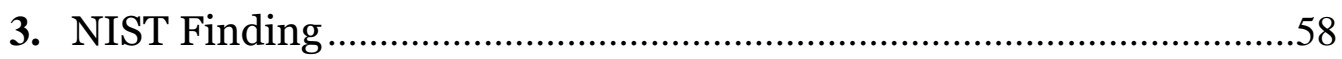

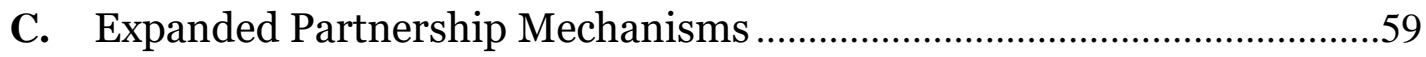

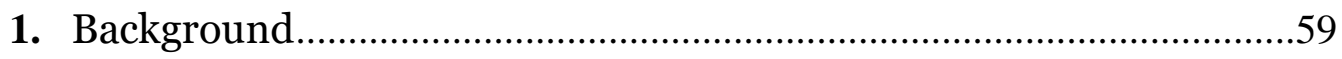

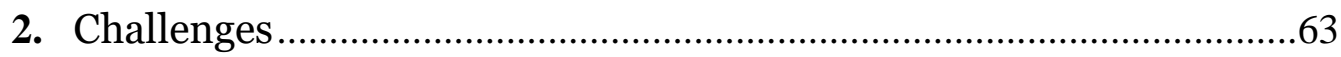

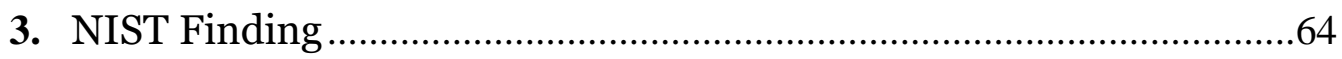

D. Technology Commercialization Incentives .............................................66

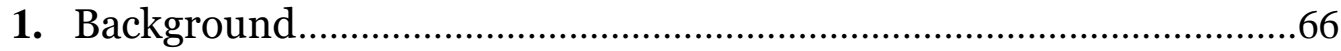

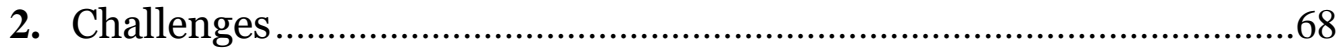

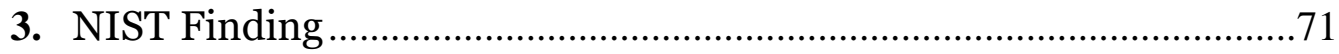

Strategy 3. Build a More Entrepreneurial R\&D Workforce .......................................73

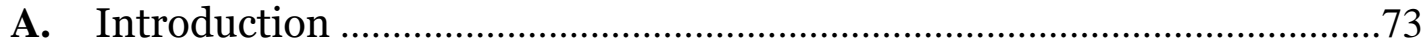

B. Technology Entrepreneurship Programs ………………..........................74

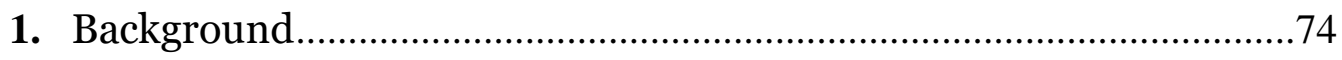

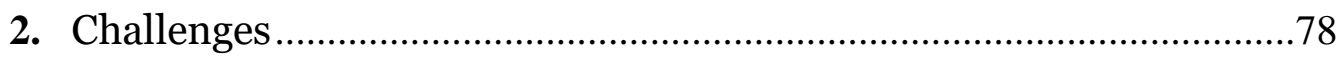

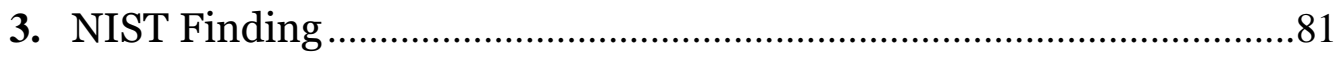

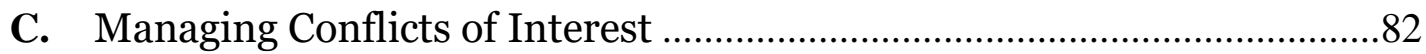

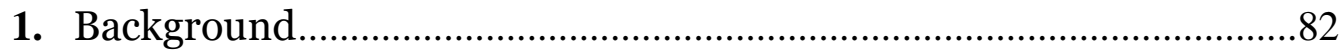

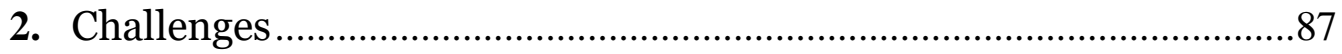

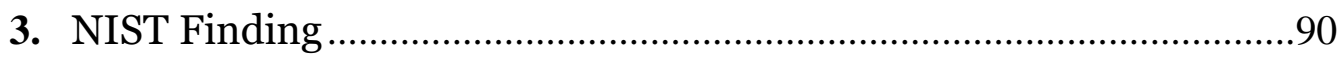

Strategy 4. Support Innovative Tools and Services for Technology Transfer ........93

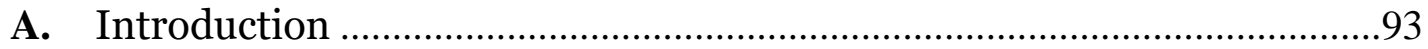




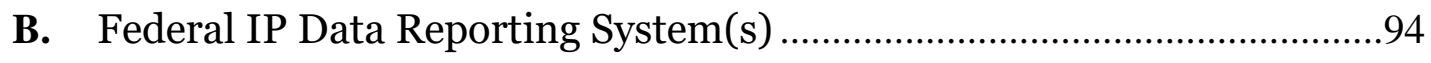

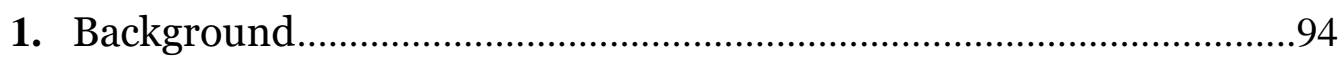

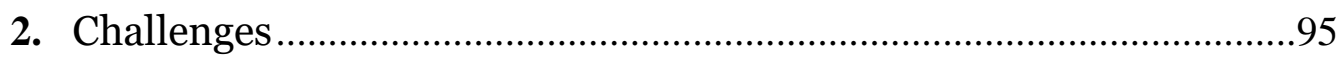

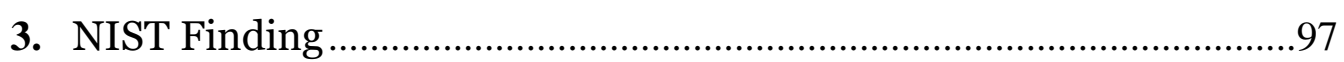

C. Access to Federal Technologies, Knowledge, and Capabilities .................98

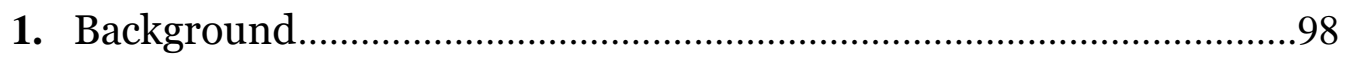

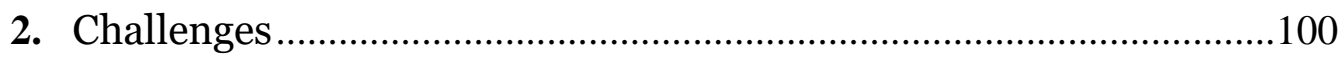

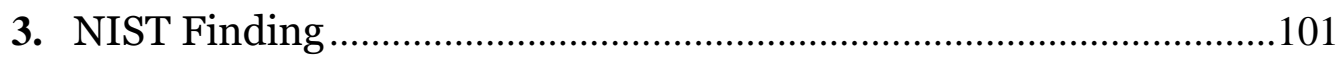

Strategy 5. Improve Understanding of Global Science and Technology Trends and

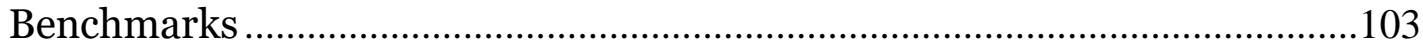

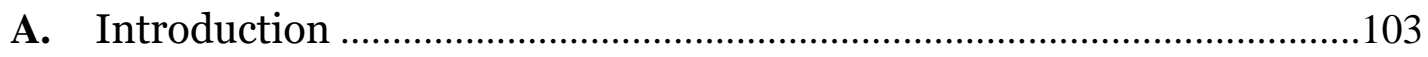

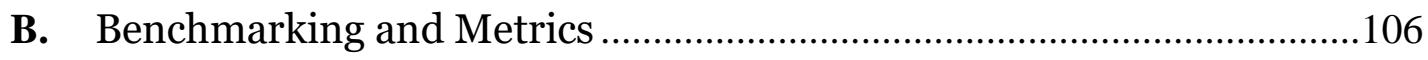

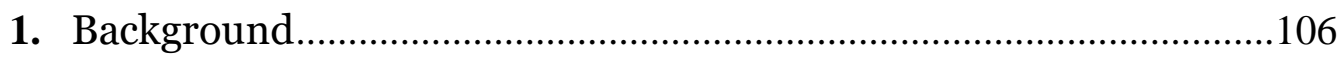

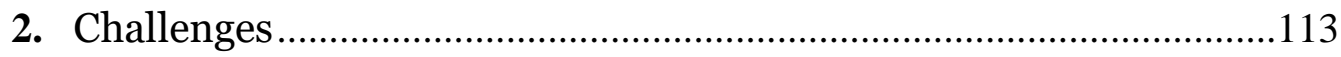

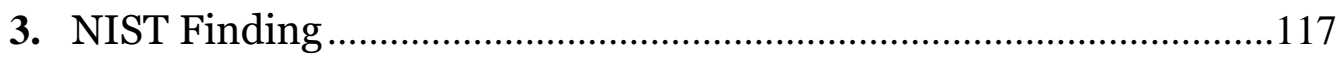

Summary and Conclusions ……………........................................................119

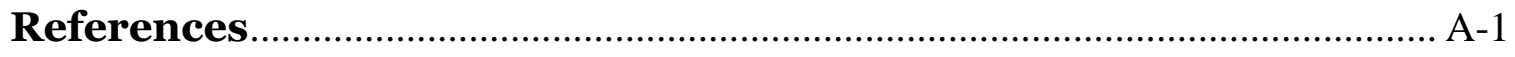

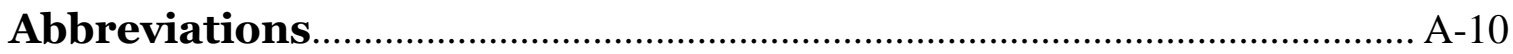

Appendix 1. Select Technology Transfer Mechanisms in Use by Federal Agencies

A-13

Appendix 2. Comparison of SPP, CRADA, and ACT Attributes ......................... A-14 
This page intentionally left blank 


\section{INTRODUCTION}

Since the 19th Century, American economic prosperity and national security have been based upon innovation-the process of invention and commercialization of new ideas into products and services in the marketplace. Victory in World War II was enabled by technological pre-eminence-radar, atomic weapons, gyroscopic bomb sights-and the production of goods on a mass scale.

The United States (U.S.) has led the world in innovation, research, and technology development since World War II, but that leadership is being challenged on a global scale. ${ }^{6}$ Unlike many of its global competitors, the U.S. economic system relies on the strength of private sector companies to produce the new technologies that result from research and development (R\&D) to deliver the goods and services that drive the Nation's economy forward. The partnership between Federal R\&D, through Federal Laboratories and Federal funding for R\&D at external organizations, and the private sector has proven to be an effective model.

The intimate connection between a competitive economy and national security is recognized at the highest level. In the Administration's National Security Strategy of the United States,7 President Donald J. Trump states: "Economic security is national security." Pillar II of the Strategy, "Promote American Prosperity," highlights the need to "Lead in Research, Technology, Invention, and Innovation” as a key goal and identifies four objectives:

- Understand worldwide science and technology trends;

- Attract and retain inventors and innovators;

- Leverage private capital and expertise to build and innovate; and

- Rapidly field inventions and innovations.

America's future competitiveness will be driven in part by our ability to capture the economic and national security benefits of emerging technologies. U.S. leadership in advanced technology development, however, is threatened by a number of converging factors including declining domestic manufacturing, the relocation of technology-intensive R\&D abroad, and the changing rules around intellectual property development. ${ }^{8}$ American leadership in industries of the future such as artificial intelligence, quantum computing, Internet-of-Things, advanced manufacturing,

6 National Science Foundation. 2018. "Science and Engineering Indicators 2018." https://nsf.gov/statistics/2018/nsb20181/digest/sections/introduction

7 The White House. 2017. National Security Strategy. Washington, D.C. December 2017.

8 Department of Defense. 2018. Assessing and Strengthening the Manufacturing and Defense Industrial Base and Supply Chain Resiliency of the United States. September 2018. https://defense.gov/StrengtheningDefenseIndustrialBase 
and robotics is at risk. Over the remainder of this century, these emerging industries will help redefine the battlefield of the future as well as how Americans live.

The Federal Government's continued investment in a broad range of fundamental and mission-oriented scientific and engineering R\&D is a crucial innovation driver for the Nation, supporting job creation, national security, economic growth, and global competitiveness. These investments, along with continued collaboration and partnerships with private sector businesses, are critical for the U.S. to remain the preeminent world leader of scientific discovery, invention, and globally competitive innovations. Reliable and predictable intellectual property rights are essential to incentivize innovation and encourage private sector investment in R\&D. 9 In combination with the rapid, foundational advances in technology, innovation has never been more critical to U.S. economic competitiveness and national security than it is today. The "American system" of technology transfer is a distinctive comparative advantage in the global marketplace, and America must extract all possible value from its significant investment of human and capital resources.

To ensure that American taxpayers are reaping the full benefit of R\&D investments and that the United States is strengthening its economic competitiveness and national security, the Federal Government is working to move the Nation to a new level of innovation performance that will increase the taxpayers return on their investment in federally funded R\&D. In this Green Paper, the National Institute of Standards and Technology (NIST) identifies critical areas that-through additional interagency deliberations and decision-making by the relevant departments and agencies (including through formal established government processes)-could potentially be addressed through future legislative, regulatory, and/or policy actions that would "unleash American innovation" by removing unwarranted systemic barriers and strengthening partnerships between government, industry, and academia.

\section{AMERICAN INNOVATION FRAMEWORK}

The American innovation ecosystem is the envy of the world, advancing science and technology and making the Nation prosperous and strong. The essence of the innovation process involves bringing inventions arising from Federal investment in science and technology (S\&T) to the private sector, attracting private capital to further invest in their development, and then launching and advancing them successfully in practical commercial use. Excellence in each stage

9 National Science and Technology Council, Committee on Technology, Subcommittee on Advanced Manufacturing. 2018. Strategy for American Leadership in Advanced Manufacturing. Washington, D.C. October 2018. 
of R\&D-discovery, translation, and innovation-is vital to America's global competitiveness. This is not a rigid process, but instead relies on the pioneering spirit at the heart of American identity.

In FY 2017, the Federal Government invested approximately $\$ 150$ billion in R\&D-about one-third at Federal Laboratories across the country and two-thirds at universities and private sector R\&D institutions. ${ }^{10}$ Federal R\&D funding represents about one-third of all U.S. R\&D spending. ${ }^{11}$ The Federal Government fills a crucial gap in the innovation process by funding $R \& D$ in areas of critical importance to the Nation. Often, these R\&D topics do not carry a strong enough immediate financial incentive for R\&D investment by the private industry sector. Federal $R \& D$ investment priorities adapt to changing national needs and Administration priorities, with the expectation that this investment will strengthen the Nation's innovation base and position the United States for unparalleled job growth, continued prosperity, and national security. ${ }^{12}$ For example, current Administration R\&D priorities include security; artificial intelligence (AI), quantum information sciences, and strategic computing; connectivity and autonomy; manufacturing; space exploration and commercialization; energy; medical innovation; and agriculture.

The discoveries that result from American R\&D efforts must be transferred from the laboratory to the marketplace through innovations that bring products and services to consumers more quickly. Protection of intellectual property rights is often necessary to achieve this transfer by establishing partnerships with industry for commercial adoption. The U.S. Constitution enshrined the critical importance of private rights in innovation as an enduring, foundational principle that would sustain and guide the Nation:

Congress shall have power...to promote the progress of science and useful arts, by securing for limited times to authors and inventors the exclusive right to their respective writings and discoveries. ${ }^{13}$

10 There are over 300 Federal Laboratories, including Government-Owned, Government-Operated (GOGO) Laboratories, Government-Owned, Contractor-Operated (GOCO) Laboratories, and Federally Funded Research and Development Centers (FFRDCs). For further information, see Analytical Perspectives, Budget of the United States Government, Fiscal Year 2019, Ch. 18, https://www.gpo.gov/ fdsys/pkg/BUDGET-2019-PER/pdf/BUDGET-2019-PER.pdf.

11 National Science Board. 2018. "Science and Engineering Indicators 2018."

12 Office of Management and Budget \& Office of Science and Technology Policy. 2018. "FY 2020 Administration R\&D Budget Priorities." Memorandum for the Heads of Executive Departments and Agencies. July 31, 2018.

13 Article I, Section 8 of the U.S. Constitution establishing the Legislative Branch. 
Since then, the Federal Government has provided the framework for technology transfer through several laws, executive orders, and regulations. ${ }^{14}$ Federal technology transfer laws and activities have served the Nation well over nearly four decades, and continue to support U.S. innovation. ${ }^{15}$ From 1996 to 2015, contributions to the U.S. economy from academic technology transfer alone included up to $\$ 1.3$ trillion in gross industrial product, \$591 billion in gross domestic product, and 4.3 million jobs. ${ }^{16}$ Critical technologies such as life-saving drugs, vaccines, and medical devices, the internet, global positioning system or GPS, and countless other innovations underpinning every aspect of the American way of life are traceable to groundbreaking work at Federal Laboratories and at federally funded universities and private sector R\&D organizations.

While substantial positive benefits continue to accrue from Federal R\&D investments, the United States can do better to resolve barriers that inhibit realizing the largest and broadest commercial, economic, and national security returns possible from these investments. There are significant challenges in effectively transferring the technology, knowledge, and capabilities resulting from Federal R\&D investments to the private sector. Potentially valuable technologies, created at taxpayer expense, can remain in laboratories due to systemic barriers that limit opportunities to move these innovations to the commercial marketplace. The NIST findings described in this Green Paper, which are based on input from multiple stakeholder sources (see "Inputs to the Green Paper" on pages 19-20), focus on potential ways to enhance the American innovation framework and maximize the return on investment to the American taxpayer.

14 The term "technology transfer" refers to the broad range of mechanisms used to transfer technology, knowledge, and capabilities resulting from federally funded R\&D to productive uses, and, where appropriate, commercialization.

15 For further information on relevant technology transfer legislation, see Federal Laboratory Consortium for Technology Transfer (FLC). 2013. FLC Technology Transfer Desk Reference, https://www.federallabs.org/media/publication-library/flc-technology-transfer-desk-reference; and FLC. §2013. The Green Book, https://www.federallabs.org/media/publication-library/federaltechnology-transfer-legislation-and-policy-the-green-book.

16 Estimates based on contributions of patent licensing activity; estimates do not include broad-based spillover benefits to the U.S. economy, see Association of University Technology Managers (AUTM). 2016. Driving the Innovation Economy, https://www.autm.net/AUTMMain/media/SurveyReportsPDF/AUTM-FY2016-Infographic-WEB.pdf. 


\section{THE PRESIDENT'S MANAGEMENT AGENDA}

The President's Management Agenda (PMA), released March 20, 2018, lays out a long-term vision for modernizing the Federal Government for the 21st Century in key areas that will improve the ability of Federal agencies to deliver mission outcomes, provide excellent service, and effectively steward taxpayer dollars on behalf of the American people. ${ }^{17}$ This Green Paper provides a framework for advancing the vision put forth in the PMA through key areas that have been identified by NIST based on substantial input from stakeholders. The NIST findings will help inform future interagency deliberations and decision-making that can deliver real improvements in how Federal Laboratories and federally funded universities and private sector $\mathrm{R} \& \mathrm{D}$ organizations support economic development through research and innovation.

\section{THE PMA VISION}

The PMA's vision for reform is to enable the Federal Government to adapt to changing needs over time, with a focus on pursuing deep-seated transformation rather than short-term fixes. The reform agenda identifies five root cause challenges facing the Federal Government to meet the needs of the 21st Century: 1) accumulated regulatory burden, 2) structural issues, 3) decisionmaking and processes, 4) leadership and culture, and 5) capabilities and competencies. To get traction on these complex and interconnected challenges, the PMA recognizes the need for broader, system-level thinking across agencies and functional disciplines for a whole-ofgovernment effort to tackle barriers to change.

The PMA established Cross-Agency Priority (CAP) Goals targeting 14 specific areas in which multiple agencies must collaborate to effect change and report progress in a manner that the public can easily track. Each CAP Goal is expected to move from vision to action by acknowledging shortcomings, setting a modern vision, and delivering on concrete goals that adapt Federal programs, capabilities, and the Federal workforce to efficiently, effectively, and, through an accountable approach, meet mission demands and public expectations. CAP Goals report quarterly, providing the public an open and transparent assessment of the progress being made on milestones and key performance indicators. ${ }^{18}$

17 The White House. 2018. President's Management Agenda. https://www.whitehouse.gov/wpcontent/uploads/2018/03/The-President\%E2\%80\%99s-Management-Agenda.pdf.

18 Quarterly CAP Goal reports publish in March, June, September, and December at https://www.performance.gov/ 


\section{THE LAB-TO-MARKET CAP GOAL}

The Lab-to-Market (L2M) CAP Goal aims to improve the transfer of technology from federally funded R\&D to the private sector to promote U.S. economic growth and national security. The L2M CAP Goal is designed to enable the United States to adapt to a rapidly changing global innovation landscape by:

- Improving the transition of federally funded innovations from the laboratory to the marketplace by reducing the administrative and regulatory burdens for technology transfer and increasing private sector investment in later-stage R\&D;

- Developing and implementing more effective partnering models and technology transfer mechanisms for Federal agencies; and

- Enhancing the effectiveness of technology transfer by improving the methods for evaluating the investment returns and economic and national security impacts of federally funded R\&D and using that information to focus efforts on successful approaches.

The L2M CAP Goal charges agencies to develop and implement stakeholder-informed action plans, which may include improved Federal practices and policies, regulatory reform, and legislative proposals; increased interactions with private sector experts; identification, sharing, and adoption of best practices for technology transfer; and increased transfer of federally funded innovations from laboratory to market.

The L2M CAP Goal is co-led by the U.S. Department of Commerce (DOC) via NIST and by the White House Office of Science and Technology Policy (OSTP). By statute, DOC is the lead Federal agency for technology transfer policy and practice. The Secretary of Commerce has delegated to NIST the stewardship for technology transfer policy, to promote and advance technology transfer, and to report on its progress to the Nation. ${ }^{19}$ Indeed, NIST's mission is to promote U.S. innovation and industrial competitiveness, serving also as the host organization for the Federal Laboratory Consortium for Technology Transfer (FLC) in convening America's Federal Laboratories. In these capacities, NIST is a partner with the Nation's R\&D enterprise in seeking continued advancement of U.S. innovation.

Other agencies participating in the L2M Cap Goal include the Office of Management and Budget (OMB), the Departments of Agriculture, Defense, Education, Energy, Health and Human Services, Homeland Security, Interior, Transportation, and Veterans Affairs, the Environmental

19 Statutory annual reporting requirements include (i) discussion of technology transfer best practices and effective approaches in the licensing and transfer of technology in the context of agency missions, and (ii) agency plans for securing intellectual property rights in laboratory innovations with commercial promise (see 15 U.S.C. § $3710 \mathrm{f}$ and g). 
Protection Agency, the National Aeronautics and Space Administration (NASA), the National Science Foundation (NSF), and the Small Business Administration (SBA).

The National Science and Technology Council (NSTC), through its Lab-to-Market Subcommittee (L2M SC), is working to coordinate, review, and implement interagency priorities related to the L2M CAP Goal. Other supporting interagency groups include the Interagency Working Group on Technology Transfer (IAWGTT), the Interagency Working Group on BayhDole (IAWGBD), the FLC, the Small Business Innovation Research (SBIR) Program Managers Working Group, and the Innovation $\operatorname{Corps}^{\mathrm{TM}}\left(\mathrm{I}-\mathrm{Corps}^{\mathrm{TM}}\right)$ Community of Practice. ${ }^{20}$

\section{RETURN ON INVESTMENT INITIATIVE}

On April 19, 2018, NIST, in coordination with OSTP, launched the Return on Investment (ROI) Initiative to advance the PMA and its L2M CAP Goal. The ROI Initiative was formally announced at the Unleashing American Innovation Symposium, ${ }^{21}$ in which leaders from across government, industry, and academia exchanged views on current obstacles, best practices, and potential solutions to address systemic barriers to catalyze the full potential of American innovation (Figure 1).

The ROI Initiative's vision is to "unleash American innovation" into our economy and its goal is to "maximize the transfer of Federal investments in science and technology into value for America in ways that will (a) meet current and future economic and national security needs in a rapidly shifting technology marketplace and enhance U.S. competitiveness globally, and (b) attract greater private sector investment to create innovative products, processes, and services, as well as new businesses and industries."

The objectives of the ROI Initiative are to "assess and, where appropriate, streamline and accelerate the transfer of federally funded technology by (a) identifying critically needed improvements to Federal technology transfer policies, practices, and efforts; and (b) seeking broad input from Federal R\&D, intellectual property (IP), and technology transfer stakeholders.”

20 For further on the L2M CAP Goal supporting organizations, see NIST. Lab to Market, https://www.nist.gov/tpo/lab-market.

21 National Institute of Standards and Technology in cooperation with the Office of Science and Technology Policy. 2018. "Unleashing American Innovation Symposium.”

https://www.nist.gov/tpo/return-investment-roi-initiative/unleashing-american-innovationsymposium. 
As part of the ROI Initiative, NIST implemented an open, inclusive, and collaborative process through which NIST would identify and assess options for supporting the ROI Initiative's objectives. This Green Paper describes what NIST found through careful consideration of stakeholder input to reduce or remove barriers and facilitate accelerated technology transfer in ways that could improve the return on federally funded R\&D investment as well as further the missions of Federal agencies.

As a Green Paper, this document provides a summary of key stakeholder inputs and identifies NIST findings that will help inform future deliberations, decision-making and implementing actions that could further enhance the U.S. innovation engine at the public-private interface. While development of this Green Paper was a productive way to have a dialogue, implementation of any of the NIST findings that would require specific policy, legislative, and/or regulatory actions must be considered, decided upon, and implemented by the relevant departments and agencies, including via formal established government processes. These processes include appropriate interagency review and in many cases formal public comment.

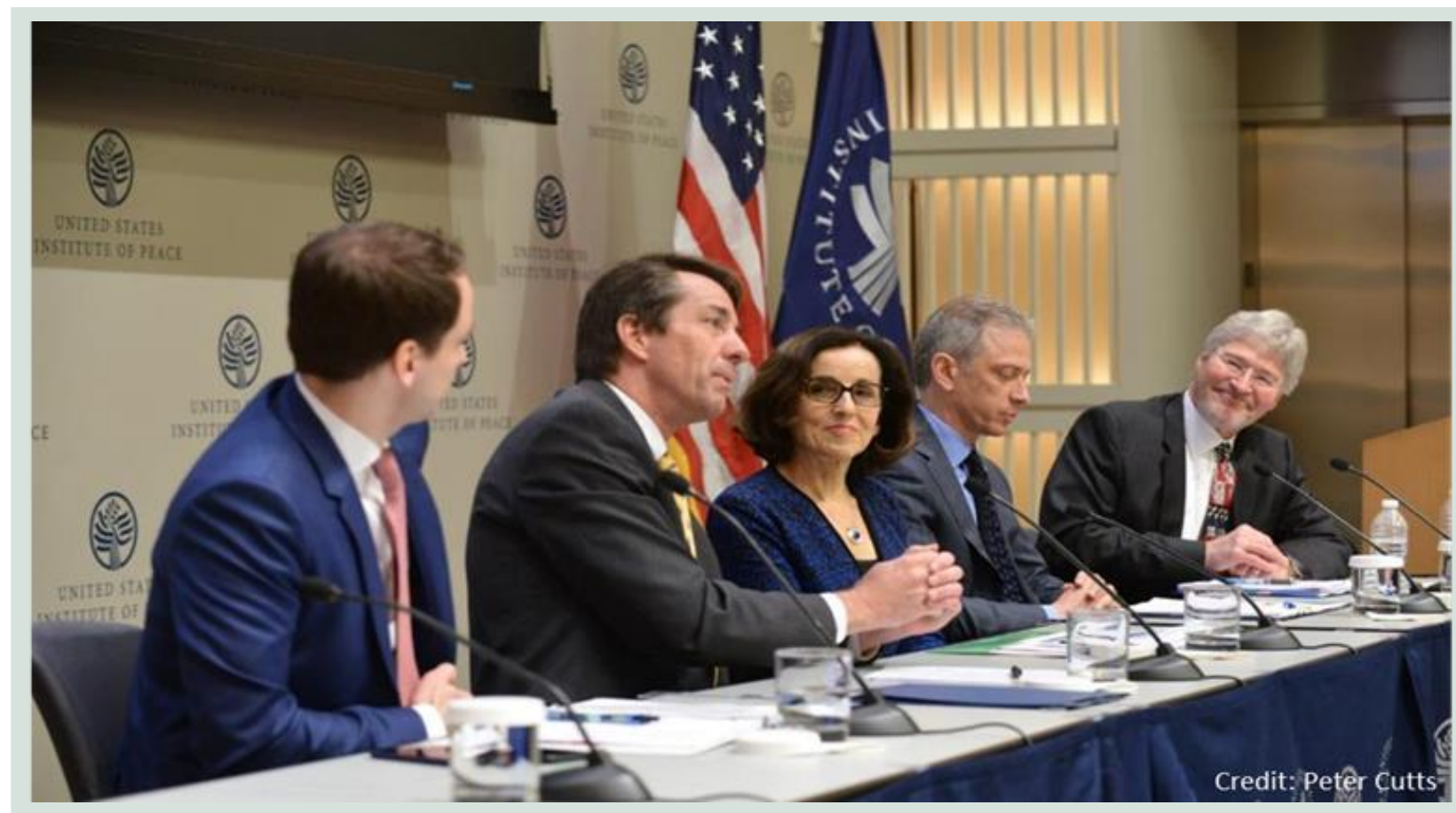

Figure 1. Federal panelists at the Unleashing American Innovation Symposium, held at U.S. Institute of Peace, Washington, D.C. on April 19, 2018.

Shown: Michael Kratsios, Deputy Assistant to the President and Deputy U.S. Chief Technology Officer; Dr. Christopher Austin, Director, National Center for Advancing Translational Sciences, National Institutes of Health; Dr. France Córdova, Director, National Science Foundation; Andrei Iancu, Under Secretary of Commerce for Intellectual Property, and Director, United States Patent and Trademark Office; and Dr. Walter Copan, Under Secretary of Commerce for Standards and Technology, and Director, National Institute of Standards and Technology. 


\section{INPUTS TO THE GREEN PAPER}

NIST engaged in several outreach efforts to ensure that Federal R\&D, intellectual property, and technology transfer stakeholders had an opportunity to provide inputs to inform this Green Paper. This included a Request for Information (RFI) that NIST published in the Federal Register, ${ }^{22}$ four public meetings, a summit hosted by NIST, extensive consultations with interagency working groups responsible for technology transfer issues, and multiple stakeholder engagement sessions:

- The RFI requested responses on topics related to Federal technology transfer principles and practices, challenges, and solutions to improve the transfer of technology, knowledge, and capabilities resulting from Federal R\&D investments. ${ }^{23}$

- Four public meetings were held to gather stakeholder feedback and comments: San Jose, CA (May 17, 2018); Denver, CO (May 21, 2018); Chicago, IL (May 31, 2018); and Gaithersburg, MD (June 14, 2018).

- The Maryland Technology Transfer Summit, held on April 20, 2018, was organized by the Maryland Department of Commerce and hosted by NIST. The event included Federal and State policy makers, industry leaders, technology managers, and universities and research institutes, among others. ${ }^{24}$

- Agency stakeholder groups included the Interagency Working Group for Technology Transfer, the National Science and Technology Council's Lab-to-Market Subcommittee, and the Federal Laboratory Consortium's Executive Board.

- $\quad$ NIST formed a Subcommittee on Technology Transfer under its Visiting Committee on Advanced Technology (VCAT). ${ }^{25}$ The VCAT, comprised of high-level executives of technology companies and academic leaders, was briefed on the ROI Initiative at each

2283 FR 19052. "Request for Information Regarding Federal Technology Transfer Authorities and Processes." Federal Register: The Daily Journal of the United States Government, May 1, 2018. https://www.federalregister.gov/documents/2018/05/01/2018-09182/request-for-informationregarding-federal-technology-transfer-authorities-and-processes.

23 Selected RFI responses have been cited throughout the document; the full collection of RFI responses and public forum transcripts is available at https://www.nist.gov/tpo/return-investment-roiinitiative/roi-sources-information

24 Maryland Department of Commerce and National Institute of Standards and Technology. "2018 Maryland Technology Transfer Summit.” https://www.nist.gov/news-events/events/2018/o4/2018maryland-technology-transfer-summit.

25 See 15 U.S.C. $§ 278$. Visiting Committee on Advanced Technology. 
of its three meetings in 2018. This Subcommittee provided specific feedback on the draft Green Paper that was addressed in the final paper. ${ }^{26}$

- $\quad$ NIST hosted multiple stakeholder engagement sessions. ${ }^{27}$

In addition, this Green Paper integrates NIST findings from an extensive review of prior reports and studies related to federally funded $R \& D$ technology transfer policies and practices (refer to References).

Following the initial input, NIST released a draft version of the Green Paper on December 6, 2018. This draft communicated and presented an organized set of ideas to further the dialogue and examine potential benefits and improvements. NIST provided a feedback period for public input through February 5, 2019. This final version of the Green Paper further refines the ideas based on that feedback and identifies NIST findings that can help to inform future deliberations, decision-making, and implementation actions by the relevant departments and agencies that have primary or shared responsibilities in the relevant program areas.

\section{DEFINITIONS USED IN THE GREEN PAPER}

In this Green Paper, ROI is not intended to be defined in classic economic terms. Instead, ROI as used here takes a broad approach that emphasizes the underlying social and public mission inherent in the development of Federal research into products and services benefiting American taxpayers. The "return" is interpreted to encompass a wide variety of benefits of technology transfer, both tangible and intangible to the investor, namely American citizens. It should not be viewed in the narrow context of revenue generation, but rather as contributions to broader economic prosperity, national security, and societal impact. The "return" is to the American society as a whole in accordance with each agency's unique statutory mission. "Investment" refers to federally funded R\&D both performed by the government (intramural) and by universities and the private sector (extramural).

26 At its February 2019 meeting, the VCAT commended NIST's efforts "to develop a roadmap for increasing the outcomes from the Federal Government's investment in research and development." https://www.nist.gov/document/finalsubcommitteeroireportpdf.

27 Including the Association of University Technology Managers, the Licensing Executives Society, the Council on Government Relations, the Council on Competitiveness (Technology Leadership and Strategy Initiative), the State Science and Technology Institute, FLC, the Association of Public and Land Grant Universities (Commission on Innovation, Competitiveness, and Economic Prosperity), the Association of American Universities (Council on Federal Relations), and the American Chemical Society (Chief Technology Officers Summit). 
In the context of Federal activities, technology transfer often refers to the movement of knowledge and results-such as products, techniques, tools, data, and inventions-from intramural Federal R\&D out of laboratories and into practical application. ${ }^{28}$ Given that about twothirds of Federal R\&D expenditures support research by non-Federal scientists and engineers, technology transfer, for the purposes of this Green Paper, also encompasses the activities of these extramural partners. In addition, throughout this Green Paper, "the process by which existing knowledge, facilities, or capabilities developed under Federal R\&D funding are used to fulfill public and private need" is referred to as technology transfer. ${ }^{29}$

\section{STRUCTURE OF THE GREEN PAPER}

The L2M CAP Goal is executed through five strategies that also form the foundation for how this Green Paper is organized:

1. Identify regulatory impediments and administrative improvements in Federal technology transfer policies and practices;

2. Increase engagement with private sector technology development experts and investors;

3. Build a more entrepreneurial R\&D workforce;

4. Support innovative tools and services for technology transfer; and

5. Improve understanding of global science and technology trends and benchmarks.

Each chapter in this Green Paper provides an introductory background, notes the challenges, and explains NIST's findings for streamlining and accelerating Federal technology transfer policies and practices. The final chapter of the Green Paper summarizes the NIST findings that are based on the input that NIST received from technology transfer stakeholders and thatsubject to further interagency deliberations, decision-making, and implementation actionscould potentially unleash American innovation and provide even greater return on investment to the American taxpayer.

28 NAS. 1997. Enabling America: Assessing the Role of Rehabilitation Science and Engineering. Washington, D.C.: National Academy Press. https://www.nap.edu/read/5799/chapter/1

29 Federal Laboratory Consortium for Technology Transfer (FLC). 2013. FLC Technology Transfer Desk Reference: A Comprehensive Introduction to Technology Transfer. Cherry Hill: Federal Laboratory Consortium for Technology Transfer. 


\section{NEXT STEPS FROM THE GREEN PAPER}

Implementation of any of the NIST findings in this Green Paper that would require specific policy, legislative, and/or regulatory actions must follow established government processes and would require further deliberations, decision-making, and implementation actions by the relevant departments and agencies that have primary or shared responsibilities in the respective program areas. These processes include appropriate interagency review and in many cases formal public comment. The typical process to advance regulatory and legislative proposals are briefly described in the Green Paper. ${ }^{30}$

Subject to future interagency deliberations and decision-making, certain actions to address NIST findings in the Green Paper could potentially be undertaken through the Lab-to-Market CAP Goal as milestones under specific CAP Goal strategy areas. Any such CAP Goal milestones would be developed and reviewed by the NSTC Lab-to-Market Subcommittee, approved by the CAP Goal co-leads, and tracked via the PMA website. ${ }^{31}$

$3^{30}$ See call out boxes in Strategy 1, Sections E and G.

${ }^{31}$ The PMA website can be accessed at: https://www.performance.gov/CAP/CAP_goal_14.html 


\section{STRATEGY 1. IDENTIFY REGULATORY IMPEDIMENTS AND ADMINISTRATIVE IMPROVEMENTS IN FEDERAL TECHNOLOGY TRANSFER POLICIES AND PRACTICES}

The first of the five strategies of the L2M CAP Goal is focused on identifying and reducing regulatory impediments and administrative barriers in Federal technology transfer policies and practices..$^{32}$ The intent of the strategy is to make it easier for industry to work with Federal Laboratories and access federally funded R\&D by removing both real and perceived barriers.

The ownership and transfer of federally funded science and technology developed at government institutions, universities, and corporations is governed by a series of laws and associated regulations and policy that originally date back to the $1980 \mathrm{os}$. While the basic structure is still strong due to inherent flexibilities, the R\&D environment has changed dramatically. Federal agencies and their laboratories are responsible for managing intellectual property and research partnerships independently based on the overall framework, thereby facilitating the transfer of technology through a distributed approach. The distributed approach allows Federal agencies to align their technology transfer efforts with the mission focus of their R\&D, but this mission-based variability between agencies makes it more difficult to identify and address systemic barriers without stifling creativity.

This chapter describes NIST's findings related to the first L2M CAP Goal strategy to address barriers that stakeholders have indicated slow or prevent technology transfer. While the BayhDole Act and Stevenson-Wydler Act provide essential authorities that facilitate the transfer and translation of federally funded R\&D to innovative products, processes, and services for the American people, there are numerous provisions that stakeholders indicated would benefit from clarification. A common concern noted throughout the stakeholder responses are the difficulties in understanding and accessing operations across agency technology transfer policies and practice because of differing authorities between agencies as well as differing interpretations of shared legislation guiding technology transfer efforts.

\section{A. INTRODUCTION}

In the early 1980 , Congress passed the first two of a series of laws that are designed to enable more widespread development of federally funded inventions: the Stevenson-Wydler Technology

32 PMA. 2018. "Improve Transfer of Federally-Funded Technologies from Lab-to-Market." Last updated December 18, 2018. https://www.performance.gov/CAP/CAP_goal_14.html 
Innovation Act of 1980 (P.L. 96-480)33 and the Bayh-Dole Act of 1980 (P.L. 96-517).34 StevensonWydler Act, as amended, governs how Federal Laboratories transfer technology to non-Federal entities, and enables Federal entities to provide access to Federal Laboratory assets (both researchers and facilities) to outside organizations through research partnerships and other means. 35 These laws require each laboratory with 200 or more technical staff to have an office dedicated to technology transfer, ${ }^{6}$ mandate that technology transfer be a responsibility of all science and engineering professionals consistent with their mission responsibilities, 37 and establish a principle of royalty sharing for Federal inventors. ${ }^{8}$ Congress also encouraged access to government researcher expertise and laboratory facilities by establishing a mechanism called a Cooperative Research and Development Agreement (CRADA), which can be used to form publicprivate partnerships with other Federal agencies, State or local governments, industrial organizations, and nonprofit organizations including universities. 39 To encourage commercial development of products developed under a CRADA, the CRADA partners receive preferential rights to license intellectual property developed under the partnership. 40

The Bayh-Dole Act established uniform rules that generally allow companies, nonprofits, and universities to retain title to federally funded research inventions in order to facilitate their further development. ${ }^{41}$ This right is limited to patentable inventions that arise from federally funded research and is subject to a few limitations to protect U.S. taxpayer investment, namely U.S. manufacturing preference, government use licenses, and march-in rights to ensure commercialization. ${ }^{2}$ Through this law and amendments, Congress also incentivized the

33 P.L. 96-480, codified at 15 U.S.C. $\S \S 3701-15$.

34 P.L. 96-517, codified at 35 U.S.C. $§ \S ~ 201-14$, Also known as the University and Small Business Patent Procedures Act of 1980.

35 Trademark Clarification Act of 1984 (P.L. 98-620); Federal Technology Transfer Act of 1986 (P.L. $99-$ 502); National Competitiveness Technology Transfer Act of 1989 (P.L. 101-189); National Technology Transfer and Advancement Act of 1995 (P.L. 104-113); Technology Transfer Commercialization Act of 2000 (P.L. 106-404)

3615 U.S.C. $§ 3710($ b) Establishment of Research and Technology Applications Offices

3715 U.S.C. $\$ 3710(\mathrm{a})(2)$

3815 U.S.C. $§ 3710 c$ - Distribution of royalties received by Federal Agencies

3915 U.S.C. $\S 3710 a-$ Cooperative research and development agreements

4015 U.S.C. $\S 3710 a(b)(1)$

4135 U.S.C. $§ 202-$ Disposition of rights.

4235 U.S.C. $§ 204$ - Preference for United States Industry, 15 U.S.C. $§ 3710 a(b)(1)(A)$ government use license, 35 U.S.C. § 203 - March-in rights 
commercialization of federally funded inventions by requiring that the inventor get a share of the royalties. 43 The Bayh-Dole Act and amendments also allow Federal agencies and GovernmentOwned, Government-Operated (GOGO) Laboratories to issue exclusive licenses to governmentheld patents for the full life of the patent. 44 They also allow the contractors who operate Government-Owned, Contractor-Operated (GOCO) Laboratories to hold title and make commercialization decisions on patents of GOCO Laboratory-developed inventions.

The Economist Technology Quarterly called the Bayh-Dole Act, "[p]ossibly the most inspired piece of legislation to be enacted in America over the past half century...this unlocked all the inventions and discoveries that had been made in laboratories throughout the United States with the help of taxpayers' money."45

Private investment, practical application of innovations, and economic growth depend on a strong system of IP protection. The Leahy-Smith America Invents Act46 (AIA) was enacted in 2011 to modernize the U.S. patent system and, among other things, better align it with other systems by instituting a first-inventor-to-file system rather than the former first-to-invent system. Several RFI comments were received about the AIA and its implementation by the U.S. Patent and Trademark Office (USPTO). NIST will communicate the RFI input received to the USPTO. The 2019 Commission on the Theft of American Intellectual Property also noted a number of recommendations to strengthen the U.S. IP system to maintain global competitiveness. 47

\section{B. GOVERNMENT USE LICENSE}

\section{BACKGROUND}

The term "government use license" refers to the "nonexclusive, nontransferable, irrevocable, paid-up license to practice the invention or have the invention practiced throughout the world by or on behalf of the Government," that applies to any federally funded invention. While there are

43 U.S.C. $\S 202(c)(7)$

4435 U.S. C. § 209 - Licensing federally owned inventions

45 The Economist. 2002. "Innovation's golden goose.” The Economist Technology Quarterly. December. 2002. https://www.economist.com/technology-quarterly/2002/12/12/innovations-golden-goose

46 Public Law 112-29 https://www.uspto.gov/sites/default/files/aia_implementation/20110916-pub1112-29.pdf

47 IP Commission 2019 Review. 2019. "Progress and Updated Recommendations - February 2019." http://www.ipcommission.org/report/ip_commission_2019_review_of_progress_and_updated_rec ommendations.pdf 
slight differences in statutory language, the government use license applies to inventions stemming from research partnerships with Federal Laboratories (15 U.S.C. § 3710a(b)(1)(A)), 48 Federal employee inventions (15 U.S.C. $§ 3710 d(a)$ ), 49 and federally funded inventions produced by contractors and grantees (35 U.S.C. $§ 202(c)(4)$ ).50 The primary benefit of the government use license is that the government can use inventions made with government research funding for its mission-driven purposes without a threat of legal challenges for patent infringement. ${ }^{51}$ It has been long recognized that government use includes direct use by the agency for its own acquisition purposes, even if this may involve a different contractor.52,53

\section{CHALLENGES}

Stakeholders commented that the purpose of the government use license needed to be clarified and its use should be construed consistently and narrowly. It was also noted by stakeholders that an overly broad interpretation of this right would be contrary to the stated intent of the Bayh-Dole Act to allow rights to be elected and retained by the contractor.54 In addition, GAO found that there were few statistics on how often Federal agencies exercise their use rights. 55 While disseminating statistics on government use would be helpful, stakeholders noted it is

48 "A nonexclusive, nontransferable, irrevocable, paid-up license from the collaborating party to the laboratory to practice the invention or have the invention practiced throughout the world by or on behalf of the Government."

49 “...subject to reservation by the Government of a nonexclusive, nontransferable, irrevocable, paid-up license to practice the invention or have the invention practiced throughout the world by or on behalf of the Government."

50 “...the Federal agency shall have a nonexclusive, nontransferable, irrevocable, paid-up license to practice or have practiced for or on behalf of the United States any subject invention throughout the world...”

51 U.S. Government Accountability Office (GAO). 1999. Reporting Requirements for Federally Sponsored Inventions Need Revision. https://www.gao.gov/assets/230/227817.pdf

52 Night Vision Corp v. United States, No. 06-5048. U.S. Court of Appeals https://caselaw.findlaw.com/us-federal-circuit/1393887.html

53 GAO. 2009. Information on the Government's Right to Assert Ownership Control over Federally Funded Inventions. https://www.gao.gov/assets/300/293020.pdf

54 "Contractor" is defined in 35 U.S.C. 201(c) as "any person, small business firm, or non-profit organization that is a party to a funding agreement"; "funding agreement" is defined in 35 U.S.C. 201(b) to refer to contracts, grants, and cooperative agreements. Bayh-Dole rights and requirements were extended to all contractors, regardless of size, through Executive Order 12591.

55 GAO. 1999. "Reporting Requirements for Federally Sponsored Inventions Need Revision." https://www.gao.gov/assets/230/227817.pdf 
nevertheless important to better define the circumstances under which use of the government use license would be appropriate consistent with the original legislative intent.

An issue that has been noted is the potential use of the government use license to obtain discounts on products developed from federally funded R\&D, primarily pharmaceuticals. A 2003 GAO report concluded that the government use license does not bestow the broader right to purchase royalty-free (i.e., discounted) products that happen to incorporate a federally funded invention if not produced under the government's license. 56

\section{NIST FINDING}

NIST Finding 1. According to stakeholders, the scope of the "government use license" is not well defined. Market uncertainty is created by the lack of a clear definition of "government use" that is limited to use directly by the government-or a government contractor in the performance of an agreement with the government-for a government purpose only, including continued use in research and development by the government. The scope of the government use license should not extend to goods and services made, sold, or otherwise distributed by third parties if the government-or a government contractor in the performance of an agreement with the government-does not directly use, provide, or consume those goods and services.

\section{A. GOVERNMENT USE LICENSE FOR EXTRAMURAL R\&D PROGRAMS}

The definition of the government use license for extramural R\&D programs falls within the scope of the Bayh-Dole Act implementing regulations. According to stakeholders, there is a lack of clarity regarding: (i) the definition of government use license and its use directly by the government-or a government contractor in the performance of an agreement with the government-for government's mission driven purposes only and not for the use of a third party not authorized to act on behalf of the government, 57 and (ii) the appropriate processes and use of the government use right based on a consistent interpretation of its defined scope of use. 58

56 GAO. 2003. Agencies' Rights to Federally Sponsored Biomedical Inventions. https://www.gao.gov/new.items/do3536.pdf

5737 CFR 401.2 and 37 CFR 401.14(b) could be appropriate places to consider clarifications to the definitions.

5837 CFR 401.14 could be an appropriate place to consider clarifications to the definitions. 


\section{B. GOVERNMENT USE LICENSE FOR INTRAMURAL AND PARTNERSHIP R\&D PROGRAMS}

According to stakeholders, there is no current regulatory authority under the StevensonWydler Act to allow for a definition of "government use" that applies across all agencies, consistent with regulations implementing the Bayh-Dole Act.59 As a result, agencies could individually adopt internal policies, but there is a lack of clarity regarding: (i) the definition of government use license and its use directly by the government for government purpose only and not for use by a third party not authorized to act on behalf of the government, and (ii) the appropriate processes and use of the government use right based on a consistent interpretation of its defined scope of use.

\section{MARCH-IN RIGHTS}

\section{BACKGROUND}

The foundation of the Bayh-Dole Act supports the principle that inventions resulting from federally funded research should benefit the American people by the development of the inventions into commercially available products and services by achieving practical application of the invention that benefits the public. The Federal Government reserves the right to ensure that a contractor, an assignee, or exclusive licensee of intellectual property developed with Federal funding is taking effective steps to further develop the invention so that it is available to the public. In limited circumstances the government may compel action, or march in, to, "require the contractor, an assignee or exclusive licensee of a subject invention to grant a nonexclusive, partially exclusive, or exclusive license in any field of use to a responsible applicant or applicants," and, if the contractor, assignee, or exclusive licensee refuses, then the Federal Government can grant such a license itself. 60

Congress specified the conditions that must be met in order for the Federal Government to exercise its march-in rights: (1) effective steps have not occurred, or are not expected to occur, within a reasonable time to achieve "practical application" of the subject invention; (2) health and safety needs are not being reasonably satisfied; (3) public use requirements specified by Federal regulations must be met; and (4) agreements for U.S. manufacturing have not been met or have

59 The Federal regulatory process is highly collaborative and structured. See descriptive graphic in Strategy 1, Section G, Sub-Section 2.

6035 U.S.C. $§ 203$ - March-in rights; 35 U.S. C. § 209 - Licensing federally owned inventions 
been breached. ${ }^{61}$ Implementing regulations established rigorous administrative processes for agencies to initiate and exercise march-in rights. ${ }^{62}$ The Government Accountability Office (GAO) noted that this process is detailed, time-consuming, and complex, making it difficult for agencies to initiate and exercise the march-in right. 63 The use of march-in is typically regarded as a last resort, and has never been exercised since the passage of the Bayh-Dole Act in 1980, because other less intrusive means have been better suited to solve the problem.

Although the march-in right has not been used, the National Institutes of Health (NIH) has received 12 requests to initiate march-in proceedings. ${ }^{64}$ In each case, NIH determined that the criteria to exercise march-in rights were not met. In two cases, the NIH monitored plans by the company to make the product available to satisfy public need and demand. In the remaining 10 cases, two for the same drug, petitioners argued that march-in rights should be used to curtail high drug prices and ensure U.S. citizens receive public health benefits from accessible and affordable drugs. Ultimately, for each of these requests, NIH determined that the use of march-in to control drug prices was not within the scope and intent of its authority. While there is no government-wide repository of information related to march-in petitions and determinations, $\mathrm{NIH}$ published responses to several of its closed march-in requests online to demonstrate transparency in their process, and other relevant petition materials were made available via the NIH Freedom of Information Act Office. 65

As seen in the NIH march-in requests relating to drug price, much of the discussion of march-in rights focuses on the definition in the Bayh-Dole statute of "practical application." Practical application is defined in the statute to mean manufacture, practice, or to operate an invention made with Federal funds and to establish that the invention is being utilized and its benefits are available to the public on reasonable terms. The meaning of "reasonable terms" has proven to be ambiguous. In requests for the government to exercise the march-in right, "reasonable terms" has been interpreted as a reasonable price to the consumer or use to control

6135 U.S.C. $§ 203$ - March-in rights

6237 CFR 401.6 - Exercise of march-in rights

63 GAO. 2009. Federal Research: Information on the Government's Right to Assert Ownership Control over Federally Funded Inventions. Washington, D.C.: GAO.

64 Data provided to NIST by the NIH. Six of the march-in requests and NIH determinations are detailed in: Thomas, John. 2016. March-In Rights under the Bayh-Dole Act. CRS Report No. R44597. Washington, D.C. Congressional Research Service. https://fas.org/sgp/crs/misc/R44597.pdf

65 For example, see the NIH FOIA Office's documentation on the CellPro petition at NIH, "First-Party Correspondence Documents," https://www.nih.gov/institutes-nih/nih-office-director/officecommunications-public-liaison/freedom-information-act-office/cellpro-march-petition-documents. 
product or service price. ${ }^{66}$ To date, the government has interpreted reasonable terms to mean reasonable licensing terms. The original sponsors of the Bayh-Dole Act have publicly stated that their intent was to ensure that products were licensed for reasonable terms rather than being used as a price control. (Refer to box: "Statements by Senators Bayh and Dole on March-In.")

\section{Statements by Senators Bayh and Dole on March-In}

The "Bayh-Dole [Act] did not intend that government set prices on resulting products. The law makes no reference to a reasonable price that should be dictated by the government...The ability of the government to revoke a license granted under the [Act] is not contingent on the pricing of the resulting product or tied to the profitability of a company that has commercialized a product that results in part from [federally] funded research. The law instructs the government to revoke such licenses only when the private industry collaborator has not successfully commercialized the invention as a product," among other circumstances.

Source: Birch Bayh and Robert Dole, "Our Law Helps Patients Get New Drugs Sooner," Washington Post, April 11, 2002.

Stakeholders pointed to potential consequences from using march-in rights as a price control. These reasons include impeding the creation of new drugs and discouraging university and medical school licensees from making the substantial additional investments necessary to develop and commercialize new drug discoveries. A 2019 report from the Information Technology and Innovation Foundation drew similar conclusions, noting that "[m]isusing the "march-in right" provision of the Bayh-Dole Act could negatively impact U.S. life-sciences innovation and result in fewer new drugs." 67 Other responses focused on ensuring that new drugs reach the people that helped fund work through Federal basic research.

In April 2018, the Department of Health and Human Services released a report: American Patients First: The Trump Administration Blueprint to Lower Drug Prices and Reduce Out-ofPocket Costs, ${ }^{68}$ which lays out the Administration's approach to prescription drugs. The actions identified in the blueprint do not envision the use of march-in rights as a price control mechanism.

66 Peter S. Arno and Michael H. Davis. 2001. "Why Don't We Enforce Existing Drug Price Controls? The Unrecognized and Unenforced Reasonable Pricing Requirements Imposed upon Patents Deriving in Whole or in Part from Federally Funded Research," Tulane Law Review, vol. 1, pgs. 631-692, http://www.cptech.org/ip/health/bd/arnodavis012001.pdf.

67 Information Technology and Innovation Foundation. 2019. “The Bayh-Dole Act's Vital Importance to the U.S. Life-Sciences Innovation System." https://itif.org/publications/2019/o3/o4/bayh-dole-actsvital-importance-us-life-sciences-innovation-system

68 Department of Health and Human Services. 2018. American Patients First: The Trump Administration Blueprint to Lower Drug Prices and Reduce Out-of-Pocket Costs. https://www.hhs.gov/sites/default/files/AmericanPatientsFirst.pdf 
Overall, stakeholders agreed that the march-in authority should not be broadened, and that doing so would create uncertainties in the U.S. innovation system. A few ROI public forum attendees took a position calling for the elimination of the march-in provision, citing the track record on its lack of use as a proxy for ineffectiveness and indicating their opinion that funding recipients are now well-equipped to manage oversight of progress towards practical application. However, most comments focused on the perceived lack of clarity regarding the use of march-in rather than proposing elimination of the right. Additionally, according to GAO, multiple agencies support the existence of march-in rights because it acts as leverage to promote commercialization of federally funded inventions. 69

\section{CHALLENGES}

Stakeholders stated that prospective licensees are often not satisfied with obtaining anything less than exclusive licensing rights to federally sponsored inventions that involve significant risk of failure and investment to obtain FDA approval. Industry stakeholders have noted their concern that the Federal Government's march-in right is a risk to consider in making the business decision to take a license for a federally funded technology. Stakeholders elaborated that despite the fact that march-in rights have never been exercised by the government under the Bayh-Dole Act, there continues to be a general misunderstanding from prospective licensees that march-in rights take ownership rights away from inventors and licensees. ${ }^{70}$ The existence of march-in might lead to a lack of confidence that patents will be enforceable in fair court proceedings or the USPTO's Patent Trial and Appeal Board. Stakeholders report that the threat of march-in actions has prevented licensing deals that would have otherwise occurred, leading to technologies languishing in contravention to the law's stated purpose.

The National Academies recommended that agencies review their actions with respect to "Determinations of Exceptional Circumstances, government use rights, and exercise of march-in rights." 71 Stakeholders argued that proper and consistent determination and application of march-in rights across Federal agencies is critical for a clear, predictable, and reliable technology transfer system. Specifically, they referenced language in the march-in statute under the definition of "practical application" including "reasonable terms" and questioned whether that applies to creating government price controls, particularly for pharmaceuticals. It is noted that

69 GAO. 2009. Information on the Government's Right to Assert Ownership Control over Federally Funded Inventions. https://www.gao.gov/assets/300/293020.pdf

70 NIST public meeting at Chicago, IL on May 31, 2018

71 National Research Council. 2011. Managing University Intellectual Property in the Public Interest. Washington, DC: The National Academies Press. 82. 
pricing is covered by other statutes, e.g., Drug Price Competition and Patent Term Restoration Act (P.L. 98-417), which encourages the development of generic drugs by the pharmaceutical industry. As stated earlier, prescription drug pricing is also covered in a recent policy blueprint that does not envision the use of march-in rights as a price control mechanism. ${ }^{72}$ However, there is a general consensus that more clarity could be brought to the definition of the exceptional circumstances that must be met to appropriately exercise march-in rights.73

Stakeholders mentioned further ideas including explicit criteria for the technologies that are and are not subject to march-in, such as export-controlled items; stipulation of a time limit for the Federal Government to exercise march-in rights; or defining investment limits in which significant resources have been spent on technology after transfer.

\section{NIST FINDING}

NIST Finding 2. According to stakeholders, the circumstances under which the government may exercise march-in rights are not well-defined. Market uncertainty is created by the lack of a clear definition of the use of march-in rights that is consistent with statute, rather than as a regulatory mechanism for the Federal Government to control the market price of goods and services.

\section{A. CIRCUMSTANCES UNDER WHICH MARCH-IN RIGHTS MAY BE EXERCISED}

Since march-in rights are already part of the existing statute, clarifications consistent with statute fall within the scope of Bayh-Dole implementing regulations. According to stakeholders, existing regulation is not clear regarding the use of march-in rights as specified in the statute when other remedies have failed rather than a means to regulate the market for price for goods and services. Additionally, according to stakeholders, existing regulation does not permit a Federal agency that has received information that it believes might warrant a march-in action, to first-after conducting an internal review of its funding support-conduct an informal consultation with the contractor or licensee to understand the nature of the issue and consider potential alternatives to remedy the concern and to summarize the efforts made to correct the non-compliance when notifying the contractor or licensee if it intends to proceed with a potential march-in action.

72 Department of Health and Human Services. 2018. American Patients First: The Trump Administration Blueprint to Lower Drug Prices and Reduce Out-of-Pocket Costs. https://www.hhs.gov/sites/default/files/AmericanPatientsFirst.pdf

73 NIST public meeting at Gaithersburg, MD on June 14, 2018 


\section{B. AMBIGUITIES IN MARCH-IN RIGHTS PROCESSES AND TERMINOLOGY}

March-in rights processes and terminology fall within the scope of Bayh-Dole Act implementing regulations. According to stakeholders, there is a lack of clarity on: (i) whether or not to use march-in rights as a mechanism to control or regulate the market price of goods and services, and (ii) definitions for "reasonable terms" contained within the existing statutory definition of "practical application." Stakeholders indicated that the regulatory process is well suited to collect and analyze formal comments on proposed language regarding the use of reasonable licensing terms to allow a product or service to reach the marketplace rather than reasonable pricing terms to the consumer.74,75 Clarifications for "reasonable terms" and "practical application" would allow flexibility in crafting commercial or other terms in license agreements to achieve effective technology transfer and allow agencies the flexibility needed to accomplish their mission.

\section{PREFERENCE FOR U.S. MANUFACTURING}

\section{BACKGROUND}

Under the Bayh-Dole Act, any recipient of an exclusive license to a federally funded invention must agree to manufacture it substantially in the United States in order to use or sell it

7437 CFR 401.14(j) details the march-in rights in standard Bayh-Dole Act patent rights. The four enumerated circumstances that the government would elect to assert march-in rights are: 1) contractor has not taken or is not expected to take effective steps to achieve practical application of the subject invention, 2) there is a health or safety need which is not reasonably satisfied by contractor or its licensees, 3) there is a public use requirement specified by Federal regulations that are not reasonably satisfied by contractor or its licensee, and 4) march-in is necessary because of preference of U.S. manufacturing has not been met, a waiver was not granted or obtained, or licensee is in breach of such agreement. Changes that could be considered to the enumerated circumstances may include language that makes clear that march-in will not be used for anti-competitive reasons such as price control.

37 CFR 401.6 details the procedures that govern the exercise of march-in rights. Language could be considered in this section to provide procedural guidance regarding march-in right proceedings, factfinding, and determination.

7537 CFR 401.2 is the definitions section for Bayh-Dole Act rights regulation. The current definition of practical application, per 401.2(e), is "The term practical application means to manufacture in the case of a composition of product, to practice in the case of a process or method, or to operate in the case of a machine or system; and, in each case, under such conditions as to establish that the invention is being used and that its benefits are, to the extent permitted by law or government regulations, available to the public on reasonable terms." The bolded text has been used to support the use of march-in rights as a price control mechanisms as reasonable terms has been interpreted to mean "low price.” 
domestically. ${ }^{76}$ The intent of the provision is "to promote the commercialization and public availability of inventions made in the United States by United States industry and labor." 77 According to the Manufacturing USA ${ }^{\circledR} 2017$ Annual Report, the manufacturing sector makes up 8.5 percent of U.S employment, 11.7 percent of the Nation's GDP, 35 percent of productivity growth, 60 percent of exports, and 70 percent of private sector R\&D. 78

The September 2018 Department of Defense report to the President Assessing and Strengthening the Manufacturing and Defense Industrial Base and Supply Chain Resiliency of the United States 79 in response to Executive Order $13806^{80}$ makes the case for protecting American manufacturing. This report notes that it is imperative to maintain domestic manufacturing capability to meet more than current production needs with the conclusion that: “Above all, America's manufacturing and defense industrial base must support economic prosperity, be globally competitive, and have the capabilities and capacity to rapidly innovate and arm our military with the lethality and dominance necessary to prevail in any conflict."

In certain cases, institutions can request a waiver ${ }^{81}$ to the U.S. manufacturing requirement from the Federal agency that sponsored the research. Federal agencies can issue waivers in instances where "upon a showing by the small business firm, nonprofit organization, or assignee that reasonable but unsuccessful efforts have been made to grant licenses on similar terms to potential licensees that would be likely to manufacture substantially in the United States or that under the circumstances domestic manufacture is not commercially feasible." 82 For example, if

7635 U.S.C. § 204 - Preference for United States industry. U.S. Manufacturing Preference also applies to inventions produced under CRADAs, but it is a recommendation rather than a requirement. See 15 U.S.C. § $3710 a(c)(4)(A)$.

7735 U.S.C. § 200 - Policy and objective

78 NIST. 2018. Manufacturing USA 2017 Annual Report. https://nvlpubs.nist.gov/nistpubs/ams/NIST.AMS.600-3.pdf

79 Department of Defense. 2018. Assessing and Strengthening the Manufacturing and Defense Industrial Base and Supply Chain Resiliency of the United States. September 2018. https://media.defense.gov/2018/Oct/05/2002048904/-1/-1/1/assessing-and-strengthening-themanufacturing-and\%2odefense-industrial-base-and-supply-chain-resiliency.pdf

80 Executive Order 13806 is available at: https://www.whitehouse.gov/presidential-actions/presidentialexecutive-order-assessing-strengthening-manufacturing-defense-industrial-base-supply-chainresiliency-united-states/

81 The U.S. manufacturing requirement need not be waived completely by an agency. Rather, the requirement can be modified to include specific, enforceable commitments that will provide a net benefit to the U.S. economy.

8235 U.S.C. § 204 - Preference for United States industry; see also 37 CFR 401.14(i) - Preference for United States industry 
manufacturing in the U.S. would cause a significant delay or is prohibitively expensive for a primarily overseas market, then the requirement could potentially be waived. Other technologyspecific factors are also considered when agencies issue waivers, such as whether the technology will create new U.S.-based jobs that have a positive impact on the U.S. trade balance, even if it is manufactured overseas. 83

In addition to requirements in licensing, agencies are also directed to "give preference to business units located in the United States which agree that products embodying inventions made under the cooperative research and development agreement or produced through the use of such inventions will be manufactured substantially in the United States."84 Although this requirement does not have the potential to trigger march-in as under the Bayh-Dole requirement, it is still built into the terms of the resulting CRADA licensing agreement and may result in termination of the license.

\section{CHALLENGES}

Stakeholders who have attempted to comply with the requirement said that they have been confused by the meaning of the phrase "manufactured substantially in the United States." Specifically, stakeholders said that they did not understand the term "substantially," and this might not enable businesses to properly assess whether they should apply for a waiver or continue with the risk of developing a new technology. The lack of clarity can lead companies not to license technologies, which ultimately prevents new inventions and discoveries from reaching the public.

Institutions that decide to apply for a waiver have said that they sometimes experience a long and opaque process within each agency. Some institutions that have requested waivers have said that the responses are slow to come if they ever come at all. Further, there are agency-to-agency differences in preference for U.S. industry manufacturing waiver processes due to differences in the missions and technology focus areas of the different agencies.

\section{NIST FINDING}

NIST Finding 3. Existing statute requires that products embodying or using federally funded inventions be manufactured substantially in the United States. According to stakeholders, there is a lack of common tools to streamline and better understand the breadth of waiver requests to the agencies that would benefit the public in cases where the agency finds a waiver is applicable.

83 U.S. National Institutes of Health. "NIH Procedures for Request for Waivers of the U.S. Manufacturing Requirement in Licenses to Extramural Inventions."

https://public.era.nih.gov/iedison/public/utilization/ManufacturingWaiver.jsp

8415 U.S.C. $\S 3710 a(c)(4)(B)$ 


\section{A. WAIVER PROCESS FOR EXTRAMURAL R\&D PROGRAMS}

The waiver process for extramural R\&D programs falls within the scope of the Bayh-Dole Act's implementing regulations. According to stakeholders, a more transparent and streamlined waiver process could help businesses achieve practical application of inventions. Revisions that could be considered include identifying considerations for granting waivers by government agencies 85 and a government-wide point of application for requesting waivers. Each agency would still be responsible for reviewing the requests and issuing waivers, as appropriate, but the public could benefit from a more streamlined and transparent process.

\section{B. WAIVER PROCESS FOR INTRAMURAL R\&D PROGRAMS}

There is currently no path for regulations under the Stevenson-Wydler Act ${ }^{86}$ to address the waiver process for intramural R\&D programs. According to stakeholders, a more transparent and streamlined process could support the U.S. manufacturing preference within CRADAs; this is not within the scope of current legislation. It is also possible for agencies to consider adopting new internal policies regarding waivers under the Bayh-Dole Act regulations.

\section{E. COPYRIGHT OF GOVERNMENT SOFTWARE}

\section{BACKGROUND}

Since the passage of the foundational technology transfer statutes in the 1980s, the digital age has resulted in major changes in many of the products and services that result from R\&D and the way in which they are developed by the private sector and used by the public. The widespread use of computers and personal digital devices has revolutionized major parts of our daily lives.

8535 U.S.C. § 209(b) contains language on preference of the government for licensees of federally owned inventions to manufacture in US.

37 CFR 401.14(i) details the preference for U.S. industry. The waiver language is as follows: "However, in individual cases, the requirement for such an agreement may be waived by the Federal agency upon a showing by the contractor or its assignee that reasonable but unsuccessful efforts have been made to grant licenses on similar terms to potential licensees that would be likely to manufacture substantially in the United States or that under the circumstances domestic manufacture is not commercially feasible."

86 Regulatory authority to implement the Stevenson-Wydler Act is not available under current law as discussed under Strategy 1, Section G. 
The reliance on embedded computing capability is also found within ordinary products. 87 Technology transfer laws and policy do not adequately address technological development in the 21st Century; the technology landscape and marketplace has been dramatically reconfigured since the 1980s. This is particularly true for software, which has changed fundamentally in the ensuing 40 years. Software is defined in this report as a set of computer readable language instructions and statements that serve as directions, procedures, and rules for the operation of a computer system. ${ }^{88}$ Intellectual property protection for digital goods and services is critical for competing in the global high-tech marketplace.

\section{Copyright Protection for Software and the Government Works Exception}

U.S. copyright law protects "original works of authorship" fixed in a tangible medium of expression by granting to authors certain exclusive rights ${ }^{89}$ subject to a number of exceptions and limitations. ${ }^{90}$ Computer programs, ${ }^{91}$ including source code, ${ }^{92}$ video games, images created as user interfaces, photographs, films, journal publications, and databases are examples of works eligible for copyright protection. Copyright protection automatically attaches upon fixation of the work in a tangible medium of expression and extends from at least 70 years to approximately 120 years from creation. 93 Copyright registration is required to file a lawsuit for infringement in the

87 United States Copyright Office. 2016. Software-Enabled Consumer Products. December 2016. https://www.copyright.gov/policy/software/software-full-report.pdf

88 Note that this definition differs from other provisions of Federal laws and regulations. For example, FAR 52.777-14 excludes computer software documentation and databases from the definition of software but includes "computer programs and recorded information...that would enable the computer program to be produced, created, or compiled." "Computer program" under U.S. Copyright Law is defined as "a set of statements or instructions to be used directly or indirectly in a computer in order to bring about a certain result.” 17 U.S.C. $§ 101$.

8917 U.S.C. § 106.

90 See, e.g. 17 U.S.C. $\S \S 107-122$. https://www.copyright.gov/title17/

91 Note that "Computer program" under U.S. Copyright Law is different from the definition NIST uses in this report. See 17 U.S.C. § 101 (defining a "Computer program" as "a set of statements or instructions to be used directly or indirectly in a computer in order to bring about a certain result").

92 United States Copyright Office. 2017. “Copyright Registration of Computer Programs.” Circular 61. https://www.copyright.gov/circs/circ61.pdf

9317 U.S.C. § 302 - Duration of copyright: Works created on or after January 1, 1978 and 17 U.S.C. § 303 - Duration of copyright: Works created but not published or copyrighted before January 1, 1978 
United States for U.S. works and to obtain certain remedies for infringement for any works (U.S. or non-U.S.), and serves as a public claim with the United States Copyright Office. 94

According to a 1990 GAO report, some companies were unwilling at that time to invest in taking computer software to the marketplace unless it was registered with the Copyright Office because of the need to secure exclusivity that copyright protection and associated infringement remedies enable. 95 This may have contributed to the lack of lab-to-market commercialization activity of non-copyrighted or unregistered software produced by Government laboratories.

Although copyright can protect computer software, under the Government Works exception, the U.S. Government is prohibited from claiming copyright in the United States in any works prepared by officers or employees of the Federal Government in the course of their official duties. Section 105 also specifies that "the United States is not precluded from receiving and holding copyrights transferred to it by assignment, bequest, or otherwise." Copyright law thus distinguishes between works prepared by Federal officers and employees (i.e., not protected by copyright) and works that are transferred to the United States (protected). ${ }^{6}$ The exception for copyright protection in "works of the United States Government" only operates within the United States and not overseas. 97

Specific exemptions to the Government Works copyright exception are already in place for certain works produced by the Federal Government in order to enable agencies to carry out their missions. For example, NIST is permitted to secure copyright on Standard Reference Data under

94 United States Copyright Office. https://www.copyright.gov/circs/circo1.pdf. Companies may be more likely to invest in taking computer software to the marketplace when it is registered with the Copyright Office because of these incentives.

95 GAO. 1990. Copyright Law Constrains Commercialization of Some Federal Software. https://www.gao.gov/assets/150/149097.pdf

96 This distinction is important to the technology transfer licensing framework because legislative text that simply authorizes the United States to license copyrights that it holds would be understood to refer to those copyrights that are transferred to the government, rather than to works prepared by government employees.

97 Section 105 of the Copyright Act provides an exception for "Government Works" and states: "Copyright protection under this title is not available for any work of the United States Government..." Section 101 defines a "work of the United States Government" as "a work prepared by an officer or employee of the United States Government as part of that person's official duties." 
15 U.S.C. $§ 290 e, 9^{9}$ and the U.S. Postal Service is permitted to secure copyright for its designs on postage stamps, stamped envelopes, souvenir cards, and other philatelic publications.99, 100

\section{Patent Protection of Software}

Other types of intellectual property may also protect some aspects of computer software. For example, some computer-implemented inventions produced by Federal Government researchers can be patented, but this is a relatively lengthy process that is not ideally suited to the fast-paced software industry.

\section{CHALLENGES}

The challenges regarding the absence of copyright protection for software that are products of Federal R\&D are unique to government employees, and the challenges and NIST findings here are limited in scope to government employee works that are products of R\&D. Some government researchers have asserted that the Government Works exception has created a disincentive for them to envision and develop software with potential for commercial use, ${ }^{101}$ and led to slower and less efficient development of Federal software by the private sector. ${ }^{102}$ Another study identified

9815 U.S. Code $\S 290 e$ - United States copyright and renewal rights

(a) Notwithstanding the limitations under section 105 of title 17, the Secretary may secure copyright and renewal thereof on behalf of the United States as author or proprietor in all or any part of any standard reference data which he prepares or makes available under this chapter and may authorize the reproduction and publication thereof by others.

(b) The publication or republication by the Government under this chapter, either separately or in a public document, of any material in which copyright is subsisting shall not be taken to cause any abridgment or annulment of the copyright or to authorize any use or appropriation of such material without the consent of the copyright proprietor.

99 Postal Reorganization Act of 1970, Public Law 91-375, enacted in Title 39 of the U.S. Code.

https://www.law.cornell.edu/uscode/text/39

100 U.S. Postal Service Go13 Trademarks and Copyrights.

https://pe.usps.com/archive/html/dmmarchive20030810/G013.htm

${ }^{101}$ Hughes, Mary E., Susannah V. Howieson, Gina Walejko, Nayanee Gupta, Seth Jonas et al. 2011. Technology Transfer and Commercialization Landscape of Federal Laboratories, Washington, DC: IDA Science and Technology Policy Institute. "One agency asserted that the lack of copyright protection acts as a disincentive for researchers to engage in software development because their work is not protectable."

102 Howieson, Susannah V., Stephanie S. Shipp, Gina K. Walejko, Pamela B. Rambow, Vanessa Peña, et al. 2013. Exemplar Practices for Department of Defense Technology Transfer. Washington, DC: Science and Technology Policy Institute. "First, even though licensing inventions may take less time than licensing patents, the process may still take too long for software, especially in comparison to the instantaneous protection of a copyright. Second, the negotiated terms of an invention licensing agreement (that is, a license without the prospect of patent and copyright protection to enforce against 
the following issues from interviews with government researchers: "revenue is lost by freely disseminating software; there is a lack of control over potentially sensitive code; the commercial potential for partners seeking to further develop government work is diminished due to its lack of exclusivity; and in some situations, third parties subsequently assert copyright, and as a result, the government must buy back its own creations."103

Federally funded R\&D products that are not Government Works, including research performed at universities and other organizations, are eligible for copyright protection. However, embedded portions of code written by Federal employees working with these organizations must be excluded, creating a complicated framework. Government Works software that has commercial value does not have the copyright protections needed to provide a license that can maintain quality, such as ensuring software code integrity and version control, which can lead to further private investment and development to result in commercial products. Some stakeholders indicated that this lack of the ability to protect research innovations through copyright hampered opportunities to transfer software developed by Federal researchers and stated that there is a great deal of confusion about software rights in Government Works, consistent with prior GAO findings from 1990, ${ }^{104}$ and argued for establishing policies and procedures to enable transfer and licensing of federally developed software. (Refer to box: "RFI Responses on Software Ownership.”) Stakeholders stated that, while flexibility is important, inconsistency in agency approaches to software licensing, ${ }^{105}$ among other issues, can hinder the development of federally funded technology.

Agencies' ability to identify and transfer software is generally more limited than the system that is in place for patented inventions resulting from the lack of copyright protection and registration for federally developed software. It is, however, possible for private sector actors to add value to Government Works, creating derivative works which enjoy copyright protection for the additional material and modifications made by the private sector author.

According to stakeholders, the ineligibility of the Federal Government to secure copyright protection for software that results from R\&D at Government-operated laboratories has

third parties) may be limited by the willingness of the licensee to pay anything other than a one-time fee and by the laboratory/licensor to enforce downstream payments"

103 Howieson, Susannah V., Stephanie S. Shipp, Gina Walejko, Pamela B. Rambow, Vanessa Peña, Sherrica S. Holloman, Philip N. Miller. 2013. Policy Issues for Department of Defense Technology Transfer. Washington, DC: IDA Science and Technology Policy Institute. https://www.ida.org/idamedia/Corporate/Files/Publications/IDA_Documents/SFRD/2019/P4958.pdf

104 GAO. 1990. Copyright Law Constrains Commercialization of Some Federal Software. https://www.gao.gov/assets/150/149097.pdf

105 See, e.g. Pamela B. Rambow, Vanessa Peña, et al. 2013. Exemplar Practices for Department of Defense Technology Transfer. Washington, DC: Institute for Defense Analysis (noting that the Department of Commerce interprets the Stevenson-Wydler Act to permit licensing of copyright, but that Department of Defense attorneys disagree with this approach). 
frustrated endeavors to release and participate in open source development. Open source software is a type of computer software where the software code is released under a copyright license where the copyright holder grants to users the rights to modify and share to promote public accessibility. There is an argument that software that qualifies as Government Works must be protected by copyright in the United States in order to grant public users a copyright license that complies with the terms of open source use. On the other hand, the principal objective of open source licenses-

to ensure that the code is free for reuse by others-is served under existing law governing Government Works since the code in such works is free for anyone to use, adapt, and distribute.

\section{RFI Responses on Software Ownership}

"The inability for works created by Federal employees to be protected under copyright has acted as a significant deterrent in the field of software innovation. Due to the short duration of software product lifecycles, the speed of software development, and limitations around patenting software, it is often copyright that provides the primary intellectual property protection for software. Without copyright, Federal Laboratories have no asset to license, and technology transfer may be blocked. Further, if software is co-developed between a Federal Laboratory and a university, the university may license its copyright, but the Federal Laboratory will be unable to participate in the license agreement. Implications include lost opportunities to transfer software developed in Federal laboratories, lost licensing revenue, and a lack of incentive for Federal employees to develop commercially-relevant software."

\section{Source: RFI response, University of Colorado Boulder}

"The role of software in research and development has grown significantly over the years since the initial technology transfer legislation. There is an opportunity to create clear and uniform policy and procedures for asserting software copyright ownership, and in enabling transfer and licensing of federally funded software. We believe that the absence of such clear policies has created confusion and served as an obstacle to commercialization success."

\section{Source: RFI Response, National Laboratory Directors Council}

“There's an opportunity to create clear and uniform policy and procedures for asserting software copyright ownership and enabling transfer of licensing and federally funded software. We believe that the absence of such policies has created confusion and served as an obstacle to commercialization success."

\section{Source: Chicago 5/31/18 Public Forum Transcript}

"However, the transfer of software and data to private sector partners who see a commercial opportunity in such software or data analysis is often difficult due to inconsistence and inefficient mechanisms that enable such a transfer. Clear and uniform policy and procedures for the ownership, transfer and licensing of federally funded software and datasets, across all federal agencies, would be extremely welcome to all the stakeholders who seek to develop novel products and services based on federally funded software and datasets."

\section{Source: San Jose 5/17/18 Public Forum Transcript}


The possibility that the Government Works exception to copyright could hinder commercialization of Federal technologies was anticipated in 1986. The Federal Technology Transfer Act, modifying portions of the Stevenson-Wydler Act, included a requirement that the Secretary of Commerce submit a report detailing "any copyright provisions or other types of barriers which tend to restrict or limit the transfer of federally funded software to the private sector and to State and local governments, and agencies of such State and local governments."106 In their 1988 response, DOC recognized that the lack of copyright protection for software produced by Federal researchers impedes the ability to successfully translate software into commercial products and services. ${ }^{107}$ Since then, the marketplace has become increasingly digital. The Bureau of Economic Analysis (BEA) noted that in 2016, 6.5 percent of the U.S. Gross Domestic Product was digital, amounting to over $\$ 1.2$ trillion of trade. ${ }^{108}$ The rate of growth for this sector of the economy likewise showed a 5.6 percent growth compared to the overall growth of 1.3 percent.

While some stakeholders supported enabling Federal entities to secure software ownership rights, NIST acknowledges that opinions on this subject vary. ${ }^{109}$ While not all Government Works that represent products of $R \& D$ would be appropriate for copyright, this inconsistency with industry norms has created confusion in the private sector and served as an obstacle to commercialization.

\section{NIST FINDING}

NIST Finding 4. According to stakeholders, the "Government Works" exception to copyright protection for software products of $R \& D$ at GovernmentOwned, Government-Operated Laboratories constrains commercialization.

\section{A. SOFTWARE PRODUCTS OF R\&D AT FEDERAL LABORATORIES}

Unlike universities and other federally funded R\&D entities, existing statute does not allow GOGO Laboratories to secure copyright protection for the commercialization of Government

10615 U.S.C. $\S 3710(\mathrm{~g})(3)(\mathrm{A})$

107 NIST. 1988. Report to the President and Congress Required by the Technology Transfer Act of 1986 on Barriers to the Commercialization of Federal Computer Software and Feasibility and Cost of Compiling an Inventory of Federally Funded Training Software. U.S. Department of Commerce, May 1988. https://www.nist.gov/sites/default/files/documents/2019/03/19/ec_3430_10oth_congress.pdf

108 See https://www2.ntia.doc.gov/node/1090

109 Several comments submitted following the release of the December draft of this Green Paper opposed the idea of providing copyright protection for software created by Federal employees. 
Works software that are products of R\&D. According to stakeholders, a narrowly tailored change to the Government Works exception would be consistent with the original intent of the Bayh-Dole Act, while recognizing the transformational shift of including digital products like software in a 21st Century definition of IP. ${ }^{110}$ (Refer to box: "Executive Branch Legislative Requests.”)

\section{Executive Branch Legislative Requests}

Executive agencies can help to develop draft legislative language that is reviewed and approved by the Department, OMB, etc., in accordance with OMB circular A-19 and transmitted to Congress.

- Discussion within the Interagency Workgroup for Technology Transfer (IAWGTT)

- Discussion within the Lab-to-Market Subcommittee of the National Science and Technology Council

- NIST review and clearance

- Department of Commerce review and clearance

- Submission to OMB for interagency coordination and clearance

- Legislative Referral Memorandum (LRM) for agency comment and clearance

- Final legislative request transmitted to Congress

110 RFI Response, Software Information and Industry Association: "Therefore, while the existing Federal technology transfer laws have served well for decades, this process is valuable to clarify and extend these policies to ensure that they are not focused too narrowly on the transfer of technology-and particularly patented technology - but promote all forms of knowledge and innovation. Federal policies should clarify the goal to ensure software that is protected by copyright or trade secrets, or other IP that derives from Federal R\&D, are also valuable outputs, and where appropriate, can be effectively leveraged by the private sector to maximize innovation and job growth. What these other forms of intellectual property share with patents is that they have long been recognized for their role in promoting the necessary framework for commercialization of new discoveries, the key incentive BayhDole sought to promote." 


\section{BACKGROUND}

Trade secrets represent a type of intellectual property that "consists of information and can include a formula, pattern, compilation, program, device, method, technique, or process"111 that provides an economic advantage over competitors or consumers, is generally not known, and is subject to efforts reasonable under the circumstances to maintain its secrecy. ${ }^{112}$ Unlike patents and copyrights, which are enforceable throughout the length of time of the issued protection, the ability to protect a trade secret is lost in the event that a trade secret holder fails to take appropriate actions to maintain secrecy or if the information is reverse engineered or independently developed by a competitor or otherwise disclosed. Small businesses receive disproportionately greater benefits from trade secret protections than larger businesses as larger businesses can generally afford to maintain and enforce costlier patent and other intellectual property protections. ${ }^{113}$ However, trade secrets have some benefits over patents in that trade secrets have a potentially unlimited duration, no territorial limits, and no applications to file or fees to pay. ${ }^{114}$

While trade secrets are often used by businesses, working with a Federal Laboratory creates barriers to maintaining trade secrets for the resulting products, as government functions are generally geared toward publication to disseminate research results and, when applicable, patenting as the means of protecting research results without unduly restricting disclosure. Patents by their conception in the U.S. Constitution are a means of disclosing information in exchange for a limited period of protection.

Federal Laboratories, which do not have the authority to create and protect their own trade secrets, already have requirements to protect incoming trade secrets. Beginning in 1948 with the Federal Trade Secrets Act, there has been Federal protection against the disclosure of proprietary information provided to the government. ${ }^{115}$ There are now both civil and criminal remedies for

\footnotetext{
111 U.S. Patent and Trademark Office. 2018. “Trade Secret Policy.” Last modified July 11, 2018. https://www.uspto.gov/patents-getting-started/international-protection/trade-secret-policy 112 Ibid.

113 David S. Almeling. 2009. "Four Reasons to Enact a Federal Trade Secrets Act, 19.” Fordham Intell. Prop. Media \& Ent. L. J. 769, 786-87.

114 U.S. Patent and Trademark Office. "Trade Secrets Protection in the U.S." https://www.nist.gov/sites/default/files/documents/mep/marinaslides.pdf

11518 U.S.C. § 1905 - Disclosure of confidential information generally
} 
misappropriation of trade secrets under Federal law, ${ }^{116}$ and the U.S. is obligated to provide trade secret protection under the Agreement on Trade-Related Aspects of Intellectual Property Rights (TRIPS). ${ }^{117}$ Trade secrets and commercial and financial information are also exempted from mandatory disclosure under the Freedom of Information Act (FOIA). Federal trade secret protections decrease the likelihood that the government will disclose proprietary information when entering into R\&D collaborations with the private sector. In addition, these protections provide a signal to the private sector that they can rely on robust legal enforcement for violations that disclose their intellectual property and, in turn, spur R\&D investments and collaborations that would otherwise have been viewed by industry collaborators as too risky to pursue. ${ }^{118}$

The rapidly changing landscape of information and communication technologies and the growing availability of information in the digital public domain are challenges to maintaining secrecy and protection of trade secrets. Since it is easier to store, access, and disseminate trade secrets in the digital environment, there is an increased risk of disclosure or misappropriation. ${ }^{119}$

Existing statutory authority under the Bayh-Dole Act protects newly discovered material from disclosure until a patent can be filed for patentable inventions. ${ }^{120}$ This extends to joint inventions from a CRADA partnership or other collaborations as well. Sole inventions of partners are generally protected as proprietary under the terms of an agreement.

\section{CHALLENGES}

Stakeholders commented on industry's general perceptions that the Federal Government does not sufficiently protect information needed to enter the marketplace, and that this situation is one of the major obstacles to private sector engagement and establishing public-private R\&D collaborations. There is a perceived lack of transparency and consistency in the Federal Government's protection and enforcement of trade secrets. It was noted that government may

116 Procurement-related laws (1994) - provide both civil and criminal penalties for the Federal Government disclosure of non-government information gained through procurement (41 U.S.C. § 423); The Economic Espionage Act (1996) - regulates the theft or misappropriation of trade secrets for the benefit of any foreign government (18 U.S.C. $\S \S 1831-1839$ ); The Defend Trade Secrets Act (2016)creates Federal civil cause of action for the disclosure of trade secrets (P.L. 114-153).

117 The TRIPS Agreement binds all members of the World Trade Organization, see World Intellectual Property Organization, http://www.wipo.int/wipolex/en/other_treaties/details.jsp?treaty_id=231

118 Png, Ivan P. L. 2012. "Law and Innovation: Evidence from State Trade Secrets Laws” June 15, 2012, http://dx.doi.org/10.2139/ssrn.1755284

119 U.S. Patent and Trademark Office. "Trade Secrets Protection in the U.S." https://www.nist.gov/sites/default/files/documents/mep/marinaslides.pdf

${ }^{120} 35$ U.S.C. $\S 205$ 
lack access to new cybersecurity technology and applications that could provide proof of information ownership and ensure that information exchanged through $\mathrm{R} \& \mathrm{D}$ collaborations is secure.

Authorities under CRADAs provide protection of information "obtained in the conduct of research or as a result of activities"121 and provides a 5-year time limit for that protection. ${ }^{122}$ (For more information on CRADAs, see Strategy 2 Section C). Thus, CRADA Data Protections are consistent and clear in statute. However, the 5-year limit is sometimes inadequate for technologies that take a long time to reach maturity or are at an earlier stage of development. For example, technology development occurs in the nuclear sector over decades, and collaborators and industry may find the 5-year limit insufficient to meet their needs to bring a developed product to market.

There are already serious liabilities and consequences for mishandling trade secrets and related proprietary information that may discourage agencies from accepting the risk associated with trade secret protection. Some agencies, such as the Department of Energy (DOE), have issued standard procedures for the submission and protection of trade secrets and commercial or financial information that is privileged or confidential, where such information is submitted by applicants for DOE assistance including research partnerships. ${ }^{123}$ However, there is a lack of clear, Federal-wide guidance or regulation for accepting and managing this information for technology transfer activities.

\section{NIST FINDING}

NIST Finding 5. According to stakeholders, current limits on the protection of proprietary information discourage some R\&D collaborations with Federal Laboratories.

\section{A. CRADA INFORMATION PROTECTION PERIOD}

Stakeholders said that the 5-year statutory protection period for CRADA information may be too short for early stage technology or technologies that require additional time to reach the marketplace. Under the existing statute, agencies do not have the authority to extend the CRADA information protection period beyond the 5 years.

\footnotetext{
12115 U.S.C. $\S 3710 a(c)(7)(A)$

12215 U.S.C. $§ 3710 a(c)(7)(B)$

123 Procedures for Submitting to the Department of Energy Trade Secrets and Commercial or Financial Information That Is Privileged or Confidential, 76 FR 26579 (2011).
} 


\section{G. STRENGTHEN TECHNOLOGY TRANSFER AT FEDERAL}

\section{LABORATORIES}

\section{BACKGROUND}

The Stevenson-Wydler Act of 1980, as amended, is the key foundational legislation that defines and delineates how the technology transfer function will be conducted by Federal Laboratories-including GOGO and GOCO Laboratories. Among its key features, the StevensonWydler Act:

- Establishes the technology transfer function and describes the role and responsibilities of technology transfer at all Federal R\&D agencies and laboratories ${ }^{124,125 ;}$

- Authorizes a mechanism for public-private partnerships through Cooperative Research and Development Agreements ${ }^{126}$;

- Provides for policies that describe distribution and use of royalties from Federal Laboratory inventions ${ }^{127}$;

- Requires annual reporting on Federal technology transfer ${ }^{128 ;}$ and

- Creates the Federal Laboratory Consortium for Technology Transfer. ${ }^{129}$

\section{CHALLENGES}

Unlike the Bayh-Dole Act, for which the Secretary of Commerce is given authority to develop implementing regulations, the Stevenson-Wydler Act does not authorize the promulgation of regulations that would ensure consistent implementation of the Act's provisions.

The process and procedures related to granting this authority are well understood through the regulations that implement the Bayh-Dole Act by the Secretary of Commerce. As it is a clear objective of the Administration to reduce regulation and regulatory burden on businesses, regulation under this Act would be directed at streamlining government operations rather than

\footnotetext{
12415 U.S.C. $\S 3710$ (b) Establishment of Research and Technology Applications Offices and (c) Functions of Research and Technology Applications Offices

125 Federal Laboratories with 200 or more full-time equivalent scientific, engineering, and related technical positions are required to dedicate at least one full-time equivalent professional to staff an ORTA.

12615 U.S.C. $\S 3710 \mathrm{a}$

12715 U.S.C. § $3710 c$

12815 U.S.C. § 3710 (f) and (g)

12915 U.S.C. $\S 3710(\mathrm{e})$
} 
increasing a reporting or compliance burden on citizens. The process of promulgating a regulation is collaborative across agencies and requires both agency and public input. (Refer to box: "Federal Regulatory Process - Collaborative and Structured.") The technology transfer offices across the Federal Laboratories have developed and maintained a strong network throughout the Federal enterprise via both well-established interagency committees and working groups as well as other less formal mechanisms. These mechanisms work well in identifying and implementing best practices. However, policies do not have the ability to impact legal interpretations of the statute, which may vary at different agencies.

Regulations are a primary vehicle used by the Federal Government to implement laws. Outdated, unnecessary, and burdensome regulations are market-dampening forces that would benefit from streamlining. Updating regulations that ensure optimal performance by Federal agencies can serve to address market failures, reduce entry barriers, encourage greater competition, and spur innovation.

In 2007, the DOC delegated responsibility to NIST for implementing the Bayh-Dole regulations (37 C.F.R. § 401 and 37 CFR § 404). In 2018, NIST updated the regulations to synchronize the rules with the America Invents Act, incorporate provisions from Executive Order 12591 that have been in effect since 1987, and address provisional patent applications and other related issues. (Refer to box: "Example of Bayh-Dole Act Rulemaking (2016-2018).") The fact that the Stevenson-Wydler Act does not grant regulatory authority to any one Federal agency to issue regulations that would have government-wide applicability has contributed to a measure of uncertainty for the public due to what stakeholders said was the inconsistent interpretation of the law's requirements by different Federal agencies. 


\section{Federal Regulatory Process - Collaborative and Structured}

The regulatory process is a collaborative and structured system used by Federal agencies to issue rules to administer and enforce the legislative acts of Congress. Specific legislation enables a Federal agency's regulatory authority. Regulations are also used to amend or remove previously issued regulations. Regulations are codified in the Code of Federal Regulations. Federal agencies follow rulemaking processes to issue regulations, which includes the following steps for technology transfer regulations:

- Discussion within the Interagency Workgroup for Technology Transfer (IAWGTT) or the Interagency Workgroup for Bayh-Dole (IAWGBD)

- Discussion within the Lab-to-Market Subcommittee of the National Science and Technology Council

- NIST review and clearance

- Department of Commerce review and clearance

- For significant rules, submission to OMB for interagency review

- Receipt of interagency and OMB comments and integration of those comments into new version

- Final OMB clearance

- Proposed rule (also called a Notice of Proposed Rulemaking or NPRM) published in Federal Register

- Receipt and consideration of public comments

- Meetings with stakeholders, consistent with ex parte rules

- $\quad$ Revisions discussed with working groups (IAWGTT, IAWGBD, NSTC Lab-to-Market subcommittee)

- $\quad$ NIST clearance of revised rule with response to comments

- Department of Commerce clearance of revised rule with response to comments

- For significant rules, submission to OMB for interagency review of revised rule

- Receipt of interagency and OMB comments and integration of those comments into new version

- Final OMB clearance

- Final Rule published in Federal Register

- For major rules, delayed effective date to allow for congressional review under the Congressional Review Act 


\section{Example of Bayh-Dole Act Rulemaking (2016-2018) ${ }^{130}$}

- Regulatory agency: NIST

- Enabling legislation: Bayh-Dole Act

- $\quad$ NIST drafts proposed regulation, July 2016

- Interagency discussions as noted above

- Department of Commerce review and clearance

- Significant rule; submitted to OMB for interagency review and OMB clearance

- Proposed rule published in Federal Register with public comment period

- Receipt and consideration of public comments

- Interagency review and final OMB clearance

- Published final rule in Federal Register

- Regulation effective date May 14, 2018

- Changes to 37 CFR 401 and 37 CFR 404

\section{NIST FINDING}

NIST Finding 6. The Stevenson-Wydler Act does not authorize the promulgation of regulations that would ensure consistent implementation of the Act's provisions.

\section{A. REGULATORY AUTHORITY UNDER STEVENSON-WYDLER ACT}

Unlike the Bayh-Dole Act, which grants this regulatory authority to the Secretary of Commerce, the Stevenson-Wydler Act does not authorize the promulgation of implementing regulations. Many requirements of the Bayh-Dole Act that are implemented through regulations promulgated under authorities granted to the Secretary of Commerce are also pertinent to

130 "Rights to Federally Funded Inventions and Licensing of Government Owned Inventions," A Rule by the National Institute of Standards and Technology. Federal Register.

https://www.federalregister.gov/documents/2018/04/13/2018-07532/rights-to-federally-fundedinventions-and-licensing-of-government-owned-inventions 
partnership agreements under the Stevenson-Wydler Act. The government use license, preference for U.S. manufacturing, technology transfer agreements, and the ability to measure and report progress are all examples of areas that are addressed in regulation for extramural research but require new legislative action to address the same issues for intramural research. Addressing these common agency concerns through the same collaborative interagency process that DOC leads with respect to the implementation of the Bayh-Dole Act is not within the scope of the Stevenson-Wydler Act. This results in a lesser degree of responsiveness to provisions that the agencies have identified as impairing their abilities to effectively conduct technology transfer.

\section{H. PRESUMPTION OF GOVERNMENT RIGHTS TO EMPLOYEE INVENTIONS}

\section{BACKGROUND}

Like many employers, the Federal Government does have a presumed assignment of intellectual property rights for work-related inventions. Executive Order 10096, signed January 23, 1950 by President Harry Truman, ${ }^{131}$ provides that "[t]he Government shall obtain the entire right, title and interest in and to all inventions made by any Government employee (1) during working hours, or (2) with a contribution by the Government of facilities, equipment, materials, funds, or information, or of time or services of other Government employees on official duty, or (3) which bear a direct relation to or are made in consequence of the official duties of the inventor." The provisions of this Executive Order are included in 37 CFR 501 et seq. for the purposes of determining Federal employee invention rights.

In the Stanford $v$. Roche case, ${ }^{132}$ the U.S. Supreme Court noted that the Bayh-Dole Act allows a contractor to "elect to claim title," but does not automatically vest title to the contractor. Following this decision, an action was taken to amend the Bayh-Dole Act implementing regulations 133 to require that a contractor acquire a present assignment of rights from the employee in order to ensure that the government interest is protected. Although not directly addressed by the courts, this same consideration may be invoked to protect the government right to employee inventions under Executive Order 10096. The Executive Order does contain a presumption that the Federal Government will retain the entire right, title, and interest to Federal employee inventions:

${ }^{131}$ The Executive Order is available at: https://www.archives.gov/federal-register/codification/executiveorder/10096.html

132 (No. 09-1159 ) 583 F. 3d 832, https://www.law.cornell.edu/supct/html/o9-1159.ZS.html

133 37 CFR 401.14(f)(2), see https://www.federalregister.gov/documents/2018/04/13/201807532/rights-to-federally-funded-inventions-and-licensing-of-government-owned-inventions 
[I]t shall be presumed that an invention made by an employee who is employed or assigned (i) to invent or improve or perfect any art, machine, manufacture, or composition of matter, (ii) to conduct or perform research, development work, or both, (iii) to supervise, direct, coordinate, or review Government financed or conducted research, development work, or both, or (iv) to act in a liaison capacity among governmental or nongovernmental agencies or individuals engaged in such work, or made by an employee included within any other category of employees specified by regulations issued pursuant to section 4(b) hereof, falls within the provisions of paragraph (a), above, and it shall be presumed that any invention made by any other employee falls within the provisions of paragraph (b), above. Either presumption may be rebutted by the facts or circumstances attendant upon the conditions under which any particular invention is made and, notwithstanding the foregoing, shall not preclude a determination that the invention falls within the provisions of paragraph (d) next below.

In addition to the requirements in the Executive Order, Congress clarified in a policy statement that "[t]echnology transfer, consistent with mission responsibilities, is the responsibility of each laboratory science and engineering professional."134

\section{CHALLENGES}

The current practice described in the implementing regulations for employee inventions (37 CFR 501) requires taking an affirmative action to prove that the government right exists rather than following the presumption in Executive Order 10096. An attorney is needed to examine and make a finding as an administrative action, adding time and cost to each invention disclosure. This creates a considerable amount of burden and expense considering the number of inventions reported annually. 135 Given the broad applicability of this presumption as stated by Congress in the Stevenson-Wydler Act statutory policy statement, most inventions should be presumed to require assignment to the U.S. Government without further review. In cases where there is a question of rights, a rights determination could be performed by the agency and the current appeal rights retained.

In addition to the administrative costs associated with the rights determination for each invention, the requirement of assignment still relies on the Executive Order and regulations, rather than a firm basis in statute. Although the Executive Order has been in place for nearly seven decades, there are still questions about ownership of rights from employees in certain professions

13415 U.S.C. $3710($ a)(2)

135 Ex. 4,830 inventions were reported in FY 2015.

NIST. 2018. Federal Laboratory Technology Transfer Fiscal Year 2015.

https://www.nist.gov/sites/default/files/documents/2018/04/30/fy2015_fed_tt_report.pdf 
and in cases where employees hold additional positions outside the Federal Government. While the test in the Executive Order has been useful, there have been claims that employees developed inventions related to government work while on a dual appointment or in another work arrangement such as co-location with a university. The Stanford $v$. Roche case has moved employers to obtain a present assignment of rights, but the order of these claims has not been established.

\section{NIST FINDING}

NIST Finding 7. According to stakeholders, the process to determine a present assignment of invention rights by Federal employees to the Federal Government is overly burdensome.

\section{A. ASSIGNMENT OF RIGHTS IN INVENTIONS BY GOVERNMENT EMPLOYEES}

While executive Order 10096 requires a present assignment of invention rights by Federal employees to the Federal Government, simplified and streamlined regulations to implement this assignment could be considered to lower administrative burden while protecting rights of employees to their non-government invention rights.

\section{B. LEGAL BASIS FOR INVENTION RIGHTS FOR GOVERNMENT EMPLOYEES}

The Federal employee's requirement to report inventions and assign all rights, title, and interest in work-related inventions to the Federal Government is only contained in an Executive Order; there is currently no legislation in this area. 
This page intentionally left blank 


\section{STRATEGY 2. INCREASE ENGAGEMENT WITH PRIVATE SECTOR TECHNOLOGY DEVELOPMENT EXPERTS AND INVESTORS}

The second of five strategies of the L2M CAP Goal is focused on increasing engagement with private sector technology development experts and investors. The NIST findings, based on input from stakeholders, focus on topics that could make it easier for the private sector to partner with Federal agencies and to attract private sector investment for translational R\&D, technology maturation, and commercialization. This chapter discusses findings regarding existing partnership mechanisms for technology transfer and ways that technology transfer might be accelerated through expanded partnership mechanisms. The findings also highlight innovation ecosystems that include incubators, accelerators, public-private co-location, personnel exchanges, and research parks.

\section{A. INTRODUCTION}

For the Nation to see significant return on its investment in R\&D, the science and technology developments must be transferred to the private sector to enable practical application through further development and/or commercialization. There are critical components that enable this transfer to occur, including: (1) the availability of effective legal mechanisms to actualize the partnership and transfer of potentially impactful innovation from the lab to the private sector; (2) an ability to make connections between the federally funded R\&D performer and private industry so that industry is aware of existing technologies, expertise, and capabilities; and (3) a sufficient level of technology readiness to be of interest to private industry. Providing such information to the right private sector partner increases the chance of impact in the American marketplace.

\section{B. STREAMLINED PARTNERSHIP MECHANISMS}

\section{BACKGROUND}

Government-wide and agency-specific legislation and regulations provide a variety of legal mechanisms to facilitate engagement with the private sector. These mechanisms can be grouped into the following categories:

- Intellectual property protection, such as patents and copyrights;

- Property transfers, such as material transfer agreements;

- Research partnership agreements, such as CRADAs;

- $\quad$ Resource use agreements, such as those for use of facilities; 
- Educational agreements, such as training;

- Personnel exchange mechanisms, such as for guest researchers and fellows; and

- Agreements with intermediaries, such as partnership intermediary agreements.

The use of these mechanisms varies across agencies, reflecting the differences in agency missions as well as legislative authorities and practices across Federal Laboratories (Appendix 1).

Standard and required terms for these agreements vary based on legislation, regulations, and other governing policies. For instance, comparing the main partnering agreements used by the DOE's National Laboratories-Strategic Partnership Projects (SPPs), CRADAs, and Agreements for Commercializing Technology (ACT) ${ }^{136}$-demonstrates differing technology transfer mechanisms used to provide flexibility depending on the project, intellectual property ownership and indemnification concerns, among other contract terms (Appendix 2).

\section{CHALLENGES}

Stakeholders remarked that private companies and universities perceive collaboration with Federal Laboratories to be difficult due to differing authorities, processes, and required terms across agencies. Each Federal agency, however, has a statutorily defined mission. Inherently, those agency missions have a direct impact on technology transfer, because technology transfer must be conducted in a manner consistent with those missions. Agency terms vary regarding intellectual property rights, financial terms, and indemnification, among others. Inconsistent technology transfer mechanisms can frustrate potential partners and have a negative impact on technology transfer, particularly for institutions that are attempting to partner with multiple agencies. Adding to the confusion, there is contradictory statutory language. For example, there is a discrepancy in statute on who can be a CRADA partner in the CRADA authority (e.g., CRADA partner can be one or more non-Federal parties) versus the CRADA definition (e.g., CRADA partner can be other Federal agencies in addition to non-Federal parties). ${ }^{137}$

${ }^{136}$ DOE announced the ACT as a pilot program in December 2011, for further on the basis for development of the ACTs see Susannah V. Howieson, Brian J. Sergi, and Stephanie S. Shipp. 2013. Department of Energy Agreements for Commercializing Technology. IDA Science and Technology Policy Institute.

13715 U.S.C. § 3710a(a)(1) identifies the following organizations as potential CRADA partners: "other Federal agencies; units of State or local government; industrial organizations (including corporations, partnerships, and limited partnerships, and industrial development organizations); public and private foundations; nonprofit organizations (including universities); or other persons (including licensees of inventions owned by the Federal agency)." 
The 2018 GAO report similarly stated that, "some stakeholders had concerns about consistency in licensing practices both within the labs and across labs." 138 GAO also reported that stakeholders found the licensing process "lengthy and uniquely regulated, which can deter companies from licensing federal inventions." ${ }^{139}$ Stakeholders noted the added burden of navigating technology transfer processes and high transaction costs related to negotiating intellectual property terms. Stakeholders also noted that successful technology transfer of Federal Government R\&D investment is impeded by administrative bottlenecks and roadblocks posed by multiple, time-consuming layers of agency review and processing as well as difficulty communicating the purpose and rationale of agreement requirements to prospective licensees.

Royalties collected by Federal agencies are disbursed in accordance with provisions in the Stevenson-Wydler Act as codified in 15 U.S.C. $§ 3710 c$. The royalties are shared with all inventors of the licensed invention, with a maximum amount not to exceed $\$ 150$, ooo per year to any one person, unless the President approves a larger award. ${ }^{140}$ This cap has been in place for several decades. The National Defense Authorization Act (Public Law 115-91) ${ }^{141}$ authorized an increase for Department of Defense employees up to $\$ 500,000$ per year subject to approval at the level of the Secretary, unless the employee leaves the laboratory, which reduces the amount back to the $\$ 150,000$. Additionally, the statute states that royalties shall be retained and disbursed to inventors for "inventions." 142 Stakeholders indicated that there may be confusion and uncertainty among several agencies as to whether royalties can be collected and disbursed for transfers of technology that do not meet the definition of an "invention," such as software and biological materials.

15 U.S.C. § 3710(d)(1) defines a CRADA as an "agreement between one or more Federal laboratories and one or more non-Federal parties..."

138 U.S. Government Accountability Office (GAO). 2018. Federal Research: Additional Actions Needed to Improve Licensing of Patented Laboratory Inventions. https://www.gao.gov/assets/700/692606.pdf. 139 Ibid.

14015 U.S.C. $\S 3710 c(a)(3)$

${ }^{141}$ In Public Law 115-91, Section 233, Congress approved a pilot program to improve incentives for technology transfer from DoD laboratories. In Section 233(b)(2)(A), inventor share of royalties is capped at $\$ 500,000$ per year to any one person, unless a larger award is approved by the respective DoD branch Secretary. Section 233(b)(2)(B) caveats that an inventor leaving the laboratory shall be capped at \$150,000 unless the head of the agency approves a larger award. It should be noted that the pilot program will terminate 5 years after the date of the enactment of the Act, per Section 233(e).

14215 U.S.C. $\S 3710 c(a)(1)$ 


\section{NIST FINDING}

NIST Finding 8. According to stakeholders, improved clarity and use of best practices government-wide would streamline partnership agreements and increase transparency for $R \& D$ partners.

\section{A. USE OF BEST PRACTICES FOR TECHNOLOGY TRANSFER}

According to stakeholders, "speed-of-business"-based best practices and tools for technology transfer that deliver modern, streamlined, and responsive customer-experience could be better communicated government-wide. ${ }^{143}$

\section{B. LICENSING POLICIES AND PRACTICES}

According to stakeholders, publishing guidelines for government licensing practices for intellectual property at Federal Laboratories could help in enabling the statutory goal to promote commercial use of inventions while maintaining flexibility to tailor the specific financial terms of each license. ${ }^{144}$

\section{PURPOSE OF GOVERNMENT LICENSE ROYALTIES}

According to stakeholders, the purpose and intent of government licensing is not explicitly clarified either in the statute or regulations under the Bayh-Dole Act. Clarification of the purpose of royalties for licensing at Federal Laboratories could help promote compliance by the licensee to the terms of development and achieve practical application of technology, while promoting fairness and access to government owned technologies. ${ }^{145}$

143 These might include, for example, technology transfer taxonomy, menu-based customizable model agreements and templates; mission-aligned strategic portfolio-based intellectual property management; options for performance incentives and improved and available training for R\&D executives/officials as well as technology transfer/licensing professionals.

144 Responsive to May 2018 GAO Report (GAO-18-327) titled "Additional Actions Need to Improve Licensing of Patented Federal Inventions” (https://www.gao.gov/assets/700/692606.pdf). GAO recommended that: The Secretary of Commerce should instruct NIST to (1) fully report the range of challenges in Federal patent licensing, such as those outlined in this report, by, for example, leveraging its survey of practices at Federal technology transfer offices, past FLC studies, and agency reports and including that information in its summary reports to Congress; (2) clarify the link between establishing patent license financial terms and the goal of promoting commercial use, through appropriate means, such as the upcoming rule-making process and updating relevant guidance; and (3) facilitate formal information sharing among the agencies to provide Federal Laboratories with information on financial terms in comparable patent licenses, as appropriate.

145 In response to May 2018 GAO Report (GAO-18-327) Recommendation 2 in footnote 138. 37 CFR § 404.2 could be an appropriate place to consider language changes that describe the government policy 


\section{ROYALTIES FROM LICENSED INTELLECTUAL PROPERTY}

Formal authorization of royalty payments to Federal employees for non-invention forms of licensed intellectual property and extending to Federal employees at all agencies the increase in royalty cap of up to \$500,000 per year authorized in the FY 2018 National Defense Authorization Act (Public Law 115-91) are not within the scope of current legislation.

\section{E. CONFLICTING LANGUAGE IN CRADA AUTHORITY}

The current statute has a discrepancy regarding who can be a CRADA partner. ${ }^{146}$ Addressing difficulties executing CRADAs between Federal agencies, for example, between a Federal agency and another agency's GOCO Laboratory, is outside the scope of current legislation.

\section{EXPANDED PARTNERSHIP MECHANISMS}

\section{BACKGROUND}

Many agencies-especially large agencies such as the Department of Defense (DOD), NIH, and DOE-have received authority for expanded mechanisms and have developed innovative models for partnering with industry. These models have the potential to significantly benefit other Federal agencies as well. Examples of such partnership mechanisms include the use of nonprofit foundations, partnership intermediaries, ACT, and Other Transaction Authority (OTA).

Nonprofit foundations support Federal R\&D agencies by employing mechanisms that Federal agencies cannot always readily pursue, such as receiving and actively seeking gifts and other monetary donations from private donors and organizations. For example, the Foundation for the National Institutes of Health (FNIH) can raise non-federally appropriated funds that

on license royalties. It has generally been accepted that the government will use royalties to promote practical application of an invention as a method to ensure compliance by the licensee, promote fairness, and encourage invention to promote economic growth. It is not viewed as an alternative to appropriated funding or as funding mechanism.

14615 U.S.C. § 3710a(a)(1) identifies the following organizations as potential CRADA partners: "other Federal agencies; units of State or local government; industrial organizations (including corporations, partnerships, and limited partnerships, and industrial development organizations); public and private foundations; nonprofit organizations (including universities); or other persons (including licensees of inventions owned by the Federal agency)." 15 U.S.C. $§ 3710(d)(1)$ defines a CRADA as an "agreement between one or more Federal laboratories and one or more non-Federal parties..." 
support agency R\&D activities. ${ }^{147}$ In addition, foundations sponsored or initiated by Federal and State entities have facilitated technology commercialization and generated revenue to reinvest in R\&D. Foundations act synergistically with agency and Federal Laboratory technology transfer offices and serve to increase the capacity for identifying collaborative $R \& D$ and other opportunities.

Federal Laboratories may also use Partnership Intermediary Agreements (PIAs) ${ }^{148}$ to perform services that support cooperative or joint activities with small businesses, institutions of higher education, and other defined educational institutions. PIAs are a legal agreement between a Federal agency and an agency of-or nonprofit entity affiliated with-a State or local government as defined in statute. PIAs expand the capabilities of Federal Laboratories and establish a mechanism to coordinate technology deployment with regional economic development.

For example, the Maryland Technology Development Corporation (TEDCO), a public instrumentality of the State of Maryland, entered into PIAs with numerous DOD facilities since 2000, thereby using State funding to commercialize Federal R\&D. DOD uses a partnership intermediary, TechLink, operated by Montana State University, to provide information about all of DOD's active patents and assistance to non-Federal parties interested in licensing DOD technology. This capability could be made available to other agencies with additional resources. The FLC currently provides a link on their website to TechLink.

Nonprofit private foundations that operate on behalf of a Federal agency can be congressionally mandated or created within an agency to advance its mission. Most foundations for Federal agencies are established via acts of Congress. A few, including the United States Department of Agriculture (USDA)'s Agricultural Technology Innovation Partnership (ATiP) Foundation, are PIA arrangements. The main differences include: foundations have broad application, including technology transfer, while PIAs are narrowly focused to technology transfer functions; and foundations are essentially "start-ups" based on congressional action, while a PIA is a legal agreement between an agency and an existing nonprofit or State entity. Nonprofit foundations may enter into R\&D collaboration and service agreements with industry and with nonprofit, State, and local organizations.

One congressionally mandated example of a foundation is FNIH, authorized under Public Law 101-613 titled “The National Institutes of Health Amendments of 1990." The FNIH's primary duties include: (a) raising private funds to support the NIH mission; (b) creating innovative

\footnotetext{
147 "The FNIH manages the solicitation of funds by private donors for NIH research projects with appropriate firewalls." https://www.nih.gov/news-events/news-releases/nih-end-funding-moderatealcohol-cardiovascular-health-trial

14815 U.S.C. $§ 3715$ - Use of partnership intermediaries
} 
public-private biomedical partnerships that complement the NIH mission; providing a neutral forum to engage all partners to work together between NIH, Federal partners, industry, academia, and the philanthropic community; (c) accelerating transition of basic research findings into biomedical interventions and public health applications; and (d) enabling private partners to expand the number of funded NIH grants, among others. According to its 2017 Annual Report, FNIH has raised more the $\$ 1$ billion since its inception. ${ }^{149}$

University research parks and open campuses represent initiatives in which geographic proximity to local, State, and regional ecosystems can be leveraged to increase collaborative R\&D and technology maturation. A university research park is a property-based venture with numerous responsibilities: developing property master plans for research and commercialization; creating partnerships with universities and other research institutions; encouraging the growth of new companies; translating technology; and driving technology-led economic development. ${ }^{150}$ In a 2012 survey of university research parks, 88 percent of the respondents indicated that research parks provide access to business and commercialization services. ${ }^{151}$

Similarly, an open campus is a business model that facilitates collaborative engagement between Federal and private sector researchers through access to researchers, unique facilities, and additional collaboration resources. ${ }^{152}$ Open campuses aim to extend an organization's R\&D activities to other dispersed geographic facilities and organizations. Research and development is typically focused on the originating organization's mission priorities. Participating organizations and facilities receive a unique opportunity to collaborate face-to-face with researchers working on state-of-the-art problems and potentially benefit from the transfer of the results into commercial markets.

One Federal example is the Army Research Laboratory's (ARL) Open Campus initiative. ${ }^{153}$ Through the Open Campus initiative, ARL leverages regional expertise and facilities to accelerate

149 Foundation for the National Institutes of Health. 2017 Annual Report: Shaping the Future of Human Health. Available at: https://fnih.org/2017-annual-report/about-us/

150 Association of University Research Parks, n.d. "What is a Research Park?” Accessed Oct 11, 2018. https://www.aurp.net/what-is-a-research-park

${ }^{151}$ Battelle Technology Partnership Practice. 2013. Driving Regional Innovation and Growth: Results of the 2012 Survey of North American Research Parks. Prepared for Association of University Research Parks (AURP), August 2013.

https://aurp.memberclicks.net/assets/documents/aurp_batelllereportv2.pdf

152 United States Army. 2014. “Army Research Lab Open Campus Opportunities” Accessed 10/3/2018. https://www.arl.army.mil/www/pages/2357/ARL_Open_Campus_Opportunities.pdf

153 United States Army. “Army Research Lab, Extended.” Accessed Oct 1, 2018. https://www.arl.army.mil/opencampus/ARLExtended 
the discovery, innovation, and transition of science and technology of relevance to the Army. Partner researchers and institutions are given access to unique ARL facilities; real data sets and expertise; generation of joint intellectual property; incubation of spin-off companies for the pursuit of science and technology innovations; and maturation and rapid transition of intellectual property rights and technologies to the industrial marketplace. As of March 2017, the ARL open campus had 105 active CRADAs, 234 CRADA projects, and 775 visiting researchers; there was \$29.9 million of in-kind research in FY 2016.154 Another example is the DOE Oak Ridge National Laboratory's Manufacturing Demonstration Facility (MDF). ${ }^{155}$ The MDF is the DOE's first facility established to provide affordable and convenient access to R\&D expertise, facilities, and tools to facilitate rapid adoption of advanced manufacturing technologies to enhance the competitiveness of the U.S. workforce.

Open campuses associated with Federal Laboratories can help facilitate researcher and knowledge exchange by enabling prospective private and other R\&D collaborators to have access to state-of-the-art research facilities and other collaborative space. Open campuses tend to be "outside the fence," meaning R\&D collaborators experience streamlined facility access and security procedures than would otherwise be in place for "inside the fence."

One approach to grant non-Federal researchers access to unique government facilities is by leasing underutilized government property to the private sector. These agreements often occur when agencies hold land that is vital to their mission in the long-term, but they are currently not utilizing the facility or property at full capacity. Through these leases, private industry can work in close proximity to Federal researchers, which might enhance the outcomes of associated research partnerships. This has been used to establish open campuses and research parks at multiple Federal Laboratories, including 2008 Planetary Ventures Bay View at NASA Ames Research Center, the Rolls-Royce Outdoor Jet Engine Testing Facility at John C. Stennis Space Center, Falcon Hill National Aerospace Research Park at Hill Air Force Base, and the USDA Agriculture Research Service Beltsville Agricultural Research Center.

$\mathrm{ACT}^{156}$ is an innovative DOE partnering mechanism for GOCO Laboratories, using as authorization the Atomic Energy Act. 157 DOE authorized the use of ACTs as a permanent mechanism in October 2017 after piloting the program for 6 years. The ACT enables (i) DOE

\footnotetext{
154 Tien Pham, n.d. "ARL Open Campus - A New Model for Army Science and Technology." https://sites.nationalacademies.org/cs/groups/pgasite/documents/webpage/pga_180834.pdf 155 Oak Ridge National Laboratory. "Manufacturing Demonstration Facility." https://www.ornl.gov/mdf ${ }^{156}$ See https://www.energy.gov/technologytransitions/frequently-asked-questions-about-act 157 The Atomic Energy Act of 1954 (Public Law 83-703), codified in Title 42 of the U.S. Code.
} 
Laboratory contractors to engage in partnerships with terms that are more compatible with industry practices (e.g., business-friendly intellectual property rights, indemnification terms, best-effort performance, advance payments); (ii) supports Industry-Lab Partnerships that leverage Federal assets; and (iii) complements SPP, CRADA and User Agreements. ${ }^{158}$ DOE is currently piloting an extension of the ACT, called FedACT, that expands the use of ACT to allow organizations to partner with DOE's National Laboratories on federally funded projects. The ACT authority is not intended to replace other technology transfer mechanisms. Rather, it is intended to provide an alternative mechanism for creating partnerships in cases where standard DOE terms could not be negotiated.

\section{CHALLENGES}

According to stakeholders, the non-homogenous authorization of partnership mechanisms means that not all agencies can establish partnership agreements at the "speed-of-business" and attract private sector investment for translational R\&D, technology maturation, and commercialization efforts. Some of these partnership mechanisms also provide the means to build and leverage innovation ecosystems that include incubators, accelerators, public-private colocation, personnel exchange, and research parks.

Although CRADAs have proven to be an effective mechanism for collaboration, several agencies have been authorized to use OTA, which enables Federal agencies to pursue faster agreement negotiations and reduce the risks for businesses that seek to partner with the government. One example is the Space Act Agreements ${ }^{159}$ used by NASA to win the space race with the Soviet Union and still in use today. In addition to NASA, the following agencies currently have OTA authorizations: DOD, DOE, the Department of Homeland Security (DHS), the Department of Transportation (DOT), and USDA. ${ }^{160,161}$ Collectively, these agencies represented

158 ACT: Mechanism that allows DOE GOCO National Laboratories to partner with businesses and other non-Federal entities with greater flexibility than CRADAs or Strategic Partnership Projects (SPP) agreements. ACT allows a GOCO contractor to negotiate terms and conditions that are more consistent with private industry practice, such as IP rights, payment arrangements, indemnification, and development of multi-party R\&D partnerships. ACT is a contractual agreement based specifically on DOE statutory authorities.

159 National Aeronautics and Space Act of 1958 Public Law 85-568, 51 U.S.C. § 20113€. See https://www.nasa.gov/partnerships/about.html

160 GAO. 2016. Use of 'Other Transaction' Agreements Limited and Mostly for Research and Development Activities. https://www.gao.gov/assets/680/674534.pdf

${ }^{161}$ USDA received OTA Authorization in the Agricultural Improvement Act of 2018, P.L. 115-334 Sec. 7128 Agriculture Advanced Research and Development Authority. 
nearly 80 percent of the Federal R\&D budget in FY 2017. ${ }^{162}$ Considering an extension of OTA to all agencies for R\&D purposes would allow the remaining, mostly smaller, agencies to also use agreements that offer greater speed, flexibility, and accessibility in performing research and prototyping activities, and can be used to design and implement innovative business models within the government that would otherwise not be feasible. ${ }^{163}$ In order to preserve the intent of the Bayh-Dole Act to grant rights in inventions to recipients of Federal funding, any expanded use of OTA for R\&D collaborations should be constrained by a written confirmation by a warranted procurement official that existing mechanisms cannot achieve the goals of the intended $R \& D$ partnership. As discussed earlier, singular authority to promulgate government-wide regulations under the Stevenson-Wydler Act may also help clarify broader implementation of OTA.

Additionally, only DOE GOCO Laboratories are currently able to use ACT authority to open the unique knowledge, capabilities, and facilities at these laboratories to greater commercial development without hampering their intended government mission and function.

There are few foundations currently supporting Federal agencies, which is potentially due to confusion over whether agencies have the authority to establish foundations. Possibly another point of confusion may be whether agencies can use appropriated dollars to support a foundation if the foundation was not explicitly authorized by Congress. In general, congressionally established foundations have benefited from appropriated agency funding to partially support their operations.

\section{NIST FINDING}

NIST Finding 9. According to stakeholders, all Federal Laboratories do not have equal authorities to form partnership agreements at the speed of business and to attract private sector investment for translational R\&D, technology maturation, and commercialization.

\footnotetext{
162 National Science Foundation, National Center for Science and Engineering Statistics. "Survey of Federal Funds for Research and Development, Fiscal Years 2016-17.” Last updated June 2013. http://www.nsf.gov/statistics/fedfunds/

163 An overview of the Other Transaction Authority is available at: https://www.transform.af.mil/Portals/18/documents/OSA/OTA_Brief.pdf?ver=2015-09-15-073050867
} 


\section{A. ACT AUTHORITY}

Expansion of ACT authority is outside the scope of current legislation, as is regulatory authority under the Stevenson-Wydler Act ${ }^{164}$ that would permit a regulatory mechanism to expand the ACT authority ${ }^{165}$ to all GOCO Laboratories.

\section{B. OTHER TRANSACTION AUTHORITY}

Existing statute does not provide all agencies with OTA $^{166}$ to support translational R\&D collaboration ${ }^{167}$ by simplifying, accelerating, tailoring, and executing partnership agreements at the speed of business. If expanded more broadly, details on when and how to use the OTA for $\mathrm{R} \& \mathrm{D}$ collaborations could be included in legislation or through rules developed for implementation via regulatory authority under the Stevenson-Wydler Act. ${ }^{168}$ This could include a requirement for a written confirmation by a warranted procurement official that existing mechanisms cannot achieve the goals of the intended R\&D partnership. Any expansion of OTA should not be intended to change or limit existing authorities for agencies who already have OTA authorizations.

\section{NONPROFIT FOUNDATIONS}

The scope of existing legislation does not provide all Federal R\&D agencies the ability to establish Non-Profit Foundations. These foundations have the potential to advance the accomplishment of agency missions by attracting private sector investment to accelerate technology maturation, transfer, and commercialization of an agency's R\&D outcomes. ${ }^{169}$

164 Regulatory authority for implementation of provisions of the Stevenson-Wydler Act is not within the scope of current legislation, as discussed under Strategy 1, Section G.

165 See https://www.energy.gov/technologytransitions/frequently-asked-questions-about-act

16615 U.S.C. $\S 3710$ could be an appropriate place to consider a new section to create Other Transaction Authority which would expand to all applicable agencies the ability to use Other Transaction Authority (OTA). Only a few agencies are currently authorized to use OTAs.

167 To also include incubators, accelerators, public-private co-location, personnel exchange, and university-based research parks.

168 Regulatory authority for implementation of provisions in the Stevenson-Wydler Act is not within the scope of current legislation, as discussed under Strategy 1, Section G.

16915 U.S.C. $\S 3705$ details cooperative research centers and may be an appropriate place to consider modifications to extend the authority for agencies to develop nonprofit foundations. 


\section{OUTLEASING AUTHORITY}

Although some Federal R\&D agencies have legislated authority to outlease real property, this practice is not available to all agencies under the current law. The ability to make the most use of existing real property assets through the Enhanced Use Lease Authority (EULA), or other mechanisms for non-excess property, while retaining the potential for future government use is a potential way to increase interactions with Federal Laboratories but must be considered in the broader budgetary context.

\section{TECHNOLOGY COMMERCIALIZATION INCENTIVES}

\section{BACKGROUND}

Developing early-stage research discoveries into products for Federal or commercial use requires significant investment in capital and labor. According to GAO, "potential industry partners are often reluctant to assume the risks of investing in technologies whose potential has not been demonstrated with a prototype, performance data, or similar evidence."170

To address this issue and encourage industry partner interest, the Federal Government supports a variety of programs-some of which require a cost-sharing arrangement between an agency and a private company or other organization. Such programs involve both cross-cutting programs, such as those supporting small businesses, and agency-specific programs that support specific sectors:

- $\quad$ SBIR and Small Business Technology Transfer (STTR) Programs - the Federal Government's largest source of early-stage technology funding-are administered by the Small Business Administration through 11 Federal agencies with about \$2.5

170 U.S. Government Accountability Office (GAO). 2009. Technology Transfer: Clearer Priorities and Greater Use of Innovative Approaches Could Increase the Effectiveness of Technology Transfer at Department of Energy Laboratories. Washington, D.C.: GAO. GAO-09-548.

http://www.gao.gov/assets/300/290963.pdf 
billion ${ }^{171}$ annually set aside and about 160,000 awards granted; ${ }^{172}$ STTR requires collaboration with a not-for-profit research institution. ${ }^{173}$

- $\quad$ NIST pioneered the SBIR - Tech Transfer program, which links SBIR to federally owned patents for rapid commercialization. Other agencies have adopted this model.

- The DOD Rapid Innovation Program aims to transition technologies into applications that can be used on defense weapon systems and focuses on more mature technologies that would have an immediate impact. ${ }^{174}$

- The DOD Manufacturing Technology (ManTech) Program aims to advance the state-ofthe art for defense-essential manufacturing capabilities and supports manufacturing innovation institutes, which provide companies with access to facilities and risk sharing to bring new products to market and increase U.S. manufacturing competitiveness. ${ }^{175}$

- DOE Technology Commercialization Fund is funded via a set-aside of 0.9 percent of DOE's budget for applied energy research, development, demonstration, and commercial application and matches funds with private partners. ${ }^{176,177}$

- NIH, through its National Center for Advancing Translational Sciences programs-an institute of NIH-funds transition via its Clinical and Translational Science Awards. ${ }^{178}$

${ }^{171}$ SBIR is funded with $3.2 \%$ of extramural research budget for all agencies with a budget greater than $\$ 100$ million per year; STTR is funded with $0.45 \%$ of extramural research budget for all agencies with a budget greater than $\$ 1$ billion per year. SBA Office of Investment \& Innovation presentation on December 2016, slide 8 and 10. https://www.sbir.gov/sites/default/files/SBIR\%20Overview\%20DEC\%202016.pptx.

172 Ibid, slide 4.

173 Small Business Innovation Research (SBIR). “About SBIR.” Accessed October 1, 2018. https://www.sbir.gov/about

174 U.S. Department of Defense (DOD). n.d. “Rapid Innovation Fund.” Accessed Oct 11, 2018. https://defenseinnovationmarketplace.dtic.mil/business-opportunities/rapid-innovation-fund/

175 DOD. n.d. “Manufacturing Technology Program.” Accessed Oct 11, 2018. https://www.dodmantech.com/

176 U.S. Department of Energy (DOE). n.d. “Technology Commercialization Fund.” Accessed Oct 11, 2018. https://www.energy.gov/technologytransitions/services/technology-commercialization-fund

177 Section 1001 of the Energy Policy Act of 2005

178 National Institutes of Health (NIH). n.d. "Clinical and Translational Science Awards (CTSA) Program.” Accessed Oct 11, 2018. 
- NSF requires, through cooperative agreements, cost-sharing with academic and other organizations for its Engineering Research Centers, ${ }^{179}$ Industry-University Cooperative Research Centers (IUCRC), and Partnerships for Innovation ${ }^{180}$ programs.

- NIST supports the U.S. manufacturing sector through its Manufacturing Extension Partnership ${ }^{{ }_{1} 181}$ and, with DOD and DOE, the Manufacturing USA ${ }^{\circledR}$ program. ${ }^{182}$

\section{CHALLENGES}

The Congressional Research Service reports that a significant amount of funding, time, and energy is necessary to facilitate the adoption of the new technology by commercial entities. ${ }^{183}$ Additional analysis found that university-developed technologies "are so underdeveloped that they are doomed to remain in the laboratory unless incentives are added to induce ongoing collaboration between the inventors and the entrepreneurs seeking to take them to market." 184 Stakeholders echoed the same sentiment. Stakeholders also reported that it can be difficult to attract prospective private sector licensees for federally funded patents. Additionally, prior research has noted that "[t]he chasm between the immature state of the work emerging from the research laboratory and the level of maturity needed to attract a large corporate transferee was identified as one of the largest barriers to technology transfer." 185

NIST also finds that there are hurdles on the non-technical aspects of the commercialization process. For example, companies, particularly start-ups and small businesses, need capital to perform customer discovery and validation, which involve a substantial number of interviews and follow up meetings, and to iterate on their prototypes based on feedback. Start-ups, particularly

179 National Science Foundation (NSF). n.d. “Engineering Research Centers (ERC).” Accessed Oct 11, 2018. https://www.nsf.gov/funding/pgm_summ.jsp?pims_id $=5502$

180 NSF. n.d. "Partnerships for Innovation (PFI)." Accessed Oct 11, 2018. https://www.nsf.gov/funding/pgm_summ.jsp?pims_id=504790

${ }^{181}$ National Institute of Standards and Technology (NIST) and U.S. Department of Commerce, n.d. "Manufacturing Extension Partnership ${ }^{\circledR}$ (MEP)." Accessed Oct 11, 2018. https://www.nist.gov/mep

182 Manufacturing USA ${ }^{\circledR}$, n.d. “Manufacturing USA ${ }^{\circledR}$.” Accessed Oct 11, 2018. https://www.manufacturingusa.com/

183 Schacht, W. H. 2012. The Bayh-Dole Act: Selected issues in patent policy and the commercialization of technology. Library of Congress, Washington DC: Congressional Research Service.

184 Mary Elizabeth Hughes, Susannah Vale Howieson, Gina Walejko, Nayanee Gupta, Seth Jonas, Ashley T. Brenner, Dawn Holmes, Edward Shyu, and Stephanie Shipp. 2011. Technology Transfer and Commercialization Landscape of the Federal Laboratories. Washington, DC: IDA Science and Technology Policy Institute.

185 Wang, M., S. L. Pfleeger, D. M. Adamson, G. Bloom, W. Butz, D. Fossum, M. Gross, A. Kofner, H. Rippen, T. K. Kelly, and C. T. Kelley Jr. 2003. Technology Transfer of Federally Funded R\&D. Santa Monica, CA: RAND Science and Technology Policy Institute. 
those that may be interested in SBIR and STTR programs, may lack the capital to perform these essential functions for successful commercialization of their products. In addition, there are costs associated with obtaining patents and for identifying potential commercial partners; while some programs do allow for a portion of funding to be used for obtaining IP protection, many do not (Refer to box: "RFI Response on the Need for Resources for the Intellectual Property Process"). The protection of IP rights is an essential tool in attracting private capital. Stakeholders noted the difficulty of fulfilling the requirements to patent and license inventions in order to secure rights under the Bayh-Dole Act. This was particularly notable for small businesses and small institutions that do not have resources to invest in obtaining patent protection. The comments noted a need to allow a portion of award funds to be allocated to properly protect and sustain the government's investment in $\mathrm{R} \& \mathrm{D}$. Since the government retains a use license while in some instances placing the full cost on the contractor, it was noted that there is an imbalance in the requirements for cost and ensuing rights. When they work with federally funded technologies, small companies could also benefit from assistance on patenting and licensing, commercialization planning, and market assessments. NIST will communicate these suggestions to SBA. (Refer to box: "What We Heard: SBIR.”)

RFI Response on the Need for Resources for the Intellectual Property Process "It is challenging for universities and other recipients of Federal research funding to independently pay for technology and product research and development, as well as for preparation, filing, prosecutions and maintenance of patents and applications...Lack of funding for patenting and commercialization activities poses a fundamental challenge to a university's ability to transfer federally funded technologies."

Source: RFI-State University of New York 


\section{What We Heard: SBIR}

There were numerous suggestions and very strong data presented as evidence to support the SBIR/STTR Program as "America's Seed Fund." Below is a summary of what we heard from the RFI:

- Ensure the continued funding and sustainment/increase of the SBIR and STTR programs.

- Develop broader and more flexible approach to include translational research.

- Initiate an SBIR for Federal Laboratories.

- Expand "Phase zero" proof-of-concept pilot program (already implemented by NIH).

- Provide for additional flexibility in how SBIR/STTR funds can be used including market assessment, customer discovery, and technology transfer.

- $\quad$ Expand connections between SBIR and I-Corps ${ }^{\mathrm{TM}}$ to provide training.

- Promote the protection and use of Phase II inventions to Phase III.

- Better align the Federal Acquisition Regulation and Defense Federal Acquisition Regulation Supplement with SBIR.

- Increase geographic dispersion of awards.

- Reduce paperwork - consider shorter or modified Phase I applications.

- Further study SBIR metrics to inform how updates can maximize effectiveness.

Several stakeholders addressed the importance of $\mathrm{R} \& \mathrm{D}$ tax credits to stimulate private investment. Changes to the tax code, however, might be difficult at this time since major tax legislation was enacted into law very recently. ${ }^{186}$ NIST will communicate these suggestions to appropriate policy making bodies. (Refer to box: “What We Heard: Tax Incentives.”)

186 Public Law No: 115-97 (12/22/2017) 


\section{What We Heard: Tax Incentives}

Below is a summary of what we heard from the RFI:

- Provide tax incentives to investors to encourage them to take more risk early on in a technology project or tech start-up.

- Remove restrictions placed on public-private use of tax-exempt bond financed facilities through IRS Procedure 2007-047.

- Need for an improved R\&D tax credit.

- Provide incentives for companies to partner with universities for R\&D.

- Broaden basic research definition.

- $\quad$ Expand the corporate R\&D tax credit.

Many stakeholders noted that a new technology commercialization appropriation is needed. The scope of this Green Paper does not include programmatic funding proposals.

\section{NIST FINDING}

NIST Finding 10. According to stakeholders, recipients of Federal funding could benefit from a limited use of R\&D funds awarded via government grants, contracts, and cooperative agreements to enable intellectual property protection. A summary of public comments on SBIR/STTR technology maturation funding will be provided to the U.S. Small Business Administration. A summary of public comments on tax incentives for $R \& D$ will be provided to the appropriate policymaking bodies.

\section{A. LIMITED USE OF R\&D FUNDS FOR PATENTING}

Since the Bayh-Dole Act requires the contractor to secure a government use license to federally funded inventions, a regulatory change could be considered to make it possible to allow a reasonable amount of awarded R\&D funds (up to a specified maximum) to be used by the contractor to secure the government's right and interest to a patented invention. ${ }^{187}$

187 For example, 37 CFR 401.14(f) may be an appropriate place to consider a change to all a certain percentage of the award could be used to protect the government's right and interest in an invention through the contractor's election to patent. Any future action should not increase the size of any award. 
This page intentionally left blank 


\section{STRATEGY 3. BUILD A MORE ENTREPRENEURIAL R\&D WORKFORCE}

The third of five strategies of the L2M CAP Goal is focused on building a more entrepreneurial R\&D workforce to unleash American innovation. The NIST findings, based on input from stakeholders, focus on people and their roles in start-ups, job creation, and economic growth. Technology transfer activities are greatly enhanced through an R\&D workforce that is more knowledgeable about the needs of industry and with the flexibility to support industry's needs. This chapter discusses findings that, if addressed, could stimulate a more entrepreneurial mindset for the Federal R\&D workforce in areas such as skill building, mentoring, training, professional development, education, and personnel exchanges. It also describes findings regarding constraints to entrepreneurial activities posed by conflict of interest policies.

\section{A. INTRODUCTION}

The R\&D workforce is the foundation of the American R\&D enterprise and the greatest asset for U.S. innovation and industrial competitiveness. Federally funded researchers, engineers, and managers develop new innovative technologies, identify commercialization opportunities, and transfer technology to industry, or start companies themselves. Further, since passage of the Federal Technology Transfer Act of 1986, which amended the Stevenson-Wydler Act of 1980, "technology transfer, consistent with mission responsibilities, [has been] a responsibility of each laboratory science and engineering professional." 188 By empowering both the intramural and extramural R\&D workforce to be more entrepreneurial, the Federal Government ensures that its funds will be used with an eye towards practical application and commercialization, resulting in a greater return on investment to the American taxpayer.

At its core, technology transfer is a person-to-person "contact sport" requiring robust engagement between motivated researchers and engaged industry representatives. Innovators need to be knowledgeable about the needs of industry, while those in industry need to be flexible and responsive, to effectively transfer technology. Truly revolutionary technologies can languish if a strong business acumen is not available to meet the challenges of bringing a technology to market. The skills needed to develop a value proposition and assemble a team to run a business are not within the classical training of researchers. Training and flexible solutions could enhance entrepreneurial mindsets that enable the inventor to take a new product to market, or to communicate the discovery and its implications to a business that will eventually translate the new ideas into tomorrow's products and services.

18815 U.S.C. $§ 3710$ (a) - Utilization of Federal Technology, Policy 


\section{B. TECHNOLOGY ENTREPRENEURSHIP PROGRAMS}

\section{BACKGROUND}

Training and professional development programs are mechanisms used across government, business, and education to acquire specific skills or areas of knowledge. These programs impart important competencies that are not necessarily learned on the job. The Federal Government uses entrepreneurial training and professional development to give the R\&D workforce the tools they need to be more enterprising.

Researchers play a critical role in technology transfer because they have the best understanding of the technology itself and its functional uses, along with the needed know-how, but not necessarily the commercial opportunities and path forward. Most scientists and researchers lack experience in business formation, ${ }^{189}$ may be unaware of how to collaborate with industry, and may not understand the commercial viability of their innovations. ${ }^{190}$ This skill gap can lead to an inability to balance basic research and the identification of commercialization opportunities, and can hinder the effective transfer of technology. ${ }^{191}$ In general, entrepreneurial training programs teach researchers to understand the needs of industry, to commercialize technology, and to recognize their potential to add to the technology transfer and start-up ecosystem. Federally funded training programs not only educate researchers on how to navigate this balance, but also establish an avenue for product development.

Federal agencies use training and professional development in diverse ways to achieve their unique goals and needs. Some agencies use mentoring as a complement to other entrepreneurial programs. For example, the NIST Science and Technology Entrepreneurship Program (N-STEP) program provides mentors to researchers and associates affiliated with NIST to evaluate research for business potential and helps develop new businesses that can commercialize the research results. ${ }^{192}$ The DOE Lab-Embedded Entrepreneurship Programs (LEEP) take top entrepreneurial

189 West, Darrell. 2012. "Improving University Technology Transfer and Commercialization.” Issues in Technology Innovation, Num 20. https://www.brookings.edu/research/improving-universitytechnology-transfer-and-commercialization/

190 GAO. 2014. Federal Laboratory Commission Should Increase Communication with Potential Customers to Improve Initiatives. https://www.gao.gov/products/GAO-15-127

191 Hughes, Mary E., Susannah V. Howieson, Gina Walejko, Nayanee Gupta, Seth Jonas et al. 2011. Technology Transfer and Commercialization Landscape of Federal Laboratories, Washington, DC: IDA Science and Technology Policy Institute.

192 TEDCO. "Providing opportunities to Maryland researchers." Website accessed 9/26/2018. https://www.tedcomd.com/funding/tech-transfer/n-step 
scientists and engineers and embed them within DOE National Laboratories to perform earlystage R\&D that may lead to the launch of energy or manufacturing businesses in the future. ${ }^{193}$ Other agencies have established mentoring networks to counsel entrepreneurs, such as the SBA SCORE program, which consists of 13,000 volunteer businessmen and businesswomen. Additional programs are designed to directly provide innovation training and professional development, most notably the NSF Innovation $\operatorname{Corps}^{\mathrm{TM}}\left(\mathrm{I}-\operatorname{Corps}^{\mathrm{TM}}\right) .{ }^{194}$

I-Corps $^{\mathrm{TM}}$ is an accelerated version of the Stanford University's Lean Launchpad course. ${ }^{195,196}$ Founded in 2011, this experiential learning program seeks to give federally funded extramural researchers a course in start-up entrepreneurship. I-Corps ${ }^{\mathrm{TM}}$ teams-composed of a technical lead, entrepreneurial lead, and business (or industry) mentor-engage in a 7-week curriculum 197 to understand customer problems that their technology may address, potential addressable markets, and the potential pathways forward to commercialize their technology concepts. I-Corps ${ }^{\mathrm{TM}}$ teams are exposed to feedback from potential customers with the goals of understanding their markets and learning how to identify fail-fast issues and pivot to alternative paths forward. I-Corps ${ }^{\mathrm{TM}}$ teams also develop regional networks, engage in customer discovery work, and receive hands-on training on entrepreneurship and ecosystem development.

I-Corps ${ }^{\mathrm{TM}}$ started at NSF and some agencies, such as DHS, DOD, ${ }^{198}$ and NASA ${ }^{199}$ partner with NSF to send awardees through NSF I-Corps ${ }^{\mathrm{TM}}$ programs. Other agencies have developed their own programs based on I-Corps ${ }^{\mathrm{TM}}$ and adapted the curriculum for their research

193 Department of Energy. “Lab-Embedded Entrepreneurship Programs.” Accessed 9/26/2018. https://www.energy.gov/eere/amo/lab-embedded-entrepreneurship-programs

194 National Science Foundation (NSF). “I-Corps ${ }^{\text {TM }}$." Website accessed 9/26/2018. https://www.nsf.gov/news/special_reports/I-Corps ${ }^{\mathrm{TM}}$ /

195 Stanford. 2014. "Stanford's Lean LaunchPad Course Sets Students on Entrepreneurial Trajectory." Accessed 9/26/2018. https://stvp.stanford.edu/blog/stanfords-lean-launchpad

196 National Science Foundation (NSF) was directed by Congress to continue funding I-Corps ${ }^{\mathrm{TM}}$ and encouraged to expand the program in Section 601 of the American Innovation and Competitiveness Act of 2017, Public Law 114-329.

197 The I-Corps ${ }^{\mathrm{TM}} 2016$ Teaching Handbook is available for download and view at https://venturewell.org/wp-content/uploads/I-Corps ${ }^{\mathrm{TM}}$-Teaching-Handbook-Jan16.pdf

198 U.S. Department of Defense (DOD). 2018. "I-Corps ${ }^{\mathrm{TM}}$ @ DoD Funding Announcement.” https://basicresearch.defense.gov/News/Articles/News-Display/Article/1490285/I-Corps ${ }^{\mathrm{TM}}$-dod- $^{-}$ funding-announcement/

199 National Aeronautics and Space Administration. 2018. "I-Corps ${ }^{\mathrm{TM}}$ Program.” Accessed 10/1/2018. https://sbir.nasa.gov/content/I-Corps ${ }^{\mathrm{TM}}$. 
communities. Examples of agency-based programs include I-Corps ${ }^{\mathrm{TM}} @ \mathrm{NIH},{ }^{200,201}$ National Security Agency's (NSA) version of I-Corps ${ }^{\mathrm{TM}}$ for the Intelligence Community, ${ }^{202} \mathrm{I}^{-C o r p s}{ }^{\mathrm{TM}}$ at ARPA-E,203 Energy I-Corps ${ }^{\mathrm{TM}}$ at DOE, 204 and the USDA I-Corps ${ }^{\mathrm{TM}}$ Agricultural Research Service (ARS) pilot program. ${ }^{205}$ Some States have also collaborated with NSF to create I-Corps ${ }^{\mathrm{TM}}$ programs, such as I-Corps ${ }^{\mathrm{TM}} @$ Ohio. ${ }^{206}$ Most agencies provide entrepreneurial training for extramural researchers funded under their research programs, while some programs, such as NIH's Clinical and Translational Science Awards (CTSA), train professionals working on translating science into practical applications. ${ }^{207}$ For example, the University of Michigan created a supplementary training program for CTSA called Fast Forward Medical Innovation (FFMI) fastPACE to accelerate entrepreneurial training. ${ }^{208}$

Stakeholders perceived government entrepreneurial training and professional development programs, especially I-Corps ${ }^{\mathrm{TM}}$, to be very successful. Stakeholders remarked on the success of ICorps $^{\mathrm{TM}}$ in preparing scientists, engineers, and graduate students to extend their focus beyond the laboratory. From 2011 to June 2018, I-Corps ${ }^{\mathrm{TM}}$ trained 1,223 teams representing 248 universities

200 National Institutes of Health (NIH). 2018. “The I-Corps ${ }^{\mathrm{TM}}$ at NIH.” Accessed 10/1/2018. https://sbir.cancer.gov/programseducation/icorps.

${ }^{201}$ Domain focused programs include the I-Corps ${ }^{\mathrm{TM}} @ \mathrm{NIH}$, which includes cross-cohort learning on sector-specific topics like regulatory strategy for therapeutic candidates, and a National I-Corps ${ }^{\mathrm{TM}} \mathrm{NSF}$ Cohort, which may focus topics of a more granular nature, such as business model differences between a manufactured product versus a business service. NSF also has built a relationship with Science Foundation Ireland (SFI) to send their teams through the NSF program. The program is called ICorps@SFI. Additionally, the DOE also has an I-Corps program called Energy I-Corp, that DoE manages and is separate from the NSF program, and is specialized for energy opportunities.

202 The White House. 2015. "Fact Sheet: President Obama Announces New Commitments from Investors, Companies, Universities, and Cities to Advance Inclusive Entrepreneurship at First-Ever White House Demo Day." https://obamawhitehouse.archives.gov/the-press-office/2015/o8/o4/fact-sheetpresident-obama-announces-new-commitments-investors-companies

203 ARPA-E. "I-Corps ${ }^{\mathrm{TM}}$ at ARPA-E." Accessed 10/1/2018. https://arpa-e.energy.gov/?q=site-page/ICorps $^{\mathrm{TM}}$-arpa-e.

204 Department of Energy. “Energy I-Corps.” Accessed 10/1/2018. https://www.energy.gov/eere/technology-to-market/energy-i-corps

205 Bahar, Mojdeh. "I-Corps ${ }^{\mathrm{TM}}$ ARS-A New Twist on NSF's I-Corps ${ }^{\mathrm{TM}}$ Model." https://meeting.federallabs.org/wp-content/uploads/2018/o4/I-Corps ${ }^{\mathrm{TM}}$-at-ARS-I-Fast-at-NIFAM.Bahar_.pptx

206 I-Corps ${ }^{\text {TM }}$ Ohio. Accessed 10/1/2018. https://icorpsohio.org/

207 NIH. “About the CTSA Program.” Accessed 10/1/2018. https://ncats.nih.gov/ctsa/about.

208 Servoss, Jonathan et al. 2017. "fastPACE Train-the Trainer: A scalable new educational program to accelerate training in biomedical innovation, entrepreneurship, and commercialization." Journal of Clinical and Translational Science, Volume 1, Issue 5. 
from 47 States, D.C., and Puerto Rico. ${ }^{209,210}$ NSF has also used I-Corps ${ }^{\mathrm{TM}}$ programs to promote inclusion in science and technology entrepreneurship through efforts such as funding targeted ICorps $^{\mathrm{TM}}$ sites, ${ }^{211}$ and to promote a more entrepreneurial mindset. ${ }^{212}$ Teams that went through ICorps $^{\mathrm{TM}}$ raised $\$ 300$ million in follow-on funding and started 583 start-up companies, with six of those start-ups being successfully acquired by a larger company. ${ }^{213}$

Federal agencies also use accelerator and incubator programs to stimulate entrepreneurship. A seed accelerator is defined as "a fixed-term, cohort-based program, including mentorship and educational components, that culminates in a public pitch event or demo-day." 214 Accelerator programs typically offer funding and other support services to potential start-up companies in return for a share of equity in the company. Accelerators generally attempt to expedite the growth of an existing company in a few weeks or months. Alternatively, incubators recruit individuals with promising ideas and nurture them over a longer period of time with the hope of establishing a business model and company based on a particular innovation. ${ }^{215}$

Federal accelerator programs include the SBA Growth Accelerator Fund Program launched in 2014. From 2014 to 2017, SBA funded approximately 235 accelerators and incubators. ${ }^{216}$ Cyclotron Road, embedded within DOE's Lawrence Berkeley National Laboratory, is an example of an incubator that recruits entrepreneurial technology fellows. Fellows receive access to

209 NSF. "I-Corps ${ }^{\mathrm{TM}}$ Curriculum and Resources." Accessed 10/1/2018. https://www.nsf.gov/news/special_reports/I-Corps ${ }^{\mathrm{TM}} /$ resources.jsp.

210 In addition to the nine NSF I-Corps Nodes, there are also 99 sites that contribute to the national infrastructure of I-Corps ${ }^{\mathrm{TM}}$ - providing additional geographic reach beyond the nine Nodes. Link to a recent map of sites: https://www.nsf.gov/news/special_reports/i-corps/sites.jsp

${ }^{211}$ NSF. 2017. "NSF promotes inclusion in tech entrepreneurship through eight I-Corps ${ }^{\text {TM }}$ Sites." https://www.nsf.gov/news/news_summ.jsp?cntn_id=190921

212 VentureWell. 2016. "How an Entrepreneurial Mindset Can Make Research More Effective: Reflections from an I-Corps ${ }^{\mathrm{TM}}$ Alumnus.” https://venturewell.org/entrepreneurial-mindset-can-make-researcheffective-reflections-corps-alumnus/

213 National Science Foundation (NSF). "I-Corps ${ }^{\text {TM }}$ Curriculum and Resources." Website accessed 9/26/2018. https://www.nsf.gov/news/special_reports/I-Corps ${ }^{\mathrm{TM}} /$ resources.jsp

214 Susan G. Cohen, University of Richmond, and Yael V. Hochberg (Massachusetts Institute of Technology and the National Bureau of Economic Research. 2014. "Accelerating Startups: The Seed Accelerator Phenomenon,” March 2014, http://seedrankings.com/pdf/seed-acceleratorphenomenon.pdf

215 Conner Forest. 2018. “Accelerators vs. Incubators: What Startups Need to Know.” TechRepublic. June 25, 2018. https://www.techrepublic.com/article/accelerators-vs-incubators-what-startups-need-toknow/

216 See SBA Growth Accelerator Fund Competition: https://www.sba.gov/content/sba-growthaccelerator-fund-competition 
laboratory scientists and equipment to pursue technology development, raise capital, build a business case, and ideally commercialize their products. Since 2015, Cyclotron Road has awarded more than $\$ 15$ million to 41 fellows who have generated an additional \$75 million in early stage funding from varied sources to support their projects. ${ }^{217}$

\section{CHALLENGES}

Stakeholders overwhelmingly provided positive evaluations of I-Corps ${ }^{\mathrm{TM}}$ and indicated that these successes could be expanded. (Refer to box: "RFI Recommendations for I-Corps ${ }^{\mathrm{TM}}$ Expansion.”) The NSF I-Corps ${ }^{\mathrm{TM}}$ is organized around nine regional I-Corps ${ }^{\mathrm{TM}}$ Nodes designed to support regional needs. ${ }^{218}$ While these regional nodes are intended to sustain a national ecosystem, the limited geographic reach of I-Corps ${ }^{\mathrm{TM}}$ caps its effectiveness in regions that are geographically distant from its nodes. Furthermore, agencies provide I-Corps ${ }^{\mathrm{TM}}$ training for the extramural researchers funded under their grants, so agencies without I-Corps ${ }^{\mathrm{TM}}$-like programs or agreements with the NSF I-Corps ${ }^{\mathrm{TM}}$ program do not have access to the training.

Stakeholders also indicated that I-Corps ${ }^{\mathrm{TM}}$ and I-Corps ${ }^{\mathrm{TM}}$-like programs could be improved by targeting populations interested in commercialization. For example, graduate students or postdoctoral researchers may be a target audience to start companies. Entrepreneurial training could also be paired with other training programs to reach groups interested in commercialization-for example, the NASA and NIH I-Corps ${ }^{\mathrm{TM}}$-like programs fund groups that have already received Phase I funding from the SBIR/STTR programs. ${ }^{219}$ Agencies could expand this by pairing entrepreneurial training with SBIR/STTR awards or requiring that SBIR/STTR Phase I awardees participate in an entrepreneurial training or professional development program before becoming eligible to receive a Phase II award. ${ }^{220}$ Other stakeholders recommended addressing industry need by establishing training programs relevant to "hot" technologies or specializing I-Corps ${ }^{\mathrm{TM}}$ nodes to address specific branches of research. (Refer to box: "RFI Recommendation to Better Target Training Programs.”)

217 Cyclotron Road, n.d. “Home.” Accessed Oct 11, 2018. http://www.cyclotronroad.org/home/

218 The nine nodes are spread out around the Nation. See a list of the nodes here: https://www.nsf.gov/news/special_reports/I-Corps ${ }^{\mathrm{TM}} /$ nodes.jsp

219 See Chapter on Strategy 2 of this report for an introduction and overview of SBA SBIR/STTR programs.

220 Blank, Steve. 2012. "Innovation Corps: A Review of the New National Science Foundation Program to Level Research Investments.” https://science.house.gov/sites/republicans.science.house.gov/files/documents/HHRG-112-SY21WState-Sblank-20120716_o.pdf 


\section{RFI Recommendations for I-Corps ${ }^{\mathrm{TM}}$ Expansion}

"We urge NIST and the administration to continue to support the I-Corps ${ }^{\mathrm{TM}}$ program at the NSF and to encourage that other Federal research agencies establish and expand I-Corps ${ }^{\mathrm{TM}}$ programs."

Source: RFI response, Association of American Universities (AAU), Association of Public and Land-grant Universities (APLU), Council on Governmental Relations (GOGR), Association of American Medical Colleges (AAMC), and American Council on Education (ACE)

"UC supports the expansion of the successful NSF I-Corps ${ }^{\mathrm{TM}}$ program into other agencies. This program helps train academics in entrepreneurship by giving them the tools to effectively commercialize the results of their research."

Source: RFI response, University of California (UC)

\section{RFI Recommendation to Better Target Training Programs}

"CMU recommends that these programs also include support for establishing regional Lab hubs and I-Core nodes focused on emerging technologies-such as autonomy, AI, quantum computing and critical areas of advanced manufacturing."

Source: RFI response, Carnegie Mellon University (CMU)

Leveraging regional innovation ecosystems has proven to be a successful approach to increasing economic investment and growth centered on a geographic area. A 2014 economic analysis concluded that the establishment of an accelerator program has an impact on the geographical region where the accelerator was formed. Both start-up companies and venture capitalists are often attracted to the region. ${ }^{221}$ The establishment of accelerators and incubators can provide an opportunity for Federal Laboratories to pursue partnerships and leverage resources for technology transfer. However, a potential challenge is that there may not be sufficient leadership emphasis and incentives for laboratory researchers to engage with other stakeholders. This support can be indispensable to maximizing the effectiveness of the Federal Laboratory's technology transfer mission. ${ }^{222}$ (Refer to box: "RFI Response on Federal Laboratory Leadership Support for Technology Transfer.")

221 Daniel C Fehler and Yael V Hochberg. 2014. "Accelerators and the Regional Supply of Venture Capital Investment." September 19, 2014. http://www.seedrankings.com/pdf/accelerators-and-regionalsuppy-of-vc-investment.pdf

222 Palmintera, D. 2003. Partners on a mission: Federal laboratory practices contributing to economic development. Office of Technology Policy, Technology Administration, U.S. Department of Commerce. 
RFI Response on Federal Laboratory Leadership Support for Technology Transfer

"With some notable exceptions, Federal Laboratory directors do not view tech transfer as central to their core mission. In fact, since some Federal Laboratories support tech transfer through overhead budget lines, tech transfer is in direct competition for funding with operational expenses including security, IT, training, and infrastructure upgrades. Additionally, Federal Laboratories are encouraged and rated on their ability to keep their overhead low, so increasing funding for tech transfer within the overhead budget line is often discouraged. Commercialization performance at Federal Laboratories will continue to lag universities until laboratory leaders are directed, funded, and incentivized to place greater emphasis on commercialization outcomes, including through accountability to meaningful metrics."

Source: RFI response, State University of New York

Most existing entrepreneurial training programs are targeted towards extramural researchers. The primary pathway for admittance in the NSF I-Corps ${ }^{\mathrm{TM}}$ program is for participants to have received an NSF award. ${ }^{223}$ For NSF I-Corps ${ }^{\mathrm{TM}}$, Federal researchers do not typically participate in these programs. Some agencies do host commercialization related training/workshops for Federal researchers. NASA, for example, hosts an annual SBIR Technology Commercialization Workshop for its employees. ${ }^{224}$ However, these training programs are of limited scope due to conflict of interest regulations. For example, I-Corps ${ }^{\mathrm{TM}}$ training is developed around the experience of taking a technology to market and understanding its commercial viability-activities that Federal researchers are typically precluded from conducting when related to their job functions. ${ }^{225}$ The inability of Federal researchers to participate in I-Corps ${ }^{\mathrm{TM}}$ and similar programs may limit the reach of current entrepreneurial programs from a large segment of the Federal R\&D portfolio. NIST will communicate these suggestions to the National Science Foundation (NSF). (Refer to box: "What We Heard: ICorps $^{\text {TM.".) }}$

223 Another pathway is for teams that have successfully completed regional I-Corps ${ }^{\mathrm{TM}}$ training at an ICorps $^{\mathrm{TM}}$ Node or I-Corps ${ }^{\mathrm{TM}}$ Site to join the National I-Corps ${ }^{\mathrm{TM}}$ program.

224 Lal, Bhavya et al. 2013. Expediting the Transfer of Technology from Government Laboratories into the Aeronautics Industry. IDA Science and Technology Policy Institute.

225 See 18 U.S.C. $\$ 208$ and §209, 5 C.F.R §2935 and §2936, and OGE guidance at https://www.oge.gov/web/oge.nsf/Use+of+Government+Position+and+Resources. For more information, see the Conflict of Interest Policies section of this chapter (Section C). 


\section{What We Heard: I-Corps ${ }^{\mathrm{TM}}$}

There were numerous suggestions regarding the success of the I-Corps ${ }^{\mathrm{TM}}$ Program. Below is a summary of what we heard from the RFI:

- Maintain and expand I-Corps ${ }^{\mathrm{TM}}$.

- Customize I-Corps ${ }^{\mathrm{TM}}$ to focus on specific areas.

- For large awards, require that the proposal include entrepreneurial training.

- Provide formal programs that are targeted to the tech-based start-ups needing longer term (>10 years) to reach a product.

- Allow Federal employees to participate in I-Corps ${ }^{\mathrm{TM}}$.

In addition to strong entrepreneurship programs externally, it is also important to have trained professionals in technology transfer to promote entrepreneurship. Technology transfer is not clearly recognized as a career choice across Federal agencies. There is a lack of uniformity in the job description, job titles, and described functions for the professionals who carry out the important functions of technology transfer offices. This hinders the ability of the Federal agencies to attract and recruit well qualified candidates, and results in a lack of adequate opportunities for continued growth and development of technology transfer professionals. The basis of technology transfer involves understanding research at the laboratory, and a scientific and technical background is common. However, technology transfer professionals must also be skilled in business applications, negotiation, capital investment, outreach, and management as well as aware of legal contracts and the patent system. Since the Office of Personnel Management (OPM) Occupational Handbook does not currently contain a jobs series for technology transfer, ${ }^{226}$ Federal agencies offer technology transfer positions in a wide variety of occupational series.

\section{NIST FINDING}

NIST Finding 11. According to stakeholders, establishing technology entrepreneurship programs at Federal R\&D agencies government-wide will help build a more entrepreneurial R\&D workforce. A summary of public comments specific to NSF's I-Corps ${ }^{\mathrm{TM}}$ Program, DOE's Lab-Embedded Entrepreneurship

226 The Occupational Handbook is available at: https://www.opm.gov/policy-dataoversight/classification-qualifications/classifying-general-schedulepositions/occupationalhandbook.pdf 
Program, and other agency entrepreneurial programs will be provided to the respective agencies.

\section{A. EXPANDED TECHNOLOGY ENTREPRENEURSHIP PROGRAMS}

According to stakeholders, Federal R\&D agencies could better leverage entrepreneurship programs representing best practices, such as NSF's I-Corps ${ }^{\mathrm{TM} 227}$ program for extramural R\&D programs, and internal experiential training programs such as DOE's Lab-Embedded Entrepreneurship Program ${ }^{228}$ for intramural R\&D programs.

\section{B. IMPLEMENTING AND OPERATING TECHNOLOGY ENTREPRENEURSHIP PROGRAMS}

Policies and practices could be adopted and communicated government-wide to implement and operate technology entrepreneurship programs at Federal R\&D agencies.

\section{JOB SERIES FOR TECHNOLOGY TRANSFER PROFESSIONALS}

A designated job series to recruit, develop, and retain well qualified professionals to pursue a career in Federal technology transfer does not currently exist. According to stakeholders, given the need for individuals with business backgrounds and scientific/technical backgrounds, a job series that is inclusive of both types of professionals required to carry out technology transfer functions could improve agencies' abilities to recruit and retain technology transfer professionals.

\section{MANAGING CONFLICTS OF INTEREST}

\section{BACKGROUND}

Technology transfer ultimately happens through the movement of ideas and knowledge. This can be accomplished by enabling personnel mobility. Rotating external technical talent into

227 National Science Foundation (NSF). “I-Corps ${ }^{\text {TM } . ” ~ W e b s i t e ~ a c c e s s e d ~ 9 / 26 / 2018 . ~}$ https://www.nsf.gov/news/special_reports/I-Corps ${ }^{\mathrm{TM}}$ /

228 Department of Energy (DOE). “Lab-Embedded Entrepreneurship Programs.” Website accessed 10/26/2018. https://www.energy.gov/eere/amo/lab-embedded-entrepreneurship-programs 
Federal science and technology projects, or vice versa, serves as a potent vehicle for technology transfer. ${ }^{229}$

A conflict of interest can be defined as a situation in which a person's official duties are at conflict with other secondary interests. Conflicts of interest are common among all professions but are especially important for Federal Government interests because workers who administer and use public funds are placed in a unique position of trust. 230

Federal ethics statutes constrain the actions of Federal employees along with extramural researchers who receive Federal funding. For government employees, the Office of Government Ethics (OGE) promulgates Federal ethics regulations across the Federal Government. The OGE groups Federal ethics rules into five areas: (1) financial conflicts and impartiality, (2) postgovernment employment, (3) outside employment and activities, (4) gifts and payments, and (5) use of government position and resources. ${ }^{231}$ Conflict of interest plays a key role in each of these areas, with the most applicable section to entrepreneurial practices being financial conflict of interest and impartiality.

The basic criminal conflict of interest statute "prohibits Government employees from participating personally and substantially in official matters where they have a financial interest." 232 Other important provisions address the ability to represent a third party before the U.S. Government; ${ }^{233}$ and prohibit the supplementation of a Federal employee's salary. ${ }^{234}$ The practical implications of these statutes include the types of businesses a Federal employee can own and operate, if or for whom they can consult, what royalties they can take from their intellectual property, and what assets they can hold.

229 U.S. Office of Personnel Management. 2018. "Hiring Information: Intergovernmental Personnel Act." Accessed September 21, 2018. https://www.opm.gov/policy-data-oversight/hiringinformation/intergovernment-personnel-act/

230 See 18 U.S.C. §208 and §209, 5 C.F.R § 2935 and § 2936, and OGE guidance at https://www.oge.gov/web/oge.nsf/Use+of+Government+Position+and+Resources.

231 United States Office of Government Ethics. “Enforcement.” Accessed 10/3/2018. https://www.oge.gov/web/oge.nsf/Enforcement

23218 U.S.C. $\S 208$ - Acts affecting a personal financial interest; United States Office of Government Ethics. "Analysis Potential Conflicts of Interest." Accessed 10/3/2018.

https://www.oge.gov/web/OGE.nsf/Financial+Conflicts+of+Interest/931A1Bo819F5E884852582200 075ECC8

23318 U.S.C. $§ 203$ - Compensation to Members of Congress, officers, and others in matters affecting the Government; 18 U.S.C. §205 - Activities of officers and employees in claims against and other matters affecting the Government

23418 U.S.C. §209 - Salary of Government officials and employees payable only by United States 
The administration of Federal ethics rules is shared among OGE, heads of agencies, designated agency ethics officials, and the Department of Justice (DOJ). The OGE promotes ethical standards and provides overall guidance and accountability. The DOJ is responsible for enforcing the criminal and civil ethics rules. Agencies have primary responsibility for their own internal ethics programs and can supplement ethics regulations to address potential conflicts unique to the agency's mission. ${ }^{235}$ In an effort to avoid conflicts of interest under Title 18, most agencies restrict Federal employees from owning businesses, equity, or consulting with companies related to their Federal work. 236,237

Extramural R\&D Programs. Each Federal agency responsible for extramural R\&D programs is required to establish conflict of interest policies for awardees. ${ }^{238}$ Conflict of interest policies differ across agencies but generally detail requirements for the non-Federal institution to review potential conflicts of interest and for extramural researchers to report both to the institution and award agency. In general, extramural researchers must report conflicts of interest and avoid significant financial conflicts of interest.

Personnel Exchange. Personnel exchange programs have varying degrees of formality ${ }^{239}$ and significantly different durations. The DOC promulgated a regulation in 2016 directed at encouraging personnel exchanges. ${ }^{240}$

The Intergovernmental Personnel Act (IPA) of $1970^{241}$ allows the temporary movement of personnel between the Federal Government and State or local governments, educational institutions, Federally Funded Research and Development Centers (FFRDCs), and nonprofits. IPAs are not available to personnel from private industry, but other mechanisms are, such as the Visiting Scholars Program at the Frederick National Laboratory for Cancer Research. ${ }^{242}$

2355 CFR 2635.106-Disciplinary and corrective action.

236 Based on interviews with Conflict of Interest program managers at Federal agencies

237 The NIST Summary of Ethics Rules 2015 lists principles that apply to entrepreneurship and are consistent with guidelines of most Federal agencies. https://ogc.commerce.gov/file/nist-summaryethics-rules-2015-updated.

2382 U.S.C. §200.112-Conflict of interest

239 Ponomariov, B., \& Boardman, C. 2012. Organizational behavior and human resources management for public to private knowledge transfer: An Analytic Review of the Literature. Paris: Organisation for Economic Cooperation and Development (OECD).

24015 CFR 17 Personnel Exchanges between Federal Laboratories and Non-Federal Entities.

24142 U.S.C. $\S 4701$

242 Frederick National Laboratory for Cancer Research, "Visiting Scholars Program." https://frederick.cancer.gov/workwithus/visitingscholars 
Entrepreneur-in-residence (EIR) programs represent similar efforts, bringing into the Federal agency outside expertise in the form of academics, software designers, business experts, policymakers, etc. who have demonstrated a significant record of innovative achievement. ${ }^{243}$ Stakeholders noted that these entrepreneurs may be posted at an agency (e.g., Department of Health and Human Services' IDEA Lab, ${ }^{244}$ DOE $^{245,246}$ ) to act as opportunity spotters, domain experts, and target industry insiders. Personnel exchanges can occur through educational partnership agreements, such as those which exist between the DOD and educational institutions, enabling DOD laboratory directors to make personnel available to teach science courses or assist in developing course materials. There also exist more specific personnel exchanges, such as the Presidential Innovation Fellows ${ }^{247}$ and the Information Technology Exchange Program. These programs are supported by the White House and the DOD, respectively.

Developing and commercializing new technologies often happens as a result of the above forms of alliances in which resources, knowledge, and skills are pooled. ${ }^{248}$ Formal (or informal) personnel exchange agreements are observable indicators of knowledge transfer and a meaningful gauge for measuring the effectiveness of these relationships. ${ }^{249}$ Such alliances have shown impact in Japan, where national universities offer visiting professorships attached to R\&D projects. ${ }^{250}$ Companies can place visiting researchers at universities to serve both as adjunct faculty members and to collaborate on $\mathrm{R} \& \mathrm{D}$ projects. These personnel exchanges, along with technology licensing,

243 Reamer, Andrew. 2017. "Federal Efforts in Support of Entrepreneurship: A Reference Guide (Working Draft).” The George Washington University. March 9, 2017.

https://gwipp.gwu.edu/sites/g/files/zaxdzs2181/f/downloads/Reamer\%2ofederal\%2oentrepreneursh ip\%20reference\%2odraft\%2003-09-17.pdf

244 U.S. Department of Health and Human Services. 2018. "Entrepreneurs-in-Residence Program.” IDEA Lab. Accessed September 21, 2018. https://www.hhs.gov/idealab/eir-program/

245 U.S. Department of Energy (DOE). 2007. “DOE's Entrepreneur in Residence (EIR) Program.” Last modified October 24, 2007. https://www.energy.gov/articles/does-entrepreneur-residence-eirprogram

246 DOE. “Technologist in Residence Program.” https://www.energy.gov/eere/amo/technologistresidence-program

247 Presidential Innovation Fellows Program. https://presidentialinnovationfellows.gov/

248 Betz, Frederic. 1996. "Industry-University Partnerships.” Handbook of Technology Management, Chapter 8. Gayner, G. ed. New York: McGraw-Hill. Pp. 250-259.

249 Lakpetch, P., \& Lorsuwannarat, T. 2012. "Knowledge transfer effectiveness of university-industry alliances.” International Journal of Organizational Analysis, 20(2), 128-186.

250 Ibid. 
proved the most influential factors for generating product innovation and increasing sales. ${ }^{251}$ The movement of university researchers to industrial firms is valuable as well, with scientific breakthroughs often attributed to contributions of the knowledge creators, through either partor full-time assignments. ${ }^{252}$ Other successful models focus on applied R\&D through partnership between representatives of industry, academia, and government. ${ }^{253}$ Looking at innovative performance as represented by the number of and citation to firms' patents has supported the idea of a direct link between innovation and the human capital of scientists, provided they are "commercially oriented."254

The various forms of personnel exchange are often described as a triple-win, ${ }^{255}$ with the home organization, the personnel involved in the exchange, and destination organization all benefiting from the interaction. The destination or host organization may fill a gap in expertise or staff shortage, benefit from fresh ideas and talent, and save money by mitigating the need to hire a full-time employee. The personnel involved in the exchange benefit by being exposed to a different organization's processes and structures, learning new skills, and experiencing professional growth. The home organization develops network ties by participating in this lending process and receives back an employee with greater experience and potentially better job performance. 256

Entrepreneurial Leave and Sabbaticals. One specific type of personnel exchange program is entrepreneurial leave and/or sabbaticals. These offer opportunities for workers to take leaves of absence or sabbaticals in which they can pursue the independent commercialization of a product developed in a laboratory. Entrepreneurial leave can be an effective way to leverage the intramural research expertise into business creation. Several GOCO Laboratories already make limited use of this practice; for instance:

${ }^{251}$ Pittayasophon, S., Intarakumnerd, P., Sumikura, K., Saito, H., \& Suzuki, J. 2016. "Firm Characteristics and Modes of University-Industry Collaboration." STI Policy Review, 7(1), 17-39.

252 Zucker, L. G., M.R. Darby and M. Torero. 2002. "Labor mobility from academe to commerce." Journal of Labor Economics, Vol. 20(3), pp. 629-660.

253 Fraunhofer-Gesellschaft. https://www.fraunhofer.de/en.html

254 Toole, A. A., \& Czarnitzki, D. 2009. "Exploring the relationship between scientist human capital and firm performance: The case of biomedical academic entrepreneurs in the SBIR program."

Management Science, 55(1), 101-114.

255 Wynne, M. 2016. “Lab-to-Market: Commercializing New Technologies by Exchanging Talent.” Retrieved from https://obamawhitehouse.archives.gov/blog/2016/11/22/lab-marketcommercializing-new-technologies-exchanging-talent

256 Howieson, S. V., Yglesias, E., Blazek, S. L., \& Tran, E. D. 2013. Federal Personnel Exchange Mechanisms. Washington, DC: Science and Technology Policy Institute. 
- Sandia National Laboratories encourages an "entrepreneurial separation to transfer technology," which is a program that allows employees to leave for a time to grow their own business. Reinstatement for employees is guaranteed if the researcher comes back within a 2-year window. In 2008, alumni from this program had created 44 companies and expanded another 46.257

- Los Alamos National Laboratory (LANL) has a similar leave program wherein employees can take up to 3 years away from the home organization to participate in a venture based on LANL-developed technologies or expertise. Medical benefits and a comparable job opening are available in the first year, with reduced funding for benefits and hiring preference possible for the year after. ${ }^{258}$

Sabbaticals for faculty at universities act as similar opportunities to step away and pursue a commercialization venture. However, these opportunities are often only available post-tenure and are not widespread across academia. A survey of more than 50 research universities showed that only half permit this type of temporary leave. ${ }^{259}$ The use of leave without pay by Federal employees for a sabbatical or entrepreneurship has limited effectiveness, since the full conflict of interest rules apply even during periods of uncompensated leave.

\section{CHALLENGES}

Prior reports and stakeholder feedback indicate that some Federal conflict of interest laws and regulations can be a barrier to R\&D employees to be more entrepreneurial or engage in business development. Definitions of conflict of interest and regulations for managing it vary across agencies and Federal Laboratories, making it difficult for investigators and their institutions to comply with the varying requirements. A 2016 report by The National Academies noted the differing policies across agencies and even in Federal-wide guidance. ${ }^{260}$ For example,

257 Sandia National Laboratories. 2008. “Sandia Entrepreneurial Program Is Back,” News Release, November 24, 2008.

258 Palmintera, D. 2003. Partners on a mission: Federal laboratory practices contributing to economic development. Office of Technology Policy, Technology Administration, U.S. Department of Commerce.

259 Blumenstyk, G. 2012. "Recipe for Start-Ups: Sabbaticals, Tenure Credit for Patents, and a Dash of 'Disorder.” Retrieved from https://www.chronicle.com/article/Recipe-for-Start-Ups-/130379/

260 National Academies of Sciences, Engineering, and Medicine. 2016. Optimizing the Nation's Investment in Academic Research: A New Regulatory Framework for the $21^{\text {st }}$ Century. https://www.nap.edu/catalog/21824/optimizing-the-nations-investment-in-academic-research-anew-regulatory 
the conflict of interest regulations for the Public Health Service ${ }^{261}$ (PHS) and NSF 262 differ significantly even though they provide funding to many of the same institutions. Stakeholders frequently mentioned the increased (and, in their view, extraneous) stringency of the PHS regulations. (Refer to box: "RFI Response on Aligning PHS Conflict of Interest Policies.") After pressure from the Department of Health and Human Services Office of the Inspector General, PHS revised their regulations, lowering the threshold for disclosing financial interests from $\$ 10,000$ to $\$ 5,000$, moving the responsibility to analyze potential conflicts of interest from investigators to institutions, and expanding the definition of required disclosures. NSF did not revise their rules to align with the new PHS policies. The differences in policies make it more burdensome for investigators and their institutions to track and comply with Federal policies. ${ }^{263}$

\section{RFI Response on Aligning PHS Conflict of Interest Policies}

"The government must seek to better align its current PHS conflict of interest policies with its interest in seeing the commercialization of, and ROI on, its NIH research investments."

Source: AAU, APLU, COGR, AAMC, and ACE

Though conflict of interest policies for Federal employees can vary from agency to agency, the greatest difference is between researchers employed by the Federal Government and by universities. Generally, universities manage the potential for conflict of interest, while most Federal agencies prohibit the potential to exist. In academia and other non-government R\&D organizations, employees are granted the ability to remain employees of the institution while starting a company or consulting with an outside organization. This allows inventors to work in an official capacity with a start-up company that has licensed the inventor's technology. Additionally, academic institutions generally allow faculty members a leave of absence to pursue entrepreneurial opportunities. Federal workers, conversely, may be discouraged from such entrepreneurial participation due to restrictions on receiving external salary while remaining in Federal employment. ${ }^{264}$ This Federal restriction runs counter to the goal of building a more entrepreneurial R\&D workforce.

\footnotetext{
261 See, for example: https://grants.nih.gov/grants/policy/coi/index.htm

262 National Science Foundation. 2005. "NSF Conflict of Interest Policies," Chapter V, Section 510, NSF Grant Policy Manual, NSF 05-131, July 2005. 263 Ibid.

26418 U.S.C. $\$ 203$ - Compensation to Members of Congress, officers, and others in matters affecting the Government
} 
According to stakeholders, the lack of a clear policy for leave of absence limits the ability of Federal researchers to directly assist industry, particularly through start-ups or other ventures, and bring products and services into the marketplace. Other restrictions include limitations on founding a start-up related to the employee's Federal work, owning equity in a start-up company, or consulting for a start-up. Stakeholders also indicated that Federal conflict of interest policies may negatively affect the proliferation of network-building activities such as consulting for industry or personnel exchange. Conflict of interest policies can also limit the ability of the government to recruit innovative and highly skilled science, technology, engineering, and mathematics (STEM) employees who may be concerned about conflicts with restrictions on partnering with a former employer or divesting financial interests. ${ }^{265}$

According to stakeholders, conflict of interest policies can diminish the effectiveness of the technology transfer process by restricting coordination between the private organization commercializing technology and the Federal researchers by whom it was developed. Several stakeholders mentioned an example of a start-up company leveraging a technology developed in a Federal Laboratory. In such a situation, the start-up would like to be able to speak or work with the inventors of the technology for technical assistance. However, if the Federal researcher has a patent on the technology, speaking with the company in an official capacity would be considered a financial conflict of interest based on the potential royalties from the patent. These rules prevent scientists from being involved and improving business ventures based in their research, thus limiting the effectiveness of those original partnerships. ${ }^{266}$ (Refer to box: "RFI Response on Requiring Federal Employees to Leave Government Service.”)

RFI Response on Requiring Federal Employees to Leave Government Service "It is unclear to me why this policy was initiated originally, but I can easily understand the rationale for it at the time. This is a complex issue with major perception concerns. I suggest that it is now outdated and can accommodate some flexibility while balancing concerns prudently. Universities (which on this topic are very different organizations) allow carefully crafted 'Leave of Absence" or 'Sabbaticals' as part of their culture. Some of these have fully paid salaries, some totally unpaid, some partially paid. An 'Entrepreneurial Leave of Absence' for 2 years (difficult to accomplish a lot in 12 months), could be offered within Federal Laboratories. At the end, the person can return to the same position without any impact on fringe benefits, pensions, etc., if they wished. This is a non-issue for agencies with guest researchers on soft money but could work well for full government employees."

Source: RFI Response, Burnside Development

265 Peña, Vanessa, Michael C. Mineiro, and Ryan M. Whelan. 2014. Federal Ethics Rules and Their Impacts on Recruiting and Retaining Federal Science, Technology, Engineering, and Mathematics (STEM) Employees. Washington, DC: IDA Science and Technology Policy Institute.

266 GAO. 2014. Federal Laboratory Consortium Should Increase Communication with Potential Customers to Improve Initiatives. https://www.gao.gov/products/GAO-15-127 


\section{NIST FINDING}

NIST Finding 12. According to stakeholders, recipients of extramural Federal R\&D funding experience challenges due to divergent agency requirements to manage conflicts of interest involving recipients of extramural Federal R\&D funding, and Federal Laboratories lack the flexibility to allow their scientists and engineers to engage in activities that support technology transfer and commercialization.

\section{A. ENTREPRENEURIAL ACTIVITIES BY EXTRAMURAL FEDERAL R\&D FUNDING RECIPIENTS}

According to stakeholders, more consistent requirements and best practices to manage conflicts of interest by engaging recipients of extramural Federal R\&D funding and Federal R\&D managers could reduce administrative burdens and increase entrepreneurial opportunities for scientists participating in federally funded research. ${ }^{267}$

\section{B. ENTREPRENEURIAL ACTIVITIES BY FEDERAL SCIENTISTS AND ENGINEERS}

According to stakeholders, sufficient flexibility to allow scientists and engineers at Federal Laboratories to engage in entrepreneurial activities ${ }^{268}$ that support technology transfer and commercialization is not within the bounds of current legislation and implementing regulations under 18 U.S.C. $\S 208-209$. Additional flexibility to allow engagement by the agency head, or designee, in consultation with the agency's legal counsel to ensure that these activities will encourage commercialization of results while not posing undue burden on the agency, could enhance entrepreneurial outcomes by Federal scientists and engineers.

\section{ENTREPRENEURIAL LEAVE AND SABBATICALS}

According to stakeholders, current legislation does allow for Federal employees to take leave without pay if approved by the agency, but ethics requirements present challenges to entrepreneurial activities by Federal employees. Allowing Federal agencies to grant scientific and technical professionals, including those who are senior executives, at Federal Laboratories

267 Consider comments received through the stakeholder engagement process and engage with

Nonfederal organizations to identify best practices to manage conflict of interest for extramural Federal R\&D recipients.

268 For example, service as an advisor or consultant to companies, service on a scientific advisory board or board of directors of companies, and equity ownership in companies. Companies may be start-ups, small, or large. 
entrepreneurial leave and sabbatical absence to engage in compensated or uncompensated entrepreneurial activities 269 (notwithstanding 18 U.S.C. $§ ~ 208-209$ ) that support technology transfer and commercialization for up to 3 years with full reinstatement privileges is not within the scope of existing legislation. ${ }^{270,271}$

269 To attempt to spin-out a technology or start a business of their own in addition to service as an advisor or consultant to companies, service on a scientific advisory board or board of directors of companies, and equity ownership in companies without fear of losing Federal employment or seniority.

27015 U.S.C. $\S 3710$ may be an appropriate place to consider authority for Federal R\&D staff to take entrepreneurial leave, provided such language notes the potential conflict with Title 18 (18 U.S.C. § 208-209).

${ }^{271}$ For Senior Executive Service career appointees to use sabbatical absence from duty for compensated work experience, changes to 5 U.S.C. § 3396(c)(1) may be contemplated, including: (a) extending the term of sabbatical from 11 months to a longer time (i.e., up to 3 years) to reflect the time-consuming nature of commercialization, (b) adding permission for appointee to engage in compensated work experience. 
This page intentionally left blank 


\section{STRATEGY 4. SUPPORT INNOVATIVE TOOLS AND SERVICES FOR TECHNOLOGY TRANSFER}

The fourth of five strategies of the L2M CAP Goal is focused on supporting innovative tools and services for technology transfer. The NIST findings, based on input by stakeholders, focus on ways that could make it easier for potential partners to discover both extramural and intramural Federal R\&D results and to access information on Federal R\&D programs, facilities, equipment and tools, expertise, services, and other relevant assets. This chapter discusses the Federal IP data reporting system(s) and access to Federal R\&D assets.

\section{A. INTRODUCTION}

Managers and business professionals need timely, accurate, and useful access to Federal R\&D, IP, and technology transfer information to identify translational R\&D, technology maturation, and commercialization opportunities and engage in collaborative partnerships. Technology managers need accurate information to identify the right private sector contacts to facilitate promising collaborations.

Effective tools and services improve awareness of Federal R\&D assets available for commercial opportunities, and avenues for public and private parties to find each other to engage. To facilitate this awareness among relevant stakeholders, tools and services provide access to resources, such as intellectual property, equipment and facilities, and information about mission and capabilities of Federal Laboratories. For extramural inventions, these tools provide a mechanism to report information and for agencies to curate data through standardized reporting requirements. Overall, tools and services assist all stakeholders both within and outside the government with timely, accurate, and potentially impactful data.

Timely and accurate information regarding extramural inventions under the BayhDole Act is also critical. The requirements to report inventions, elect rights, request extensions of time requirements, request waivers, demonstrate progress, inform the government of their limited use rights, and other interactions are an important part of the obligation of funding recipients to support technology transfer for the public benefit. Although ease of access to information can help technology transfer, development of these systems can be expensive. The costs to maintain the system and especially the currency of the data can be even higher. 


\section{B. FEDERAL IP DATA REPORTING SYSTEM(S)}

\section{BACKGROUND}

Regulations implementing the Bayh-Dole Act give the extramural funding recipient a period of 2 years to elect rights to the subject invention, or 60 days before a bar date for patenting under U.S. law. ${ }^{272,273}$ If the funding recipient elects rights, they agree to file for a patent and take steps to achieve practical application of the invention, that is, actively seek a commercial opportunity. Agencies can require additional reporting on progress to ensure that the recipient is continuing to achieve practical application. Invention reporting is also necessary to inform the government of its use right. A major issue with invention reporting is the need to properly secure proprietary information from unauthorized disclosure by the funding agency. Agencies requiring invention reporting must be cognizant of the need to keep information confidential during the patent filing process as well as any specific business plans regarding efforts to commercialize a product.

The Bayh-Dole Act and accompanying regulations require reporting to Federal funding agencies on the utilization of subject inventions. Since the adoption of the legislation, many agencies have used different processes for invention reporting. Most agencies have moved from paper-based reporting to electronic systems. The primary electronic system for invention reporting currently in use is the interagency-Edison (iEdison) system developed and maintained by NIH. The iEdison system is a web-based platform used by many government awardees to report on federally funded inventions. 274,275 There are currently more than 30 Federal agency offices that have elected to use the iEdison system. ${ }^{276}$ The iEdison system can track inventions from the reporting phase, starting with funding and invention details, through to commercialization, monitoring utilization, and profit data. Data within the iEdison database is partitioned by agency, allowing individual agencies to view their invention

\footnotetext{
${ }^{272}$ See 37 CFR 401

273 See 35 U.S.C. $§ 102($ b) as amended by the Leahy-Smith America Invents Act, Public Law 11229.

274 National Institutes of Health (NIH). n.d. "iEdison.gov." Accessed October 5, 2018. https://public.era.nih.gov/iedison

275 Edison was created in 1995 by the NIH and became iEdison in 1997 when the NSF and USAID joined. https://public.era.nih.gov/iedison/public/faq.jsp\#q2

276 NIH. 2016. “iEdison - Agency Websites.” Accessed October 5, 2018. https://era.nih.gov/iedison/agency_sites.htm
} 
reports. This partitioning does make it more difficult to discover inventions across agencies but enhances the protection of the proprietary information in the system. ${ }^{277}$

In addition to the iEdison system, agencies may use or design their own tools for this reporting function. For example, NASA developed and uses the New Technology Reporting System (e-NTR). As e-NTR only manages NASA intellectual property data, eNTR employs one standardized form for intellectual property reporting across all NASA technology transfer offices. ${ }^{278}$ NASA exploits the standardized and complete data gathered by e-NTR to build metrics and technology transfer reports, as well as collects intellectual property data for public consumption.

\section{CHALLENGES}

According to stakeholders, without a single government-wide reporting system, university technology transfer offices and federally funded researchers must devote significant resources to reporting tasks to navigate different agency platforms and reporting requirements. Even within a single agency, individual Federal Laboratories may use unique reporting platforms. The need to report in different systems with unique requirements can be time consuming and difficult for government contractors that receive funding from multiple agencies. While each system is based on the same rules, each has its own commands and operation and requires a separate login. Stakeholders noted that this lack of consistent reporting places a burden on technology transfer offices, especially smaller offices or individuals with fewer resources to devote to administrative tasks. Many stakeholders called for mandated use of a single reporting system by all agencies to meet the Bayh-Dole Act reporting requirements. (Refer to box: "RFI Response on a Unified Federal Invention Reporting System.”)

277 Bayh-Dole Act regulations note that the reported information is subject to 35 U.S.C. § 202(c)(5). As such, agencies shall not disclose such information to persons outside the government. Contractors will continue to provide confidential markings to help prevent inadvertent release outside the agency.

278 National Aeronautics and Space Administration. n.d. "New Technology Reporting System." Accessed October 5, 2018. https://invention.nasa.gov/prog/login. 
RFI Response on a Unified Federal Invention Reporting System

"[The University of California (UC)], like many universities, has experienced issues surrounding the process of required invention reporting under iEdison, an outdated system that could be more user-friendly. The fact that not all agencies use the same system is in itself problematic and inefficient. Inconsistencies in reporting requirements from one agency to the next (and even within agencies) lead to confusion and unnecessary time and effort that could better be spent engaged in the substance of technology transfer activities. UC strongly supports a single, consistent government-wide reporting process using a state-of-the-art, easy-to-use portal that is adequately funded and maintained. Agency requirements for invention reporting should be harmonized."

Source: RFI Response, University of California

Further, agencies do not always have the same reporting requirements-even agencies that use the same platform. Stakeholders echoed this concern, stating that the inconsistent requests for additional information add to the difficulties with reporting. The National Academies recommends developing a standard set of requirements to ensure that reporting requirements do not exceed those stated in the Bayh-Dole Act. 279 Stakeholders also noted issues related to the quality, timeliness, and transparency of communication between agencies and extramural partners in reporting and called for guidance to be developed in this area (See "RFI Response on Reporting System Experience.”)

\section{RFI Response on Reporting System Experience}

"Agencies should ensure that their staff are responsive when issues arise during reporting, especially while the current balky system remains in use. Metrics should be developed for the quality of the reporting system and agency responsiveness and should be disseminated regularly throughout the tech transfer community."

Source: RFI Response, Massachusetts Institute of Technology and MIT Lincoln Laboratory

ROI Public Forum attendees stated that iEdison is the most widely used reporting system, though users report that it is confusing and difficult to use, sometimes requiring professional assistance. The system has undergone few technical improvements since it was first implemented in 1995. NIH does not have a unique or explicit source of funding to maintain and update the system, and it must therefore compete with other NIH

279 National Academies of Sciences, Engineering, and Medicine. 2016. Optimizing the Nation's Investment in Academic Research. Washington, DC: The National Academies Press. 175, Recommendation 10.2. 
priorities. Inadequate funding rather than technical challenges or lack of capabilities was cited as the primary reason for the shortcomings of the iEdison infrastructure. ${ }^{280}$ This was also noted in the stakeholder feedback, which called for significant reforms to improve current invention reporting platforms. (Refer to box: "RFI Response on Improved Invention Reporting.")

Modernized data systems involved in technology transfer reporting are also important. Stakeholders overwhelmingly noted the need for simplified and streamlined reporting requirements that keep sensitive data secure and increase timely access to information and services to support transformational R\&D partnerships and technology transfer outcomes for the 21st Century. The cost of reporting and compliance can have a large impact on the government's ability to attract partners.

Perhaps even more significant than internal reporting requirements for compliance are the multiple benefits for business partners to have a single, consistent, discoverable set of information. Businesses, especially small businesses, do not have the time to discover and use multiple government websites. Making information readily accessible is a key part of the technology transfer mission.

RFI Response on Improved Invention Reporting

"We suggest that the Federal government invests significant resources to modernize and improve the process used to report the status of technology and inventions via its iEdison interface to be improved for clarity and congruency with commercialization, patent prosecution and invention disclosure practices."

Source: RFI Response, University of California, San Diego

\section{NIST FINDING}

NIST Finding 13. According to stakeholders, a modern, secure, and interoperable platform ${ }^{281}$ that is easy to access, analyze, and use is not available for reporting data on intellectual property ${ }^{282}$ resulting from extramural and intramural Federal R\&D government-wide.

280 National Academies of Sciences, Engineering, and Medicine. 2016. Optimizing the Nation's Investment in Academic Research. Washington, DC: The National Academies Press. 174.

${ }^{281}$ At a minimum, any future IP data platform should be interoperable with USPTO's public searchable database, including the assignments data that contains information on government interest licenses: https://assignment.uspto.gov/patent/index.html\#/patent/search

282 Any future IP data platform should include inventions, copyrights, and utilization metrics. 
A. SECURE, INTEROPERABLE PLATFORM FOR FEDERAL IP DATA REPORTING

According to stakeholders, a secure, modern government-wide platform for use by extramural and intramural recipients of Federal R\&D funding and those responsible for managing that IP data is not available for reporting data on intellectual property (IP) resulting from Federal R\&D.

\section{B. FEDERAL IP DATA REPORTING REQUIREMENTS}

Regulatory changes under the Bayh-Dole Act could be contemplated to streamline government-wide requirements and practices for timely and transparent reporting of extramural Federal IP data, including inventions, responses from Federal agencies on waiver of invention rights, request for assignment of invention rights, U.S. manufacturing waiver requests, and exceptions to the standard patent rights clauses. ${ }^{283}$

\section{ACCESS TO FEDERAL TECHNOLOGIES, KNOWLEDGE, AND CAPABILITIES}

\section{BACKGROUND}

According to stakeholders, aggregation and curation of Federal technology transfer information, resources, tools, and services is helpful for external stakeholders looking to engage in technology transfer. Harnessing these Federal data on a publicly accessible platform would increase visibility into the Federal innovation ecosystem and aid in opening access to Federal R\&D resources, such as Federal Laboratories, expertise, and equipment, among others.

The FLC was formally chartered by the Federal Technology Transfer Act of 1986 (15 U.S.C. $\S 3710$ ) as a cross-agency organization to foster opportunities for transferring innovative technologies from Federal Laboratories into the marketplace. As stated in FLC's 2015-2019 strategic plan, its membership represents "virtually the entire extant body of experience and expertise on practical, successful approaches to Federal

28337 CFR 401.14 could be an appropriate future changes to streamline government-wide requirements and practices 
Laboratory technology transfer, and on its beneficial outcomes." ${ }^{284}$ Today, the FLC community is made up of over 300 Federal Laboratories, facilities, and research centers, as well as their parent agencies.

To fulfill its mission, the FLC provides a number of cross-agency tools, services, and educational resources, aimed at making the technology transfer process as accessible as possible for commercialization successes. ${ }^{285}$ Specifically, the FLC serves as a clearinghouse for Federal technologies by providing the following tools and services:

- FLC Business ${ }^{286}$ : a web-based platform providing a single extensive inventory of Federal Laboratory information, including member laboratories' missions, capabilities, programs, facilities, equipment, and contacts; technologies available for licensing; funding opportunities; and publications; and

- Technology Locator 287 : a no-cost, personalized matching service that connects external users with an appropriate laboratory representative to further the user's R\&D goals.

In 2014, a GAO study recommended that the FLC "work collaboratively with agency and laboratory members to increase communication with potential customers and obtain feedback to improve its clearinghouse initiatives." 288 This recommendation was considered in FLC's development of FLCBusiness, ${ }^{289}$ which formally launched in April 2014, and has since undergone significant public testing of its user interface and search capabilities. The most recent version of the site, FLC Business 3.0, was released in September 2018 and has been updated with additional user capabilities, including refined search categories, advanced filtering options, a tech-locator chat service, upgraded editing

\footnotetext{
284 Federal Laboratory Consortium for Technology Transfer (FLC). 2015. "Strategic Plan 20152019." https://www.federallabs.org/sites/default/files/FLC_Strategic_Plan.pdf

285 FLC. n.d. "History." Accessed October 5, 2018. https://www.federallabs.org/about/history. 286 FLC. n.d. "FLC Business.” Accessed October 5, 2018. https://www.federallabs.org/FLC Business.

287 FLC. n.d. "Technology Locator Service." Accessed October 5, 2018. https://www.federallabs.org/t2-toolkit/technology-locator-service.

288 GAO. 2014. Federal Laboratory Consortium Should Increase Communication with Potential Customers to Improve Initiatives. Washington, DC. https://www.gao.gov/assets/670/666361.pdf

${ }^{289}$ For more information, see: https://www.federallabs.org/flcbusiness
} 
capabilities for laboratory profile pages, and integrated success stories and awards with laboratory profiles. ${ }^{290}$ Still, the FLC faces technical challenges in curating agency content, resulting in incomplete or out-of-date data on the platform.

Federal agencies also provide information on agency- or laboratory-specific technology transfer programs, resources, opportunities, and available technologies through their own online platforms. For example, DOE has developed a suite of online applications through its Lab Partnering Service ${ }^{291}$ to connect external users with experts, projects, and patents from across the DOE and its National Laboratories. Another example is the DHS Transition to Practice ${ }^{292}$ program, which identifies the most promising cybersecurity projects across the Federal Government with a demonstrated potential for commercialization and introduces them to potential partners or investors.

\section{CHALLENGES}

According to stakeholders, while agency-specific sites can provide additional information related to technology transfer that goes beyond what FLC's tools and services curate, they present a challenge for users who are interested in technologies from more than one agency. Technology transfer information and opportunities are dispersed on individual agency websites and awareness may not flow out to potential partners. This sentiment was prevalent in the stakeholder feedback, which pointed to lack of awareness and effective knowledge sharing as barriers for external parties engaging in the technology transfer process. Stakeholders stated the need for a centralized repository of technology transfer information and opportunities across all agencies. Rather than visiting multiple sites to identify a technology or resource, researchers and entrepreneurs could benefit from a more complete inventory in a single source, displayed in a consistent format.

To curate content for FLC Business, the FLC depends on information provided voluntarily by agency and laboratory members. To reduce the administrative burden on its members and ensure that information is up-to-date, the FLC automates this information exchange as much as possible. In 2015, the FLC contracted for the

290 Federal Laboratory Consortium for Technology Transfer (FLC). 2018. "FLC Business 3.0 is Here!” September 4, 2018. https://www.federallabs.org/news/flc-business-30-is-here.

291 U.S. Department of Energy (DOE). n.d. “Lab Partnering Service.” Accessed October 5, 2018. https://www.labpartnering.org/home.

292 U.S. Department of Homeland Security. n.d. "Transition to Practice." Accessed October 5, 2018. https://www.dhs.gov/science-and-technology/csd-ttp 
development of a web scraper tool ${ }^{293}$ to aggregate inconsistent, unstructured information with permission from agency and laboratory websites into a consistent schema for searching on FLC Business. The tool uses the visual attributes of the webpage, employing pattern recognition to gather text or downloading documents. Because the level of detail, accuracy, and accessibility of this information varies across agencies, data on FLC Business is sometimes incomplete, out-of-date, or inconsistent, and the tool must be "retrained" anytime an agency makes an update to their own website. It has also been noted that some information on agency websites is presented using software that is incompatible and inaccessible with this scraping method.

Stakeholder feedback calls for additional efforts beyond curation of content such as putting available technologies in the context of appropriate collaboration mechanisms and integrating modern capabilities such as semantic search and text analysis (Refer to box: "RFI Response on a Centralized Platform.") Stakeholders also suggested aligning tools and services with private sector needs, developing mechanisms for confidential interaction between agencies and users, and developing a government- or agency-wide technology transfer communications strategy.

RFI Response on a Centralized Platform

"A renewed attempt to develop a cross-agency platform for searching, identifying, and licensing technologies should be undertaken to take advantage of modern technologies... Rather than building a centralized database of technologies, the Federal Government could create a federated search system where agencies expose their technology inventories to search and provide associated information that can be parsed and processed such that technologies are tagged with a consistent set of taxonomies."

Source: RFI Response, RTI International

\section{NIST FINDING}

NIST Finding 14. According to stakeholders, a federated data portal that is easy for the public to access, use, and analyze is not available to provide information on (i) available IP resulting from extramural and intramural Federal $R \& D$ programs government-wide, and (ii) Federal $R \& D$ programs, facilities, equipment and tools, expertise, services, and other relevant assets that are available to the public.

293 Connotate. 2017. “Another Web Data Extraction Use Case: Consolidating Information Spread Across Dozens of Sites to Build a One-Stop Shop for Patent Information.” February 22, 2017. https://www.connotate.com/another-web-data-extraction-use-case-consolidatinginformation-spread-across-dozens-of-sites-to-build-a-one-stop-shop-for-patent-information/. 
A. FEDERATED DATA PORTAL FOR FEDERALLY FUNDED TECHNOLOGIES, KNOWLEDGE, AND CAPABILITIES

According to stakeholders, a federated data portal that is easy for the public to access, use, and analyze is not available with complete information on (i) available IP resulting from extramural and intramural Federal R\&D programs government-wide, and (ii) Federal R\&D programs, facilities, equipment and tools, expertise, services, and other relevant assets that are available to the public.

\section{B. REPORTING DATA ON FEDERAL R\&D ASSETS}

Changes to reporting requirements under the Stevenson-Wydler Act on R\&D partnership opportunities, facilities, equipment and tools, expertise, services, and other relevant assets at Federal Laboratories are outside the scope of current legislation and regulatory authority. 294

294 Regulatory authority for implementation of provisions in the Stevenson-Wydler Act is not within the scope of current legislation, as discussed under Strategy 1, Section G. 


\section{STRATEGY 5. IMPROVE UNDERSTANDING OF GLOBAL SCIENCE AND TECHNOLOGY TRENDS AND BENCHMARKS}

The fifth strategy of the L2M CAP Goal is focused on improving understanding of global science and technology trends and benchmarks. The NIST findings, based on input from stakeholders, focus on capturing, assessing, and improving Federal R\&D outcomes, impacts, and operational processes. This chapter discusses potential ways to determine, adopt, and use appropriate metrics that could accelerate technology transfer, strengthen U.S. economic competitiveness and national security, and enable even greater return on investment to the American taxpayer.

In today's global economy, it is no longer enough to demonstrate effectiveness against past performance. Instead, performance must be measured against worldwide competition. It is important to look at the transfer of technology from a broad perspective. Technology transfer is not simply the licensing of patented inventions, but the full range of options available to achieve commercialization and economic development. While each agency's definition of technology transfer varies in accordance with their unique mission, NIST defines technology transfer as: "the overall process by which NIST knowledge, facilities, or capabilities in measurement science, standards and technology promote U.S. innovation and industrial competitiveness to enhance economic security and improve quality of life."295

\section{A. INTRODUCTION}

The Stevenson-Wydler Act states that "it is the continuing responsibility of the Federal Government to ensure the full use of the results of the Nation's Federal investment in research and development." ${ }^{296}$ Understanding and measuring R\&D performance within the global context provides the foundation for informed decision-making and for assessing and improving the return on investment. Metrics, however, must be designed to advance the purpose of the Federal investment in R\&D. These measurements are very difficult to make for immediate policy decisions because the actual impacts may take

295 U.S. Department of Commerce. 2018.

Annual Report on Technology Transfer: Approach and Plans, Fiscal Year 2017 Activities and Achievements.

https://www.nist.gov/sites/default/files/documents/2018/09/19/fy2017_doc_tech_trans_an nual_report.pdf

296 Stevenson-Wydler Technology Innovation Act of 1980 as Amended through P.L. 114-329, Jan. 6, 2017 [15 U.S. Code § 3710]. 
decades to occur and be measured. (Refer to box: "RFI Response on the Length of Time to Realize the Commercial Benefits of Research and Development.”)

\section{RFI Response on the Length of Time to Realize the Commercial Benefits of Research and Development}

"Research valuation is difficult because benefits are often unanticipated or unforeseen and may not be realized until the distant future. An example is Albert Einstein's work on relativity more than a century ago to explain the relationship of space, time, and gravity. The first patented technology from this research came not from the former patent examiner, presumably because he did not envision an immediate commercial application. It was an invention of Ernest Lawrence for the particle accelerator, an instrument now extensively used in research, materials processing, and medicine...The first consumer product based on relativity is the Global Positioning System (GPS), patented in 1970... The particle accelerator and GPS systems are examples of unanticipated and unforeseen benefits of relativity research and have further led to new fields of research unimaginable to Einstein."

Source: RFI Response, Jefferson Science Associates and Southeastern Universities Research Association

Innovation in science and technology has been a cornerstone of America's progress since the Nation's founding. ${ }^{297}$ The Federal Government invests in basic research, earlystage applied research, and technology transfer efforts that will lead to the breakthroughs of the future. Federal R\&D investment adapts to changing national priorities, with the expectation that this investment will strengthen the Nation's innovation base and position the United States for unparalleled job growth, continued prosperity, and national security. Current R\&D priorities include security; AI, quantum information sciences, and strategic computing; connectivity and autonomy; manufacturing; space exploration and commercialization; energy; medical innovation; and agriculture. 298

The $R \& D$ enterprise enables the creation and transfer of knowledge via complex pathways involving discovery, translation, and innovation. ${ }^{299}$ Intellectual property, in its most elemental form, protects the knowledge, innovations, and creations that hold significant strategic value for reasons such as national security, economic competitiveness, commercial innovation, and broad public good (e.g., healthcare, infrastructure). (Refer to box: “RFI Response on the Many Pathways of Technology Transfer.”)

297 See, e.g., Office of Management and Budget, Budget of the United States Government, Fiscal Year 2019, Chapter 18 Research and Development, U.S. Government Publishing Office, Washington 2018.

298 See, e.g., Office of Management and Budget \& Office of Science and Technology Policy, FY 2020 Administration R\&D Budget Priorities, Memorandum for the Heads of Executive Departments and Agencies, M-18-22, July 31, 2018.

299 See, e.g., Furthering America's Research Enterprise, The National Academies Press, 2014. 


\section{RFI Response on the Many Pathways of Technology Transfer}

"Agency emphasis on, and support for, technology transfer is a significant driver of success at the DOE National Laboratories. We define technology transfer in the broad sense as the process of transferring scientific discoveries, technologies and authored works from our laboratories to other organizations for the purposes of furthering research, development and/or for commercialization to benefit the U.S. The DOE National Laboratories use many pathways to carry out this responsibility, including: (a) publication of our research efforts; (b) hosting scientific users at our cutting-edge user facilities; (c) conducting research and development activities with industry, academia, and others; (d) exchange of personnel via joint appointments with academia or industry exchange; (e) licensing of patents and copyrights secured through our research efforts; (f) creation or support of start-up businesses that help to move our early stage science and technology into commercial applications; and (g) novel commercialization mechanisms sponsored by the DOE that leverage the use of laboratory expertise such as the Small Business Voucher Program, the Lab Embedded Entrepreneurship Program, and the Technology Commercialization Fund."

Source: RFI Response, National Laboratory Directors Council

The innovations created through Federal R\&D investment must be managed in ways that optimize the ROI to the American taxpayer. ${ }^{300}$ These innovations, knowledge, and creations can be protected through intellectual property such as patents, copyrights, trademarks, and trade secrets. These intellectual property rights can then be leveraged through license agreements to create significant strategic value by controlling the distribution and transfer or release of assets through transaction, operation of law, or passage of time. Though Federal agencies cannot sell intellectual property, non-Federal owners can choose to sell or otherwise convey (e.g., license) their intellectual property assets.

Critical and emerging technologies also hold significant strategic value for the Nation. While the contribution of international collaborations to the scientific and technological strength of the United States is widely acknowledged, the Federal Government has established various programs to identify critical technologies and the way in which they should be protected to ensure that they are provided to foreign entities only when doing so is consistent with U.S. interests. Export control laws and regulations, for example, are designed specifically to protect the national security, economic, and foreign policy interests of the United States. The R\&D enterprise is responsible for carefully balancing the need for openness with the need to adhere to export laws and regulations, including deemed exports, that protect critical technologies-which hold significant

300 See, e.g., Managing University Intellectual Property in the Public Interest, The National Academies Press, 2011. 
strategic value-from unauthorized transfer, such as theft, espionage, reverse engineering, or illegal export.

\section{B. BENCHMARKING AND METRICS}

\section{BACKGROUND}

Metrics. Measuring the success of technology transfer and commercialization is not a new topic, and it has been widely studied.301 "Metrics" are employed as a figure of merit or proxies to better understand the performance of a system. Metrics should not become the goal itself but, rather, used to understand aspects of a system.

Technology transfer metrics may be collected for multiple purposes. There is currently a statutory requirement to collect certain "information on technology transfer activities,"302 which contribute data towards assessing the performance of the technology transfer system. They can be motivated by a need to better manage activities internal to an organization or to better understand certain phenomena such as interactions between stakeholders. They can also be used to answer external stakeholder questions-ranging from industry to universities to Congress. Still another motivation to collect metrics is for larger or more in-depth studies, such as econometric analyses, that showcase impacts. Table 1 shows different potential purposes with hypothetical examples. ${ }^{303}$

Ultimately, metrics can be an important source of information used by organizations to make decisions to improve effectiveness and efficiency. They can enable better management of the transfer of federally funded technologies for commercial and government applications. Metrics could be collected and analyzed for many aspects of Strategies 1 through 4 . One goal of metrics collection and evaluation is to ensure that the

301 See, e.g. Hill, C. and J. Roessner. "New directions in Federal laboratory partnerships with industry." Science and Public Policy 25: 297-304. 1998;

Barry Bozeman. 2013. “Technology Transfer Research and Evaluation Implications for Federal Laboratory Practice,” April 4, 2013.

30215 U.S.C. $\S 3710$ (f) requires agencies to report detailed information on (i) the number of patent applications filed; (ii) the number of patents received; (iii) the number of fully-executed licenses which received royalty income; (iv) the total earned royalty income; (v) what disposition was made of the royalty income; (vi) the number of licenses terminated for cause; and (vii) any other parameters or discussion that the agency deems relevant or unique to its practice of technology transfer.

303 Hughes, Mary E., Susannah V. Howieson, Gina Walejko, Nayanee Gupta, Seth Jonas et al. 2011. Technology Transfer and Commercialization Landscape of Federal Laboratories, Washington, DC: IDA Science and Technology Policy Institute. 
data collected are able to substantiate the value of technology transfer by measuring ROI based on the broad-based definition in the Introduction to this Green Paper.

Table 1. Motivations for Technology Transfer

\begin{tabular}{ll}
\hline \multicolumn{1}{c}{ Purpose } & \multicolumn{1}{c}{ Example } \\
\hline For internal management & $\begin{array}{l}\text { Identify specific activities that are contributing to } \\
\text { the laboratory's goals and identify those that are not }\end{array}$ \\
$\begin{array}{l}\text { To understand specific } \\
\text { phenomena }\end{array}$ & $\begin{array}{l}\text { Assess the factors that affect laboratory-industry } \\
\text { interactions }\end{array}$ \\
To answer stakeholder & $\begin{array}{l}\text { Identify how many small businesses worked with the } \\
\text { questions }\end{array}$ \\
laboratories over the past year \\
To meet official requirements \\
$\begin{array}{l}\text { Teport on the indicators required in the annual } \\
\text { support }\end{array}$ & $\begin{array}{l}\text { report on technology transfer activities } \\
\text { economic development }\end{array}$ \\
\hline
\end{tabular}

Source: Hughes, M. et al. 2011

All Federal agencies that perform R\&D have developed metrics and associated reporting requirements to assess the effectiveness and efficiency of Federal $R \& D$ investments to assist both those who fund and those who conduct R\&D. There is general agreement that reporting requirements are inherently burdensome but are critically important in characterizing the outcomes, impacts, and operations of technology transfer and commercialization.

To evaluate the performance or effectiveness of the technology transfer program activities, it is necessary to evaluate:

- the operational processes of technology transfer offices (e.g., customer service, efficiency),

- the outputs that result from internal actions (e.g., quantitative or qualitative measure of program activities or efforts),

- the outcomes that result from external adoption of outputs (e.g., measured results of the program activities), and

- the broad-based impacts on industry, economy, national security, and society (e.g., net effects of program outcomes). 
The GPRA Modernization Act of 2010304 and the Government Accountability Office305 define these terms for use in measuring and evaluating the performance of all Federal Government programs. Examples of operational process, outcome, and impact metrics based on these definitions are discussed below.

\section{OPERATIONAL PROCESS METRICS}

Operational metrics assess and improve the efficiency of the technology transfer process. Such metrics must be customer-focused and designed to develop and implement uniform processes and best practices, ${ }^{306}$ consistent interpretation and application of authorities, timely government-university-industry partnerships, and a culture that values and incentivizes technology transfer through leadership, entrepreneurship, professional development, training, and marketing. Operational metrics may also be used to track and assess the progress on the findings discussed in this document.

Operational efficiency metrics encompass transaction times (e.g., for CRADAs, licenses, and other partnership agreements), resource utilization (e.g., financial, labor, and ancillary costs), performance expectations (e.g., for R\&D staff and managers as well as technology transfer professionals), and unified reporting requirements (e.g., ease of access, use, and search). The right set of operational metrics can help streamline and accelerate technology transfer processes and better align them with the speed of today's market transforming innovations.

\section{R\&D OUTCOME METRICS}

The $\mathrm{R} \& \mathrm{D}$ enterprise uses a variety of mechanisms to disseminate intellectual property. R\&D outcome metrics based on these mechanisms help assess and improve R\&D effectiveness over the near term (e.g., within 3 years) to medium term (e.g., 3 to 8 years). The applicable time horizon will vary with the types of technologies and industries (e.g., mature versus emerging).

Metrics that arise from the traditional definition of technology transfer encompass patents (e.g., disclosures, applications, issued), copyright and trademark registrations and disputes, trade secret assertions, licenses (e.g., fees, royalties, equity), start-ups (e.g., formation, financing, buyouts), and partnerships (e.g., CRADAs and other agreements). Additionally, measures such as the ratio of patents filed to patents issued, and the ratio of patents issued to patents licensed may give a better sense of the effectiveness of patenting

30431 U.S.C. $\S 1115$ (h) Definitions.

305 GAO. 2011. Performance Measurement and Evaluation: Definitions and Relationships. GAO-11-646SP. https://www.gao.gov/assets/80/77277.pdf

306 Including consistent and universal definitions as well as appropriately standardized and simplified processes. 
than counting the numbers of patents. Likewise, it might be useful to consider the percentage of start-ups that survive (e.g., beyond 5 years).

Broader outcome metrics that may be used to more accurately and appropriately capture the full range of Federal $\mathrm{R} \& \mathrm{D}$ contributions to the Nation through technology transfer encompass publications (e.g., peer-reviewed journal articles, citations, impact factor of journals), placement of highly skilled students and postdoctoral associates (e.g., via employment in the private and public sectors), use of shared facilities, new and improved standards (e.g., testing, measurements, materials, products, process, interoperability), as well as new and improved technology services (e.g., reference materials and data, calibrations, accreditations).

\section{R\&D IMPACT METRICS}

R\&D impact metrics help assess and improve $R \& D$ effectiveness over the medium (e.g., 3 to 8 years) to long term (e.g., beyond 8 years) to assess the impacts of federally funded R\&D on national security, economic competitiveness, job creation, commercial innovation, and other areas of broad societal benefit (e.g., healthcare, infrastructure). Such metrics can be used retrospectively or prospectively to focus efforts on approaches proven to work.

Utilization metrics encompass new and/or improved products and services on the market that use intellectual property resulting from Federal R\&D, their uses, consumer base, sales activity, time to market, and jobs created, including information related to whether the intellectual property used was protected (e.g., via patents and copyrights) or not (but still had commercial value). They represent an excellent measure of impact since they are fully aligned with the purpose of Federal R\&D and technology transfer laws. Such metrics can also be tailored to measure the impact of Federal R\&D on agency missions (e.g., national security, human health, agriculture, and infrastructure).

In the long-term, R\&D impact metrics may be tied to the reputation and stature of scientists and engineers performing Federal R\&D through prestigious awards such as the Nobel Prize, Fields Medal, National Medal of Science, and National Medal of Technology and Innovation.

Examples of Data Collection. An overview and select examples of how U.S. and global S\&T metrics are applied in analyses are provided below. There is a broad community of stakeholders assessing domestic metrics, including agencies, NSF-funded researchers within the Science of Science Policy community, and other universities' technology transfer offices, and local/regional economic development authorities. A number of these organizations provided feedback on how to improve data collection for metrics. However, many in this community are focused on analysis of outcomes and impacts from extramural $\mathrm{R} \& \mathrm{D}$ programs rather than analysis of technology transfer 
outcomes and impacts from Federal laboratories. This is due, in part, to the greater availability and quality of metrics data produced by extramural funding recipients. It will be critical to consider both the similarities and differences between extramural and intramural R\&D program activities in assessing best practices for data collection and performance evaluation.

\section{U.S. DOMESTIC TECHNOLOGY TRANSFER METRICS}

NIST prepares an annual summary report to the President and the Congress on Federal Laboratory technology transfer. 307 Several metrics are used in that report including new inventions disclosed, patent applications filed, start-ups, and patents issued. The patents issued by the USPTO are broken down by technology area. The report contains data on total active licenses, total active invention licenses, total active incomebearing licenses, new licenses, new invention licenses, income-bearing licenses, total income from all active licenses, licenses granted to small business, and total earned royalty income. In addition, metrics are shown for total active CRADAs, total active traditional CRADAs, new CRADAs, small business involvement in CRADAs, and other collaborative R\&D relationships. Finally, the summary includes counts of science and engineering articles, co-authored publications and citations by field, as well as summaries of agency success stories and impact studies.

The Association of University Technology Managers (AUTM) conducts similar data collections for university research. 308 AUTM conducts a voluntary licensing activity survey that includes information on research funding, patent activity, innovation impacts, licensing income, and other indicators. They also fund research utilizing the input-output ("I-O") approach to estimate the economic impact of academic licensing and summing that impact over 20 years of available data.309 Estimates of the total number of personyears of employment supported by licensed-product sales of U.S. universities, hospitals, and research institutes are also developed. They also report AUTM-associated contributions to Gross Domestic Product (GDP), calculated using the I-O approach, are

307 National Institute of Standards and Technology (NIST) and U.S. Department of Commerce. 2017. Federal Laboratory Technology Transfer, Fiscal Year 2015. Washington, DC: U.S. Department of Commerce.

308 AUTM 2018. "What is Tech Transfer, Anyways? https://autm.net/about-tech-transfer/whatis-tech-transfer

309 Pressman, Lori Mark Planting, Robert Yuskavage, Sumiye Okubo, Carol Moylan, and Jennifer Bond. 2017. The Economic Contribution of University/Nonprofit Inventions in the United States: 1996-2015. https://autm.net/AUTM/media/AboutAUTM/Documents/AUTM_BIO_Economic_Impact_Report_2017.pdf 
compared with U.S. GDP as a whole, and to selected industry (as defined by North American Industry Classification System codes) contributions to GDP.

The use of the I-O approach for R\&D performed by Federal Laboratories provides some interesting results. NIST funded a study using the same author and a similar approach to the AUTM analysis. ${ }^{310}$ When viewed in isolation, the results look promising showing a range of economic impact up to $\$ 83.6$ billion over the study period. These estimates, however, are lower than those from university research in the AUTM report. There are a variety of potential reasons for the difference, but one of the biggest drivers is license income, which typically has not been a priority for Federal Laboratories. Federal Laboratories tend to place greater emphasis on the agency's R\&D mission over technology transfer, including license income. While the results for Federal Laboratories may be explained in this context, there is considerable opportunity for improvement in economic impact, given the critical need to strengthen American innovation, economic competitiveness, and national security.

\section{GLOBAL S\&T METRICS}

International S\&T comparisons offer policymakers the opportunity to compare a country's competitiveness, particularly in terms of R\&D and S\&T activities. Any changes made to how the U.S. measures technology transfer and the corresponding health of the Nation's technology transfer system should permit credible comparisons with how other nations are performing. Indicators that measure economic growth and competitiveness in the broadest sense capture aspects of technology transfer, but often do not offer direct measures of a nation's technology transfer activities and downstream impacts.

Investment in $\mathrm{R} \& \mathrm{D}$ is often cited as an input measure for international comparison of $R \& D$ capacity, both total R\&D spending, and also R\&D intensity, which is R\&D as a percent of GDP. R\&D indicators serve as a measure of "innovation infrastructure" or inputs to a country's capacity to innovate. Stakeholders described how countries seek to increase their R\&D efficiency by using existing funding for scientific research to incentivize universities to focus more on technology commercialization.

Another set of metrics that capture the input of knowledge capacity of a country are human capital metrics-the number of first university degrees in STEM fields or the number of researchers in a country. The number of patents filed or granted are captured

310 NIST. 2018. A Preliminary Application of an I-O Economic Impact Model to US Federal Laboratory Inventions: 2008-2015.

https://www.nist.gov/sites/default/files/documents/2018/o9/20/prelimappioeconimpactmo delfedlabinventions2008-2015.pdf 
internationally, both using USPTO data and triadic patent families, which are a special class of patents reflecting a series of corresponding patents filed at the European Patent Office, USPTO, and the Japan Patent Office, for the same invention, by the same applicant or inventor. ${ }^{111}$ Similar to metrics collected for the Annual Federal Laboratory Technology Transfer Report in the U.S., the international metrics for innovation and competitiveness and loosely technology transfer, are counting inputs to the technology transfer system.312

Economic Impact Studies. Economic impact studies that focus on institutions or regions is another approach to measuring ROI. These studies identify and use indicators to assess the collective impact of a set of investments made by a group of stakeholders, which can be Federal Government, State and local governments, and corporations or private investment on a local economy. For example, the Mid-Region Council of Governments recently completed a study assessing the economic impact of Sandia Science and Technology Park in the local economy including the increase in tax revenue and the increase in wages. 313 Other impact studies focus on the economic contributions of investments at Federal Laboratories.

Metrics that enable the demonstration of economic impact may provide feedback to agencies who can then assess the impact patterns and alter projects, programs, or policies to improve the net benefits to society through transfer of technology resulting from Federal R\&D. Measures of net benefits include net present value, social rate of return, and benefits to cost ratio. Using these measures correctly, however, depends on a choice of conceptual methods and the requirement for quality data. 314 The methods involve significant time and effort but serve as useful estimates of the financial ROI. Three basic alternatives are available:

- Measures to guide public R\&D policies such as allocation of resources, including those that influence investment decisions by firms and businesses;

- Measures to guide private industry investments in $\mathrm{R} \& \mathrm{D}$, such as net present value, return on investment, and benefit-cost ratio; or

${ }^{311}$ National Science Board. 2018. “Science and Engineering Indicators 2018.” NSB-2018-1. Alexandria, VA: National Science Foundation. Available at https://www.nsf.gov/statistics/indicators/.

312 Caroline S. Wagner, Irene Brahmakulam, Brian Jackson, Amy Wong, Tatsuro Yoda. 2001. Science and Technology Collaboration: Building Capacity in Developing Countries? RAND Corporation, MR-1357.0-WB, March 2001.

313 Sams, Rachel. "The impact Sandia Science and Technology Park has had over 20 years." https://www.bizjournals.com/albuquerque/news/2018/08/24/the-impact-sandia-scienceand-technology-park-has.html; https://sstp.org/about-sstp/economic-impact (accessed October 10, 2018)

314 See, e.g., Furthering America's Research Enterprise, The National Academies Press, 2014. 
- Measures with which to evaluate the research and innovation systems, such as productivity growth, employment growth, and other economic and societal impacts.

\section{CHALLENGES}

According to stakeholders, each stakeholder in the technology transfer process may have a different metric by which to gauge value given and received. For example, government metrics that include a monetary return on investment in the form of royalties for patents licensed are used to understand the more valuable metrics for government performance in job creation, economic competitiveness, and national security capabilities. University metrics may include licensing fees, recruitment success, academic stature, and endowments. Private sector metrics typically include a return on investment commensurate with risk, in addition to growth, market position, and liquidity.

The stakeholder feedback and literature note that the current ways to collect technology transfer data and report and analyze metrics are problematic. There are inconsistent approaches among agencies, due to the differences in agency missions, technologies, and technology transfer activities. For example, the DOD may provide incentives and track metrics for transitioning technology back into the national security industrial base through procurement actions. In contrast, research at NSF, NIH, and DOE could lead to transitions into the private sector and public consumption. A 2011 report by the Institute for Defense Analyses 315 found that the Annual Summary Report on Technology Transfer is not consistently interpreted by the agencies and laboratory-level analysis of technology transfer and commercialization are not feasible because the measures lack standardization. ${ }^{316}$

Stakeholders indicated that metrics requirements are inconsistent across Federal agencies and do not align with metrics used for evaluating university R\&D. For example, the reporting requirement for the Stevenson-Wydler Act is not equivalent to the BayhDole Act requirement. This misalignment creates metrics that are not comparable and do not provide a full characterization of the outcomes of Federal R\&D. It is important to note, however, that there is a difference in opinion about consistency. Because different organizations have different missions, it is necessary to allow variations in the metrics

315 Hughes, Mary E., Susannah V. Howieson, Gina Walejko, Nayanee Gupta, Seth Jonas et al. 2011. Technology Transfer and Commercialization Landscape of Federal Laboratories, Washington, DC: IDA Science and Technology Policy Institute.

316 It should be noted that the 2011 report predates agency responses to the 2011 Presidential Memorandum-Accelerating Technology Transfer and Commercialization of Federal Research in Support of High-Growth Businesses. As part of their response, agencies developed additional metrics that were first reported in the FY14 annual report. 
collected, reflecting the diverse mission responsibilities of Federal agencies. (Refer to box: "RFI Response on Differences in Metrics Across Sectors and Activities."

RFI Response on Differences in Metrics Across Sectors and Activities "Universities and medical schools have themselves worked to develop metrics for success of technology transfer and for proper contextualization of tech transfer in broader knowledge transfer and socio-economic development. As university-level efforts continue, we find that different and complimentary sets of measures emerge for technology commercialization, industry/entrepreneur engagement and partnerships, and economic development. Because all these activities and resulting outcomes measures are highly sensitive to individual universities' missions, size, resources, geography, and a variety of other factors, it is most appropriate for further development of appropriate measures to happen at the individual university level."

Source: RFI Response, Higher Education Associations

Meaningful process, outcome, and impact metrics have the potential to assess and improve the ROI that accrues to the American taxpayer. However, current measures that are tracked and reported do not accurately reflect the impact or effectiveness of technology transfer because they measure technology transfer outputs and outcomes, not broadbased impacts resulting from technology transfer program activities. 317 Stakeholders noted that there is not a set of consistent and universal definitions of success in technology transfer to guide metrics development. At the same time, agencies have been tasked with developing goals and metrics for measuring technology transfer and commercialization. Traditional metrics for success in technology transfer often focus on economic benefits, such as job creation or sales. Agencies with R\&D missions that do not create impacts that are defined by these traditional metrics often struggle to communicate their effectiveness. Developing broad definitions of success that recognize the diversity of agency $R \& D$ missions would enable technology transfer offices to craft metrics that more accurately describe the efficiency and effectiveness of their efforts at the cost of making crossgovernmental comparisons impossible. (Refer to box: "RFI Response on Developing New Methods for Evaluating Technology Transfer.")

317 GAO. 2012. Entrepreneurial Assistance: Efficiency and Effectiveness of Fragmented Programs are Unclear. 
RFI Response on Developing New Methods for Evaluating Technology Transfer "Agencies have received numerous presidential and departmental directives on increasing the rate of technology transfer and economic and societal impact from Federal R\&D investments. Each time the directives came with a goal of improving the results of technology transfer and commercialization activities. While agencies were tasked to develop goals and metrics, consistent and universal definitions have not been developed. Success should not be measured primarily by revenue, but by contributions to broader economic prosperity and societal impact. New methods and metrics with universal definitions should be developed to effectively capture impacts and improve measurements of effectiveness across the various recipients of Federal funding."

Source: RFI Response, Association of University Technology Managers

A 2011 GAO report found that metrics focused on counting and reporting on the number of patents, licenses, and start-ups means academic officials will emphasize those activities in their own activities, and may not see the bigger picture of technology transfer. ${ }^{318}$ It has been suggested that university reporting about technology transfer and commercialization could provide more detailed financial and performance information, and consideration should be given to the incentives its metrics provide to university administrators and faculty researchers 319 It has also been suggested that universities should publicize information on "money in versus money out" and citations to patents as a way to measure promulgation. ${ }^{320}$ Many technology licensing offices do not provide adequate information to gauge their performance, and this makes it impossible to judge their initiatives. 321

Metrics can be helpful to both those who fund R\&D and those who conduct R\&D but come with a set of challenges and tradeoffs. Stakeholders indicated that metrics should not distort behavior and lead to unintended consequences, but to transition new technologies into the marketplace as quickly and efficiently as possible to benefit society. Another challenge with developing and implementing metrics is they require stability and should not be altered frequently given the need to make comparisons over time. (Refer to box: "RFI Response on Measuring and Reporting on Effectiveness.") Having stability as an absolute requirement, may not be best under all circumstances. Measurement error,

318 GAO. 2011. Mechanisms for Collaboration and Technology Transfer Could Be Enhanced to More Fully Leverage Partner Agency and Industry Resources.

319 West, Darrell. 2012. "Improving University Technology Transfer and Commercialization." Issues in Technology Innovation, Num 20.

320 Ibid.

${ }^{321}$ GAO. 2011. Mechanisms for Collaboration and Technology Transfer Could Be Enhanced to More Fully Leverage Partner Agency and Industry Resources. 
bias, and variability are also important considerations. Further, single metrics often do not portray the complete perspective; interrelating metrics may lead to improved insights.

\section{RFI Response on Measuring and Reporting on Effectiveness}

"There is no single, obvious way to measure the success of tech transfer that everyone has somehow been missing. Metrics themselves should be seen as experimental, and their impact needs to be monitored. At the same time, metrics should not be altered lightly because stability is needed to make comparisons over time."

Source: RFI Response, Massachusetts Institute of Technology

Stakeholders also indicated that data collection for metrics could be burdensome despite their value as important indicators of the success of Federal technology transfer. Accordingly, metrics-related reporting requirements and mandates should be kept to the minimum needed to provide the necessary information. Metrics, however, must be a good representation of the phenomena they measure, otherwise they drive sub-optimal behaviors. To minimize the burden, stakeholders indicated that reporting requirements should be limited to only the information critical to evaluate technology transfer and commercialization.

Spann et. al (1993) discussed how developers could improve their rate of technology transfer and adoption by using more measures of performance, particularly those oriented to commercial success and adopter benefits. ${ }^{22} \mathrm{~A}$ recent forum involved discussion of how agencies and laboratory members could work collaboratively to develop performance goals and measures for FLC's clearinghouse initiatives and use the results to evaluate progress toward meeting FLC's goals on outreach and networking. 323

Stakeholders suggested new metrics in terms of both measured parameters and timespans that more accurately reflect the range of benefits from federally funded R\&D. Stakeholders noted that current metrics, such as number of licenses and start-ups created, do not sufficiently enable demonstration of the range of socioeconomic benefits of federally funded R\&D. A careful assessment of what should be measured and when will improve agencies' ability to fully describe the operations, outcomes, and impacts, of technology transfer and commercialization.

322 Spann, M. S., M. Adams and W.E. Souder. 1993. "Improving Federal Technology Commercialization: Some Recommendations from a Field Study.” The Journal of Technology Transfer, Vol. 18(3-4), pp. 63-74.

323 GAO. 2014. Federal Laboratory Consortium Should Increase Communication with Potential Customers to Improve Initiatives. Washington, DC. https://www.gao.gov/assets/670/666361.pdf 
Technology transfer varies across sectors in terms of the time required to execute licenses and move technologies to market. Agencies often struggle to demonstrate return on investment when various stages of the technology transfer process delay outcomes. Furthermore, short timeframes for demonstrating ROI may deter experimentation in technologies that require more time to develop or drive similar disincentives.

\section{NIST FINDING}

NIST Finding 15. According to stakeholders, current metrics to capture, assess, and improve the broad technology transfer outcomes and impacts of federally funded $R \& D$ as well as operational processes underpinning technology transfer within the context of benchmarking with global science and technology trends and metrics are inadequate. 324

\section{A. OUTCOME AND IMPACT METRICS FOR TECHNOLOGY TRANSFER}

According to stakeholders, analyses from the economic research community could provide a more meaningful view of metrics that can be used to capture, assess, and improve technology transfer outcomes and impacts based on federally funded R\&D across the broad spectrum of applications and the time required to realize R\&D impacts. Outcome and impact metrics beyond current practice and reporting requirements that can also be customized could help agencies better align their data collection with (i) the mission of Federal R\&D agencies and laboratories, and (ii) global measures to better benchmark performance.

\section{B. METRICS FOR FEDERAL LABORATORIES}

According to stakeholders, government-wide guidance for reporting broad-based technology transfer outcome and impact metrics at the Federal Laboratory level 325 could help to facilitate appropriate and relevant comparisons with universities.

324 (a) Outcome metrics: consider current outcome metrics as well as broader outcome metrics to capture full range of Federal R\&D contributions, (b) Impact metrics: consider utilization, economic impact, and broader R\&D impact metrics, and (c) Operational process metrics: consider transaction times, resource utilization, performance expectations (e.g., for R\&D staff and managers as well as technology transfer professionals), and unified reporting requirements (e.g., ease of access, use, and analysis).

325 Federal R\&D agencies generally report aggregated metrics for multiple Federal Laboratories (e.g., at the department level). 
C. REPORTING EXTRAMURAL AND INTRAMURAL TECHNOLOGY TRANSFER METRICS

Changes to metrics currently collected under the Stevenson-Wydler Act326 and the method in which they are reported are outside the scope of current legislation. An evaluation of broad-based technology transfer outcomes and impacts for intramural Federal R\&D programs by the economic research community could assist in the development of any future metrics. Pilot programs could be valuable in testing any new metrics before they are implemented government-wide. If determined to be desirable and appropriate, regulatory change under the Bayh-Dole Act could be contemplated for the reporting of broad-based technology transfer metrics for extramural Federal R\&D programs.

\section{STANDARD PROTOCOL FOR COLLECTION OF ECONOMIC IMPACT DATA}

According to stakeholders, a model data collection instrument (e.g., survey, questionnaire, question bank) for economic impact studies government-wide that is preapproved by OMB under the Paperwork Reduction Act could enable agencies to streamline data collection and analysis.

32615 U.S.C $\$ 3710(f)$ 


\section{SUMMARY AND CONCLUSIONS}

This ROI Green Paper outlines a series of NIST findings, based on input from stakeholders, that may support future actions to streamline and accelerate the transfer and commercialization of technology resulting from federally funded research and development. The purpose of this Green Paper is to summarize stakeholder input, agency feedback, and literature related to topics that could advance the President's Management Agenda Lab-to-Market Cross Agency Priority Goal.

This Green Paper highlights challenges and findings in the context of each of the five strategies inspired by the PMA L2M CAP Goal:

- Strategy 1: Identify regulatory impediments and administrative improvements in Federal technology transfer policies and practices;

- $\quad$ Strategy 2: Increase engagement with private sector technology development experts and investors;

- $\quad$ Strategy 3: Build a more entrepreneurial R\&D workforce;

- Strategy 4: Support innovative tools and services for technology transfer; and

- Strategy 5: Improve understanding of global science and technology trends and benchmarks.

The NIST findings outlined in this Green Paper identify systemic challenges raised by technology transfer stakeholders that, if addressed through future interagency action, could have the potential to unleash American innovation and generate even greater return on investment to the American taxpayer. Table 2 provides a summary of NIST's findings. 
This page intentionally left blank 
Table 2. Summary of NIST's Findings Based on Input from Stakeholders ${ }^{327}$ for ROI Initiative to Advance the President's Management Agenda and Unleash American Innovation

\begin{tabular}{|c|c|c|c|c|}
\hline \multirow[b]{2}{*}{$\begin{array}{l}\text { PMA Lab-to- } \\
\text { Market Strategy }\end{array}$} & \multirow[b]{2}{*}{ NIST Findings } & \multicolumn{3}{|c|}{ Pathway } \\
\hline & & 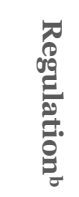 & 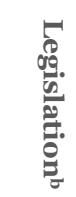 & $\stackrel{0}{\stackrel{0}{\rightleftarrows}}$ \\
\hline \multirow[t]{4}{*}{$\begin{array}{l}\text { Strategy } 1 . \\
\text { Identify } \\
\text { regulatory } \\
\text { impediments and } \\
\text { administrative } \\
\text { improvements in } \\
\text { Federal } \\
\text { technology } \\
\text { transfer policies } \\
\text { and practices. }\end{array}$} & $\begin{array}{l}\text { NIST Finding } 1 \text { - Government Use License. } \\
\text { According to stakeholders, the scope of the "government } \\
\text { use license" is not well defined. Market uncertainty is } \\
\text { created by the lack of a clear definition of "government } \\
\text { use" that is limited to use directly by the government-or a } \\
\text { government contractor in the performance of an } \\
\text { agreement with the government-for a government } \\
\text { purpose only, including continued use in research and } \\
\text { development by the government. The scope of the } \\
\text { government use license should not extend to goods and } \\
\text { services made, sold, or otherwise distributed by third } \\
\text { parties if the government-or a government contractor in } \\
\text { the performance of an agreement with the government-- } \\
\text { does not directly use, provide, or consume those goods and } \\
\text { services. }\end{array}$ & $\begin{array}{c}\text { BD } \\
\text { SWa }^{a}\end{array}$ & & \\
\hline & $\begin{array}{l}\text { NIST Finding } 2 \text { - March-In Rights. According to } \\
\text { stakeholders, the circumstances under which the } \\
\text { government may exercise march-in rights are not well- } \\
\text { defined, consistent with statute rather than as a regulatory } \\
\text { mechanism for the Federal Government to control the } \\
\text { market price of goods and services. Reserve march-in for } \\
\text { use when other remedies have failed and not solely to } \\
\text { regulate the market for price controls. There is a lack of } \\
\text { clarify for the definition of "reasonable terms" consistent } \\
\text { with original statutory intent. }\end{array}$ & $\mathrm{BD}$ & & \\
\hline & $\begin{array}{l}\text { NIST Finding } 3 \text { - Preference for U.S. } \\
\text { Manufacturing. Existing statute requires that products } \\
\text { embodying or using federally funded inventions be } \\
\text { manufactured substantially in the United States. According } \\
\text { to stakeholders, there is a lack of common tools to } \\
\text { streamline and better understand the breadth of waiver } \\
\text { requests received by agencies that would benefit the public } \\
\text { in cases where the agency finds a waiver is applicable. }\end{array}$ & $\begin{array}{c}\text { BD } \\
\text { SWa }^{a}\end{array}$ & & $\mathrm{~A}$ \\
\hline & $\begin{array}{l}\text { NIST Finding } 4 \text { - Copyright of Government } \\
\text { Software. According to stakeholders, the "Government } \\
\text { Works" exception to copyright protection for software } \\
\text { products of Federal R\&D at Government-Owned, } \\
\text { Government-Operated Laboratories constrains } \\
\text { commercialization. A narrowly tailored change to the }\end{array}$ & & SW & \\
\hline
\end{tabular}

327 "Stakeholders" is defined as RFI respondents, participants in public forums and stakeholder events, interagency partners, those who provided feedback on the Draft Green Paper, and/or references to prior reports and studies listed in the Green Paper. See additional information on pages 19-20 under "Inputs to the Green Paper". Any use of "stakeholders" in the Green Paper is not intended to imply a consensus from all participants. 


\begin{tabular}{|c|c|c|c|c|}
\hline \multirow[b]{2}{*}{$\begin{array}{c}\text { PMA Lab-to- } \\
\text { Market Strategy }\end{array}$} & \multirow[b]{2}{*}{ NIST Findings } & \multicolumn{3}{|c|}{ Pathway } \\
\hline & & 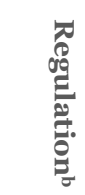 & 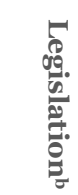 & $\begin{array}{l}\text { 울 } \\
\stackrel{9}{9}\end{array}$ \\
\hline & $\begin{array}{l}\text { "Government Works" exception would be consistent with } \\
\text { the original intent of the Bayh-Dole Act, while recognizing } \\
\text { the transformational shift of including digital products like } \\
\text { software in a 21st Century definition of IP. }\end{array}$ & & & \\
\hline & $\begin{array}{l}\text { NIST Finding } 5 \text { - Proprietary Information. } \\
\text { According to stakeholders, current limits on the protection } \\
\text { of proprietary information discourage some R\&D } \\
\text { collaborations with Federal Laboratories. The protection } \\
\text { period for CRADA information may be too short for early } \\
\text { stage technology or technologies that require additional } \\
\text { time to reach the marketplace. An extension of the } \\
\text { potential CRADA information protection period, at an } \\
\text { agency's discretion, beyond the } 5 \text { years specified in current } \\
\text { statute is not within the scope of current legislation. }\end{array}$ & & SW & \\
\hline & $\begin{array}{l}\text { NIST Findling } 6 \text { - Strengthen Technology Transfer } \\
\text { at Federal Laboratories. Any changes to policies and } \\
\text { practices under the Stevenson-Wydler Act must be enacted } \\
\text { by the Congress, unlike changes to regulations under the } \\
\text { Bayh-Dole Act which grants this regulatory authority to the } \\
\text { Secretary of Commerce. According to stakeholders, many } \\
\text { requirements of the Bayh-Dole Act which are implemented } \\
\text { through regulations promulgated under authorities } \\
\text { granted to the Secretary of Commerce are also pertinent to } \\
\text { partnership agreements under the Stevenson-Wydler Act. } \\
\text { The government use license, preference for U.S. } \\
\text { manufacturing, technology transfer agreements, and the } \\
\text { ability to measure and report progress are all examples of } \\
\text { areas that are addressed in regulation for extramural } \\
\text { research but require new legislative action to address the } \\
\text { same issues for intramural research. Addressing these } \\
\text { common agency concerns through the same collaborative } \\
\text { interagency process that Commerce leads with respect to } \\
\text { the implementation of the Bayh-Dole Act is not within the } \\
\text { scope of the Stevenson-Wydler Act. }\end{array}$ & SWa $^{\mathrm{a}}$ & SW & \\
\hline & $\begin{array}{l}\text { NIST Finding } 7 \text { - Presumption of Government } \\
\text { Rights to Employee Inventions. According to } \\
\text { stakeholders, the process to determine a present } \\
\text { assignment of invention rights by Federal employees to the } \\
\text { Federal Government is overly burdensome. Although this } \\
\text { requirement is provided in Executive Order 10096, there is } \\
\text { no clarifying legislation or simplified, streamlined } \\
\text { regulations in this area. }\end{array}$ & $\begin{array}{l}\text { EO } \\
\text { SWa }\end{array}$ & SW & \\
\hline $\begin{array}{l}\text { Strategy } 2 . \\
\text { Increase } \\
\text { engagement with } \\
\text { private sector } \\
\text { technology } \\
\text { development }\end{array}$ & $\begin{array}{l}\text { NIST Finding } 8 \text { - Streamlined Partnership } \\
\text { Mechanisms. According to stakeholders, improved } \\
\text { clarity and use of best practices government-wide would } \\
\text { streamline partnership agreements and increase } \\
\text { transparency for R\&D partners. Clarification of the } \\
\text { purpose of royalties for licensing at Federal Laboratories }\end{array}$ & $\begin{array}{l}\text { SWa }^{\mathrm{a}} \\
\mathrm{BD}\end{array}$ & SW & $\mathrm{P}$ \\
\hline
\end{tabular}




\begin{tabular}{|c|c|c|c|c|}
\hline \multirow[b]{2}{*}{$\begin{array}{c}\text { PMA Lab-to- } \\
\text { Market Strategy }\end{array}$} & \multirow[b]{2}{*}{ NIST Findings } & \multicolumn{3}{|c|}{ Pathway } \\
\hline & & 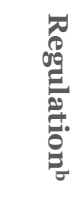 & 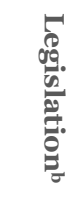 & 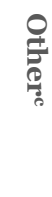 \\
\hline \multirow[t]{3}{*}{$\begin{array}{l}\text { experts and } \\
\text { investors. }\end{array}$} & $\begin{array}{l}\text { could help promote compliance by the licensee to the terms } \\
\text { of development and achieve practical application of } \\
\text { technology, while promoting fairness and access to } \\
\text { government owned technologies. The CRADA authority } \\
\text { contains conflicting language regarding who can be a } \\
\text { CRADA partner. The scope of current legislation does not } \\
\text { extend to Federal employees at all agencies the increase in } \\
\text { royalty cap of up to } \$ 500 \text {,ooo per year authorized in the } \\
\text { FY 2018 National Defense Authorization Act (Public Law } \\
115-91 \text {. }\end{array}$ & & & \\
\hline & $\begin{array}{l}\text { NIST Finding } 9 \text { - Expanded Partnership } \\
\text { Mechanisms. According to stakeholders, all Federal } \\
\text { Laboratories do not have equal authorities to form } \\
\text { partnership agreements at the speed of business and to } \\
\text { attract private sector investment for translational R\&D, } \\
\text { technology maturation, and commercialization. } \\
\text { - Expansion of Agreements for Commercializing } \\
\text { Technology (ACT) authority is outside the scope of } \\
\text { current legislation, as is regulatory authority under the } \\
\text { Stevenson-Wydler Act that would permit a mechanism to } \\
\text { expand the ACT authority to all GOCO Laboratories. } \\
\text { - Existing statute does not provide all agencies with } \text { Other } \\
\text { Transaction Authority to support translational R\&D } \\
\text { collaboration by simplifying, accelerating, tailoring, and } \\
\text { executing partnership agreements at the speed of } \\
\text { business. } \\
\text { - The scope of existing legislation does not provide all } \\
\text { Federal R\&D agencies the ability to establish Non- } \\
\text { Profit Foundations that will advance their missions } \\
\text { by attracting private sector investment to accelerate } \\
\text { technology maturation, transfer, and commercialization. } \\
\text { - The Outleasing Authority is not available to all } \\
\text { Federal Laboratories to make the most use of unused real } \\
\text { property by leasing to the private sector to support } \\
\text { technology transfer and commercialization activities. }\end{array}$ & $\mathrm{SW}^{\mathrm{a}}$ & SW & \\
\hline & $\begin{array}{l}\text { NIST Finding } 10 \text { - Technology Commercialization } \\
\text { Incentives. According to stakeholders, recipients of } \\
\text { Federal funding could benefit from a limited use of R\&D } \\
\text { funds awarded via government grants, contracts, and } \\
\text { cooperative agreements to enable intellectual property } \\
\text { protection. A summary of public comments on } \\
\text { SBIR/STTR technology maturation funding will be } \\
\text { provided to the U.S. Small Business Administration (SBA). } \\
\text { A summary of public comments on tax incentives for R\&D } \\
\text { will be provided to the appropriate policy-making bodies. }\end{array}$ & $\mathrm{BD}$ & & $\mathrm{F}$ \\
\hline $\begin{array}{l}\text { Strategy 3. Build a } \\
\text { more }\end{array}$ & $\begin{array}{l}\text { NIST Finding } 11 \text { - Technology Entrepreneurship } \\
\text { Programs. According to stakeholders, establishing } \\
\text { technology entrepreneurship programs at Federal R\&D }\end{array}$ & & & $\begin{array}{l}\mathrm{P} \\
\mathrm{F}\end{array}$ \\
\hline
\end{tabular}




\begin{tabular}{|c|c|c|c|c|}
\hline \multirow[b]{2}{*}{$\begin{array}{c}\text { PMA Lab-to- } \\
\text { Market Strategy }\end{array}$} & \multirow[b]{2}{*}{ NIST Findings } & \multicolumn{3}{|c|}{ Pathway } \\
\hline & & 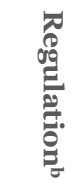 & 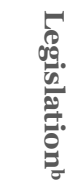 & 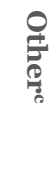 \\
\hline \multirow[t]{2}{*}{$\begin{array}{l}\text { entrepreneurial } \\
\text { R\&D workforce. }\end{array}$} & $\begin{array}{l}\text { agencies government-wide will help build a more } \\
\text { entrepreneurial R\&D workforce. A summary of public } \\
\text { comments specific to NSF's I-Corps }{ }^{\mathrm{TM}} \text { Program, DOE's } \\
\text { Lab-Embedded Entrepreneurship Program, and other } \\
\text { agency entrepreneurial programs will be provided to the } \\
\text { respective agencies. Federal R\&D agencies could better } \\
\text { leverage entrepreneurship programs representing best } \\
\text { practices, such as NSF's I-Corps }{ }^{\mathrm{TM}} \text { program for extramural } \\
\text { R\&D programs, and internal experiential training } \\
\text { programs such as DOE's Lab-Embedded Entrepreneurship } \\
\text { Program for intramural R\&D programs. A designated job } \\
\text { series to recruit, develop, and retain well qualified } \\
\text { professionals to pursue a career in Federal technology } \\
\text { transfer does not currently exist. Given the need for } \\
\text { individuals with business backgrounds and scientific/ } \\
\text { technical backgrounds, a job series that is inclusive of both } \\
\text { types of professionals required to carry out technology } \\
\text { transfer functions could improve agencies' abilities to } \\
\text { recruit and retain technology such professionals. }\end{array}$ & & & \\
\hline & $\begin{array}{l}\text { NIST Finding } 12 \text { - Managing Conflicts of Interest. } \\
\text { According to stakeholders, recipients of extramural Federal } \\
\text { R\&D funding experience challenges due to divergent } \\
\text { agency requirements to manage conflicts of interest } \\
\text { involving recipients of extramural Federal R\&D funding, } \\
\text { and Federal Laboratories lack the flexibility to allow their } \\
\text { scientists and engineers to engage in activities that support } \\
\text { technology transfer and commercialization. The scope of } \\
\text { current legislation does not allow Federal agencies to grant } \\
\text { scientific and technical professionals, including those who } \\
\text { are senior executives, at Federal Laboratories } \\
\text { entrepreneurial leave and sabbatical absence to engage in } \\
\text { compensated or uncompensated entrepreneurial activities } \\
\text { (notwithstanding } 18 \text { U.S.C. } \S 208-209 \text { ) that support } \\
\text { technology transfer and commercialization for up to three } \\
\text { years with full reinstatement privileges. }\end{array}$ & & SW & $\mathrm{P}$ \\
\hline $\begin{array}{l}\text { Strategy } 4 . \\
\text { Support } \\
\text { innovative tools } \\
\text { and services for } \\
\text { technology } \\
\text { transfer. }\end{array}$ & $\begin{array}{l}\text { NIST Finding } 13 \text { - Federal IP Data Reporting } \\
\text { System(s). According to stakeholders, a modern, secure, } \\
\text { and interoperable platform that is easy to access, analyze, } \\
\text { and use is not available for reporting data on intellectual } \\
\text { property resulting from extramural and intramural Federal } \\
\text { R\&D government-wide. Regulatory changes under the } \\
\text { Bayh-Dole Act could be contemplated to streamline } \\
\text { government-wide requirements and practices for timely } \\
\text { and transparent reporting of extramural Federal IP data, } \\
\text { including inventions, responses from Federal agencies on } \\
\text { waiver of invention rights, request for assignment of } \\
\text { invention rights, U.S. manufacturing waiver requests, and } \\
\text { exceptions to the standard patent rights clauses. }\end{array}$ & $\mathrm{BD}$ & & $\mathrm{T}$ \\
\hline
\end{tabular}




\begin{tabular}{|c|c|c|c|c|}
\hline \multirow{3}{*}{$\begin{array}{l}\text { PMA Lab-to- } \\
\text { Market Strategy }\end{array}$} & \multirow[b]{2}{*}{ NIST Findings } & \multicolumn{3}{|c|}{ Pathway } \\
\hline & & 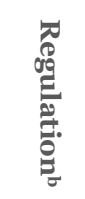 & 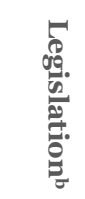 & $\begin{array}{l}\stackrel{\circ}{F} \\
\stackrel{9}{9}\end{array}$ \\
\hline & $\begin{array}{l}\text { NIST Finding } 14 \text { - Access to Federal Technologies, } \\
\text { Knowledge, and Capabilities. According to } \\
\text { stakeholders, a federated data portal that is easy for the } \\
\text { public to access, use, and analyze is not available to provide } \\
\text { information on (i) available IP resulting from extramural } \\
\text { and intramural Federal R\&D programs government-wide, } \\
\text { and (ii) Federal R\&D programs, facilities, equipment and } \\
\text { tools, expertise, services, and other relevant assets that are } \\
\text { available to the public. Changes to reporting requirements } \\
\text { under the Stevenson-Wydler Act on R\&D partnership } \\
\text { opportunities, facilities, equipment and tools, expertise, } \\
\text { services, and other relevant assets at Federal Laboratories } \\
\text { are outside the scope of current legislation and regulatory } \\
\text { authority. }\end{array}$ & & SW & $\mathrm{T}$ \\
\hline $\begin{array}{l}\text { Strategy } 5 . \\
\text { Improve } \\
\text { understanding of } \\
\text { global science and } \\
\text { technology trends } \\
\text { and benchmarks. }\end{array}$ & $\begin{array}{l}\text { NIST Finding 15 - Benchmarking and Metrics. } \\
\text { According to stakeholders, current metrics to capture, } \\
\text { assess, and improve the broad technology transfer } \\
\text { outcomes and impacts of federally funded R\&D as well as } \\
\text { operational processes underpinning technology transfer } \\
\text { within the context of benchmarking with global science } \\
\text { and technology trends and metrics are inadequate. } \\
\text { - Analyses from the economic research community s could } \\
\text { provide a more meaningful view of metrics that can be } \\
\text { used to capture, assess, and improve technology transfer } \\
\text { outcomes and impacts based on federally funded R\&D } \\
\text { across the broad spectrum of applications and the time } \\
\text { required to realize R\&D impacts. Outcome and impact } \\
\text { metrics beyond current practice and reporting } \\
\text { requirements that can also be customized could help } \\
\text { agencies better align their data collection with (i) the } \\
\text { mission of Federal R\&D agencies and laboratories, and } \\
\text { (ii) global measures to better benchmark performance. } \\
\text { - Government-wide guidance for reporting broad-based } \\
\text { technology transfer outcome and impact metrics at the } \\
\text { Federal Laboratory level could help to facilitate } \\
\text { appropriate and relevant comparisons with universities. } \\
\text { - Changes to metrics currently collected under the } \\
\text { Stevenson-Wydler Act and the method in which they are } \\
\text { reported are outside the scope of current legislation. An } \\
\text { evaluation of broad-based technology transfer outcomes } \\
\text { and impacts for intramural Federal R\&D programs by } \\
\text { the economic research community could assist in the } \\
\text { development of any future metrics. Pilot programs could } \\
\text { be valuable in testing any new metrics before they are } \\
\text { implemented government-wide. If determined to be } \\
\text { desirable and appropriate, regulatory change under the } \\
\text { Bayh-Dole Act could be contemplated for the reporting } \\
\text { of broad-based technology transfer metrics for } \\
\text { extramural Federal R\&D programs. }\end{array}$ & $\mathrm{BD}$ & SW & $\begin{array}{l}\mathrm{A} \\
\mathrm{P} \\
\mathrm{T}\end{array}$ \\
\hline
\end{tabular}




\begin{tabular}{|c|c|c|c|c|}
\hline \multirow[b]{2}{*}{$\begin{array}{l}\text { PMA Lab-to- } \\
\text { Market Strategy }\end{array}$} & \multirow[b]{2}{*}{ NIST Findings } & \multicolumn{3}{|c|}{ Pathway } \\
\hline & & 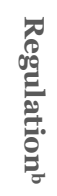 & 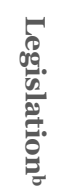 & ஓ \\
\hline & $\begin{array}{l}\text { A model data collection instrument (e.g., survey, } \\
\text { questionnaire, question bank) for economic impact } \\
\text { studies government-wide that is pre-approved by the } \\
\text { Office of Management and Budget (OMB) under the } \\
\text { Paperwork Reduction Act could enable agencies to } \\
\text { streamline data collection and analysis. }\end{array}$ & & & \\
\hline
\end{tabular}

a. Statutory authority is required to implement consistent and streamlined regulations under the Stevenson-Wydler Act (see Finding 6).

b. $\mathrm{BD}=$ Bayh-Dole Act, $\mathrm{SW}=$ Stevenson-Wydler Act, $\mathrm{EO}=$ Executive Order.

C. Other Actions: $\mathrm{P}=$ Policy and Guidance, $\mathrm{T}=$ Tool Development, $\mathrm{A}=$ Analysis, and $\mathrm{F}=\mathrm{Forward}$ Summary of Agency-Specific Comments. 
83 FR 19052. "Request for Information Regarding Federal Technology Transfer Authorities and Processes." Federal Register: The Daily Journal of the United States Government, May 1, 2018. https://www.federalregister.gov/documents/2018/05/01/2018-09182/request-forinformation-regarding-federal-technology-transfer-authorities-and-processes.

Abramson, H. Norman, Jose Encarnacao, Proctor P. Reid, Ulrich Schmoch. 1997. Technology Transfer Systems in the United States and Germany: Lessons Learned and Perspectives. 1997. National Academy Press.

ARPA-E. "I-Corps at ARPA-E.” Accessed 10/1/2018. https://arpa-e.energy.gov/?q=site-page/icorps-arpa-e.

AUTM 2018. "What is Tech Transfer, Anyways? https://autm.net/about-tech-transfer/what-istech-transfer

Bahar, Mojdeh. "I-Corps ARS—A New Twist on NSF's I-Corps Model." https://meeting.federallabs.org/wp-content/uploads/2018/04/I-Corps-at-ARS-I-Fast-atNIFA-M.Bahar_pptx

Barry Bozeman. 2013. "Technology Transfer Research and Evaluation Implications for Federal Laboratory Practice,” April 4, 2013.

Battelle Technology Partnership Service. 2013. Driving Regional Innovation and Growth, Results of the 2012 Survey of North American Research Parks. Prepared for Association of University Research Parks (AURP), August 2013.

https://aurp.memberclicks.net/assets/documents/aurp_batelllereportv2.pdf

Betz, Frederic. 1996. "Industry-University Partnerships." Handbook of Technology Management, Chapter 8. Gayner, G. ed. New York: McGraw-Hill. Pp. 250-259.

Blank, Steve. 2012. "Innovation Corps: A Review of the New National Science Foundation Program to Level Research Investments." https://science.house.gov/sites/republicans.science.house.gov/files/documents/HHRG-112SY21-WState-Sblank-20120716_0.pdf

Blumenstyk, G. 2012. "Recipe for Start-Ups: Sabbaticals, Tenure Credit for Patents, and a Dash of 'Disorder."' Retrieved from https://www.chronicle.com/article/Recipe-for-Start-Ups/130379/

Caroline S. Wagner, Irene Brahmakulam, Brian Jackson, Amy Wong, Tatsuro Yoda. 2001. Science and Technology Collaboration: Building Capacity in Developing Countries? RAND Corporation, MR-1357.0-WB, March 2001.

Conner, Forest. 2018. "Accelerators vs. Incubators: What Startups Need to Know," TechRepublic, June 25, 2018. https://www.techrepublic.com/article/accelerators-vsincubators-what-startups-need-to-know/

Connotate. 2017. "Another Web Data Extraction Use Case: Consolidating Information Spread Across Dozens of Sites to Build a One-Stop Shop for Patient Information.” February 22, 2017. https://www.connotate.com/another-web-data-extraction-use-case-consolidating- 
information-spread-across-dozens-of-sites-to-build-a-one-stop-shop-for-patentinformation/.

Daniel C Fehler and Yael V Hochberg. 2014. "Accelerators and the Regional Supply of Venture Capital Investment," September 19, 2014. http://www.seedrankings.com/pdf/acceleratorsand-regional-suppy-of-vc-investment.pdf

David S. Almeling. 2009. "Four Reasons to Enact a Federal Trade Secrets Act, 19." Fordham Intell. Prop. Media \& Ent. L. J. 769, 786-87.

Deborah J. Jackson. 2015. "What is an Innovation Ecosystem?" National Science Foundation, https://www.researchgate.net/profile/Deborah_Jackson2/publication/266414637_What_is_a n_Innovation_Ecosystem/links/551438490cf2eda0df30714f.pdf

Federal Laboratory Consortium for Technology Transfer (FLC). 2013. FLC Technology Transfer Desk Reference: A Comprehensive Introduction to Technology Transfer. Cherry Hill: Federal Laboratory Consortium for Technology Transfer.

- 2015. "Strategic Plan 2015-2019." https://www.federallabs.org/sites/default/files/FLC_Strategic_Plan.pdf

—. 2018. "FLC Business 3.0 is Here!" September 4, 2018. https://www.federallabs.org/news/flc-business-30-is-here.

_. n.d. "FLC Business." Accessed October 5, 2018. https://www.federallabs.org/FLC Business. . n.d. "FLC Technology Transfer Desk Reference." Accessed October 5, 2018. https://www.federallabs.org/media/publication-library/flc-technology-transfer-deskreference

—. n.d. "History." Accessed October 5, 2018. https://www.federallabs.org/about/history. . n.d. "Technology Locator Service." Accessed October 5, 2018. https://www.federallabs.org/t2-toolkit/technology-locator-service.

— n.d. "Technology Transfer Playbook." Accessed October 11, 2018. https://www.federallabs.org/t2-toolkit/t2-playbook

Foundation for the National Institutes of Health. 2017 Annual Report: Shaping the Future of Human Health. https://fnih.org/2017-annual-report/about-us/

Hathaway, Ian. 2016. "Accelerating growth: Startup accelerator programs in the United States," The Brookings Institution, February 17, 2016, https://www.brookings.edu/research/accelerating-growth-startup-accelerator-programs-inthe-united-states/

Howieson, Susannah V., Stephanie S. Shipp, Gina K. Walejko, Pamela B. Rambow, Vanessa Peña, et al. 2013. Exemplar Practices for Department of Defense Technology Transfer. Washington, DC: IDA Science and Technology Policy Institute.

Howieson, Susannah V., Yglesias, Elmer, Blazek, Samuel. L., \& Tran, Emma D. 2013. Federal Personnel Exchange Mechanisms. Washington, DC: IDA Science and Technology Policy Institute. 
Howieson, Susannah V., Elaine M. Sedenberg, Brian J. Sergi, and Stephanie S. Shipp. 2013. Department of Energy Technology Maturation Programs, Washington, DC: IDA Science and Technology Policy Institute.

Howieson, Susannah V., Stephanie S. Shipp, Gina Walejko, Pamela B. Rambow, Vanessa Peña, Sherrica S. Holloman, Philip N. Miller. 2013. Policy Issues for Department of Defense Technology Transfer. Washington, DC: IDA Science and Technology Policy Institute. https://www.ida.org/idamedia/Corporate/Files/Publications/IDA_Documents/SFRD/2019/P -4958.pdf

Hughes, Mary E., Susannah V. Howieson, Gina Walejko, Nayanee Gupta, Seth Jonas et al. 2011. Technology Transfer and Commercialization Landscape of Federal Laboratories, Washington, DC: IDA Science and Technology Policy Institute.

I-Corps Ohio. “I-Corps@Ohio Homepage.” Accessed 10/1/2018. https://icorpsohio.org/.

Information Technology and Innovation Foundation. March 2019. "The Bayh-Dole Act's Vital Importance to the U.S. Life-Sciences Innovation System." https://itif.org/publications/2019/03/04/bayh-dole-acts-vital-importance-us-life-sciencesinnovation-system

Internal Revenue Service. "Private Foundations.” Last updated July 23, 2018. https://www.irs.gov/charities-non-profits/charitable-organizations/private-foundations

IP Commission 2019 Review. 2019. "Progress and Updated Recommendations, February 2019." http://www.ipcommission.org/report/ip_commission_2019_review_of_progress_and_updat ed_recommendations.pdf

Lakpetch, P., \& Lorsuwannarat, T. 2012. "Knowledge transfer effectiveness of universityindustry alliances.” International Journal of Organizational Analysis, 20(2), 128-186.

Lal, Bhavya et al. 2013. Expediting the Transfer of Technology from Government Laboratories into the Aeronautics Industry. IDA Science and Technology Policy Institute.

ManTech International Corporation. "U.S. DOD Manufacturing Technology Program." Accessed October 1, 2018. https://www.dodmantech.com/

Manufacturing USA ${ }^{\circledR}$. “Manufacturing USA ${ }^{\circledR}$.” Accessed October 9, 2018. https://www.manufacturingusa.com/

Mary Elizabeth Hughes, Susannah Vale Howieson, Gina Walejko, Nayanee Gupta, Seth Jonas, Ashley T. Brenner, Dawn Holmes, Edward Shyu, and Stephanie Shipp. 2011. Technology Transfer and Commercialization Landscape of the Federal Laboratories. IDA Science and Technology Policy Institute.

National Academies of Sciences, Engineering, and Medicine. 1997. Enabling America: Assessing the Role of Rehabilitation Science and Engineering. Washington, D.C.: National Academy Press. https://www.nap.edu/read/5799/chapter/1

- 2016. Optimizing the Nation's Investment in Academic Research: A New Regulatory Framework for the $21^{\text {st }}$ Century. National Academies Press. https://www.nap.edu/catalog/21824/optimizing-the-nations-investment-in-academicresearch-a-new-regulatory 
National Aeronautics and Space Administration. n.d. "New Technology Reporting System." Accessed October 5, 2018. https://invention.nasa.gov/prog/login.

_. 2018. "I-Corps Program.” Accessed 10/1/2018. https://sbir.nasa.gov/content/I-Corps.

National Institute of Standards and Technology (NIST) and U.S. Department of Commerce. 2018. Federal Laboratory Technology Transfer, Fiscal Year 2015. https://www.nist.gov/sites/default/files/documents/2018/04/30/fy2015_fed_tt_report.pdf

_. "Manufacturing Extension Partnership ${ }^{\circledR}$." Accessed October 9, 2018. https://www.nist.gov/mep

- 2017. Federal Laboratory Technology Transfer, Fiscal Year 2015. Washington, DC: U.S. Department of Commerce.

_. 2018. “2018 Maryland Technology Transfer Summit.” https://www.nist.gov/newsevents/events/2018/04/2018-maryland-technology-transfer-summit.

- 2018. Federal Office of Research and Technology Applications Survey Results. August 2018. https://nvlpubs.nist.gov/nistpubs/ttb/NIST.TTB.1.pdf

-1988. Report to the President and Congress Required by the Technology Transfer Act of 1986 on Barriers to the Commercialization of Federal Computer Software and Feasibility and Cost of Compiling an Inventory of Federally Funded Training Software. U.S. Department of Commerce, May 1988. https:/www.nist.gov/sites/default/files/documents/2019/03/19/ec_3430_100th_congress.pd $\mathrm{f}$

- 2018. A Preliminary Application of an I-O Economic Impact Model to US Federal Laboratory Inventions: 2008-2015.

https://www.nist.gov/sites/default/files/documents/2018/09/20/prelimappioeconimpactmode lfedlabinventions2008-2015.pdf

National Institutes of Health (NIH). 2016. "iEdison-Agency Websites.” Accessed October 5, 2018. https://era.nih.gov/iedison/agency_sites.htm

—. "About the CTSA Program.” Accessed 10/1/2018. https://ncats.nih.gov/ctsa/about.

. "Clinical and Translational Science Awards Program.” Last updated October 5, 2018. https://ncats.nih.gov/ctsa

—. 2018. "The I-Corps at NIH.” Accessed 10/1/2018. https://sbir.cancer.gov/programseducation/icorps.

—.n.d. "iEdison.gov.” Accessed October 5, 2018. https://public.era.nih.gov/iedison . "NIH Procedures for Request for Waivers of the U.S. Manufacturing Requirement in Licenses to Extramural Inventions." https://public.era.nih.gov/iedison/public/utilization/ManufacturingWaiver.jsp

National Research Council. 2011. Managing University Intellectual Property in the Public Interest. Washington, DC: The National Academies Press. 82.

National Science Board. 2018. “Science and Engineering Indicators 2018.” January 2018. https://nsf.gov/statistics/2018/nsb20181/ 
. 2018. Science and Engineering Indicators 2018. NSB-2018-1. Alexandria, VA: National

Science Foundation. Available at https://www.nsf.gov/statistics/indicators/.

National Science Foundation (NSF). "Engineering Research Centers." Accessed October 9, 2018. https://www.nsf.gov/funding/pgm_summ.jsp?pims_id=5502

“I-Corps.” Website accessed 9/26/2018. https://www.nsf.gov/news/special_reports/icorps/

—. "I-Corps Curriculum and Resources." Website accessed 9/26/2018.

https://www.nsf.gov/news/special_reports/i-corps/resources.jsp

_. "Partnerships for Innovation." Accessed October 9, 2018.

https://www.nsf.gov/funding/pgm_summ.jsp?pims_id=504790

- 2017. "NSF promotes inclusion in tech entrepreneurship through eight I-Corps Sites." https://www.nsf.gov/news/news_summ.jsp?cntn_id=190921

Office of the Federal Register. n.d. "Federal Register." Accessed October 5, 2018.

https://www.federalregister.gov/documents/search?conditions $\% 5 \mathrm{Bterm} \% 5 \mathrm{D}=\% 22$ technol ogy+transfer\% 22

Palmintera, D. 2003. Partners on a mission: Federal laboratory practices contributing to economic development. Office of Technology Policy, Technology Administration, U.S. Department of Commerce.

Peña, Vanessa, Michael C. Mineiro, and Ryan M. Whelan. 2014. Federal Ethics Rules and Their Impacts on Recruiting and Retaining Federal Science, Technology, Engineering, and Mathematics (STEM) Employees. Washington, DC: IDA Science and Technology Policy Institute.

Peter S. Arno and Michael H. Davis. 2001. "Why Don’t We Enforce Existing Drug Price Controls? The Unrecognized and Unenforced Reasonable Pricing Requirements Imposed upon Patents Deriving in Whole or in Part from Federally Funded Research," Tulane Law Review, vol. 1, pgs. 631-692, http://www.cptech.org/ip/health/bd/arnodavis012001.pdf.

Pittayasophon, S., Intarakumnerd, P., Sumikura, K., Saito, H., \& Suzuki, J. 2016. "Firm Characteristics and Modes of University-Industry Collaboration." STI Policy Review, 7(1), 17-39.

Png, Ivan P. L. 2012. "Law and Innovation: Evidence from State Trade Secrets Laws" June 15, 2012, http://dx.doi.org/10.2139/ssrn.1755284

Ponomariov, B., \& Boardman, C. 2012. Organizational behavior and human resources management for public to private knowledge transfer: An Analytic Review of the Literature. Paris: Organisation for Economic Cooperation and Development (OECD).

President's Management Agenda (PMA). Modernizing the Federal Government for the 21st Century; released March 20, 2018.

- Cross-Agency Priority Goals: Improve Transfer of Federally-Funded Technologies from Lab-to-Market. https://www.performance.gov/CAP/CAP_goal_14.html

Pressman, Lori Mark Planting, Robert Yuskavage, Sumiye Okubo, Carol Moylan, and Jennifer Bond. 2017. The Economic Contribution of University/Nonprofit Inventions in the United 
States: 1996-2015. https://autm.net/AUTM/media/About-

AUTM/Documents/AUTM_BIO_Economic_Impact_Report_2017.pdf

Pressman, Lori, Mark Planting, Robert Yuskavage, Sumiye Okubo, Carol Moylan, and Jennifer

Bond. 2018. A Preliminary Application of an I-O Economic Impact Model to US Federal

Laboratory Inventions: 2008-2015. Prepared for NIST. July 11, 2018.

https://www.nist.gov/sites/default/files/documents/2018/09/20/prelimappioeconimpactmode lfedlabinventions2008-2015.pdf

Reamer, Andrew. 2017. "Federal Efforts in Support of Entrepreneurship: A Reference Guide

(Working Draft)." The George Washington University. March 9, 2017.

https:/gwipp.gwu.edu/sites/g/files/zaxdzs2181/f/downloads/Reamer\%20federal\%20entrepr eneurship\%20reference\%20draft\%2003-09-17.pdf

Sams, Rachel. "The impact Sandia Science and Technology Park has had over 20 years." https://www.bizjournals.com/albuquerque/news/2018/08/24/the-impact-sandia-science-andtechnology-park-has.html; https://sstp.org/about-sstp/economic-impact (accessed October 10, 2018)

Sandia National Laboratories. 2008. "Sandia Entrepreneurial Program Is Back," News Release, November 24, 2008.

Schacht, W. H. 2012. Technology Transfer: Use of Federally Funded Research and Development. CRS Report No. RL33527. Washington, DC: Congressional Research Service.

- 2009. The Bayh-Dole Act: Selected issues in patent policy and the commercialization of technology. Library of Congress, Washington DC: Congressional Research Service.

Schartinger, D., C. Rammer, M.M. Fischer and J. Fröhlich. 2002. "Knowledge interactions between universities and industry in Austria: Sectoral patterns and determinants," Research Policy, Vol. 31(3), pp. 303-328.

Servoss, Jonathan et al. 2017. "fastPACE Train-the Trainer: A scalable new educational program to accelerate training in biomedical innovation, entrepreneurship, and commercialization." Journal of Clinical and Translational Science, Volume 1, Issue 5.

Small Business Innovation Research (SBIR). “About SBIR.” Accessed October 1, 2018. https://www.sbir.gov/about

Spam, Adams and Souder. 1993. "Improving Federal Technology Commercialization: Some Recommendations from a Field Study” T2 Journal, 1993.

Stanford. 2014. "Stanford's Lean LaunchPad Course Sets Students on Entrepreneurial Trajectory." Accessed 9/26/2018. https://stvp.stanford.edu/blog/stanfords-lean-launchpad

Susan G. Cohen, University of Richmond, and Yael V. Hochberg (Massachusetts Institute of Technology and the National Bureau of Economic Research. 2014. "Accelerating Startups: The Seed Accelerator Phenomenon," March 2014, http://seedrankings.com/pdf/seedaccelerator-phenomenon.pdf

TEDCO. "Providing opportunities to Maryland researchers." Website accessed 9/26/2018. https://www.tedcomd.com/funding/tech-transfer/n-step 
Thacker, Paul D. "How a Flood of Corporate Funding Can Distort NIH Research." The

Washington Post. June 22, 2018. https://www.washingtonpost.com/outlook/how-corporatefunding-distorts-nih-research/2018/06/22/ad0260c8-7595-11e8-9780-

b1dd6a09b549_story.html?utm_term=.27e187c32ad0

Tien Pham, "ARL Open Campus-A New Model for Army Science and Technology," undated briefing https://sites.nationalacademies.org/cs/groups/pgasite/documents/webpage/pga_180834.pdf

Thomas, John. 2016. March-In Rights under the Bayh-Dole Act. CRS Report No. R44597. Washington, D.C.: Congressional Research Service. https://fas.org/sgp/crs/misc/R44597.pdf

Toole, A. A., \& Czarnitzki, D. 2009. "Exploring the relationship between scientist human capital and firm performance: The case of biomedical academic entrepreneurs in the SBIR program." Management Science, 55(1), 101-114.

U.S. Department of Defense (DOD). 2018. "Rapid Innovation Fund." https://defenseinnovationmarketplace.dtic.mil/business-opportunities/rapid-innovationfund/

_.2018. "I-Corps@ DoD Funding Announcement." https://basicresearch.defense.gov/News/Articles/News-Display/Article/1490285/i-corpsdod-funding-announcement/

U.S. Department of Energy (DOE). "DOE Hubs.” Accessed October 9, 2018. https://www.energy.gov/science-innovation/innovation/hubs

. "Technology Commercialization Fund." Accessed October 9, 2018. https://www.energy.gov/technologytransitions/services/technology-commercialization-fund

. 2007. "Audit Report: The Department of Energy's Management of Contractor Intergovernmental Personnel and Change of Station Assignments." Washington, D.C.: Office of Inspector General, Office of Audit Services http://www.doe.gov/sites/prod/files/igprod/documents/IG-0761.pdf.

_ 2007. "DOE's Entrepreneur in Residence (EIR) Program." Last modified October 24, 2007. https://www.energy.gov/articles/does-entrepreneur-residence-eir-program

—. 2012. "DOE Technology Transfer Mechanisms." https://www.bnl.gov/techtransfer/docs/Technology-Transfer-Mechanisms.pdf

_. n.d. "Lab Partnering Service." Accessed October 5, 2018. https://www.labpartnering.org/home.

U.S. Department of Health and Human Services. 2018. "Entrepreneurs-in-Residence Program." IDEA Lab. Accessed September 21, 2018. https://www.hhs.gov/idealab/eir-program/

U.S. Department of Homeland Security. n.d. "Transition to Practice." Accessed October 5, 2018. https://www.dhs.gov/science-and-technology/csd-ttp

U.S. Government Accountability Office (GAO). 1999. Reporting Requirements for Federally Sponsored Inventions Need Revision. Washington, DC: Government Accountability Office. https://www.gao.gov/assets/230/227817.pdf 
. 1990. Copyright Law Constrains Commercialization of Some Federal Software.

https://www.gao.gov/assets/150/149097.pdf

- 2003. Agencies' Rights to Federally Sponsored Biomedical Inventions. Washington,

DC: Government Accountability Office. https://www.gao.gov/new.items/d03536.pdf

. 2006. Status and Challenges of Employee Exchange Program. Washington, DC:

Government Accountability Office. http://gao.gov/assets/260/254567.pdf.

- 2009. Information on the Government's Right to Assert Ownership Control over

Federally Funded Inventions. Washington, DC: Government Accountability Office.

https://www.gao.gov/assets/300/293020.pdf

- 2011. Mechanisms for Collaboration and Technology Transfer Could Be Enhanced to More Fully Leverage Partner Agency and Industry Resources. Washington, DC:

Government Accountability Office.

- 2011. Performance Measurement and Evaluation: Definitions and Relationships. GAO11-646SP. https://www.gao.gov/assets/80/77277.pdf

- 2012. Entrepreneurial Assistance: Efficiency and Effectiveness of Fragmented Programs are Unclear. Washington, DC: Government Accountability Office.

- 2014. Federal Laboratory Commission Should Increase Communication with Potential Customers to Improve Initiatives. Washington, DC: Government Accountability Office. https://www.gao.gov/products/GAO-15-127

- 2014. Federal Laboratory Consortium Should Increase Communication with Potential Customers to Improve Initiatives. Washington, DC.

https://www.gao.gov/assets/670/666361.pdf

- 2018. Federal Research: Additional Actions Needed to Improve Licensing of Patented Laboratory Inventions. Washington, DC: Government Accountability Office. https://www.gao.gov/assets/700/692606.pdf.

U.S. Office of Personnel Management. 2018. "Hiring Information: Intergovernmental Personnel Act.” Accessed September 21, 2018. https://www.opm.gov/policy-data-oversight/hiringinformation/intergovernment-personnel-act/

- 2010. Report to Congress on Nursing Faculty and the Intergovernmental Personnel Act Mobility Program: The Forum, Findings, and Recommendations. Washington, D.C.: OPM. http://www.opm.gov/programs/ipa/nursing.pdf.

U.S. Patent and Trademark Office. 2018. “Trade Secret Policy.” Last modified July 11, 2018. https://www.uspto.gov/patents-getting-started/international-protection/trade-secret-policy

United States Army. “Army Research Lab, Extended.” Accessed Oct 1, 2018. https://www.arl.army.mil/opencampus/ARLExtended

_. 2014. “Army Research Lab Open Campus Opportunities” Accessed 10/3/2018. https://www.arl.army.mil/www/pages/2357/ARL_Open_Campus_Opportunities.pdf

United States Office of Government Ethics. “Analysis Potential Conflicts of Interest.” Accessed $10 / 3 / 2018$. 
https://www.oge.gov/web/OGE.nsf/Financial+Conflicts+of+Interest/931A1B0819F5E8848 52582200075ECC8

—. "Enforcement." Accessed 10/3/2018. https://www.oge.gov/web/oge.nsf/Enforcement

VentureWell. 2016. "How an Entrepreneurial Mindset Can Make Research More Effective: Reflections from an I-Corps Alumnus.” https://venturewell.org/entrepreneurial-mindsetcan-make-research-effective-reflections-corps-alumnus/

West, Darrell. 2012. "Improving University Technology Transfer and Commercialization." Issues in Technology Innovation, Num 20. https://www.brookings.edu/research/improvinguniversity-technology-transfer-and-commercialization/

White House. 1987. Executive Order 12591-Facilitating access to science and technology, https://www.archives.gov/federal-register/codification/executive-order/12591.html.

. 2015. "Fact Sheet: President Obama Announces New Commitments from Investors, Companies, Universities, and Cities to Advance Inclusive Entrepreneurship at First-Ever White House Demo Day.” https://obamawhitehouse.archives.gov/the-pressoffice/2015/08/04/fact-sheet-president-obama-announces-new-commitments-investorscompanies

— 2018. President's Management Agenda, https://www.whitehouse.gov/wpcontent/uploads/2018/03/The-President\%E2\%80\%99s-Management-Agenda.pdf.

Wynne, M. 2016. "Lab-to-Market: Commercializing New Technologies by Exchanging Talent." Retrieved from https://obamawhitehouse.archives.gov/blog/2016/11/22/lab-marketcommercializing-new-technologies-exchanging-talent

Zucker, L. G., M.R. Darby and M. Torero. 2002. "Labor mobility from academe to commerce." Journal of Labor Economics, Vol. 20(3), pp. 629-660. 
ACT

AI

API

ARL

AURP

AUTM

CAP

CRADA

CTSA

DHS

DOC

DOD

DOE

DOJ

DTSA

e-NTR

EIR

ERC

FFMI

FFRDC

FLC

FNIH

FOIA

FTE

GAO

GDP

GOCO

GOGO

GPRA

IAWGBD

IAWGTT

${\mathrm{I}-\mathrm{Corps}^{\mathrm{TM}}}^{\mathrm{TM}}$

IP
Agreements for Commercializing Technology

Artificial Intelligence

Application Programming Interface

Army Research Lab

Association of University Research Parks

Association of University Technology Managers

Cross Agency Priority

Cooperative Research and Development Agreement

Clinical and Translational Science Awards

Department of Homeland Security

Department of Commerce

Department of Defense

Department of Energy

Department of Justice

Defend Trade Secrets Act

New Technology Reporting System

Entrepreneur-in-residence

Engineering Research Centers

Fast Forward Medical Innovation

Federally Funded Research and Development Center

Federal Laboratory Consortium for Technology Transfer

Foundation for the National Institutes of Health

Freedom of Information Act

Full-time Employee

Government Accountability Office

Gross Domestic Product

Government-Owned, Contractor-Operated

Government-Owned, Government-Operated

Government Performance Results Act

Interagency Working Group on Bayh-Dole

Interagency Working Group on Technology Transfer

Innovation Corps ${ }^{\mathrm{TM}}$

Intellectual Property 


\begin{tabular}{ll} 
IPA & Intergovernmental Personnel Act \\
IUCRC & Industry-University Cooperative Research Centers \\
ManTech & Manufacturing Technology \\
MBDA & Minority Business Development Agency \\
MEP & Manufacturing Extension Partnership \\
L2M & Lab-to-Market \\
L2M SC & Lab-to-Market Subcommittee \\
LANL & Los Alamos National Laboratory \\
LRM & Legislative Referral Memorandum \\
LWOP & Leave Without Pay \\
NASA & National Aeronautics and Space Administration \\
NIH & National Institutes of Health \\
NIST & National Institute of Standards and Technology \\
NPRM & Notice of Proposed Rulemaking \\
NSA & National Security Administration \\
NSF & National Science Foundation \\
NSTC & National Science and Technology Council \\
OECD & Organisation for Economic Cooperation and Development \\
OGE & Office of Government Ethics \\
OMB & Office of Management and Budget \\
OPM & Office of Personnel Management \\
ORTA & Office of Research and Technology Applications \\
OSTP & Office of Science and Technology Policy \\
OTA & Other Transaction Authority \\
PFI & Partnerships for Innovation \\
PHS & Public Health Service \\
PIs & Principal Investigators \\
PIA & Partnership Intermediary Agreement \\
PMA & President's Management Agenda \\
PRA & Paperwork Reduction Act \\
R\&D & Research and Development \\
RFI & Request for Information \\
ROI & Return on Investment \\
RTA & Research Transaction Authority \\
\hline
\end{tabular}


S\&T

SBA

SBIR

SPP

STEM

STPI

STTR

TEDCO

TRIPS

UC

USAID

USDA

USPTO

VCAT
Science and Technology

Small Business Administration

Small Business Innovation Research

Strategic Partnership Project

Science, Technology, Engineering, and Math

Science and Technology Policy Institute

Small Business Technology Transfer

Maryland Technology Development Corporation

Trade-Related Aspects of Intellectual Property Rights

University of California

United States Agency for International Development

Department of Agriculture

United States Patent and Trademark Office

NIST's Visiting Committee on Advanced Technology 
Appendix 1. Select Technology Transfer Mechanisms in Use by Federal Agencies

\begin{tabular}{|c|c|c|c|c|c|c|c|c|c|c|c|c|}
\hline \multicolumn{2}{|c|}{ Mechanisms in Use by Agency } & \multirow{2}{*}{$\frac{\text { OO }}{\text { D }}$} & \multirow{2}{*}{$\frac{\text { O }}{\mathrm{O}}$} & \multirow{2}{*}{\begin{tabular}{|c|} 
음 \\
X
\end{tabular}} & \multirow{2}{*}{\begin{tabular}{|c|} 
岁 \\
$x$
\end{tabular}} & \multirow{2}{*}{$\frac{5}{\mathrm{o}}$} & \multirow{2}{*}{\begin{tabular}{|l} 
吕 \\
$\mathrm{X}$
\end{tabular}} & \multirow{2}{*}{\begin{tabular}{|l} 
昏 \\
$\frac{1}{z}$ \\
$x$
\end{tabular}} & \multirow{2}{*}{\begin{tabular}{|l} 
邹 \\
I \\
$X$
\end{tabular}} & \multirow{2}{*}{ 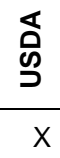 } & \multirow{2}{*}{\begin{tabular}{|l} 
D্ \\
کु \\
\end{tabular}} & \multirow{2}{*}{$\frac{\varangle}{x}$} \\
\hline Invention & Invention Disclosures & & & & & & & & & & & \\
\hline riolection & Patents & $x$ & $x$ & $x$ & $x$ & $x$ & $x$ & $x$ & $x$ & $x$ & $x$ & $x$ \\
\hline & Copyrights & & $X^{*}$ & & $x$ & & & $X^{*}$ & & & & \\
\hline \multirow{3}{*}{$\begin{array}{l}\text { Property } \\
\text { Transfers }\end{array}$} & Patent Licenses & $x$ & $x$ & $x$ & $x$ & $x$ & $x$ & $x$ & $x$ & $x$ & $x$ & $x$ \\
\hline & $\begin{array}{l}\text { Material Transfer Agreements } \\
\text { (MTA) }\end{array}$ & & $x$ & $x$ & & & & & $x$ & $x$ & & $x$ \\
\hline & Email MTAs & & & & & & & & $x$ & & & \\
\hline \multirow{3}{*}{$\begin{array}{l}\text { Research } \\
\text { Partnership } \\
\text { Agreements }\end{array}$} & CRADAs & $x$ & $x$ & $x$ & $x$ & $x$ & $x$ & $\mathrm{x}$ & $x$ & $\mathrm{x}$ & $x$ & $x$ \\
\hline & Other Transaction Authority & & & $x$ & & & & & $x$ & & & \\
\hline & Space Act Agreements & & & & & & & $x$ & & & & \\
\hline \multirow{5}{*}{$\begin{array}{l}\text { Resource Use } \\
\text { Agreements }\end{array}$} & Commercial Test Agreement & & & $\mathrm{x}$ & & & & & & & & \\
\hline & Facility Use Agreement & & $x$ & $x$ & & & & & & & & \\
\hline & Test Service Agreements & & & $\mathrm{x}$ & & & & & & & & \\
\hline & User Facilities Agreement & & $X^{*}$ & $x$ & $x$ & & & & & & & \\
\hline & Work-For-Other Agreements & & & $\mathrm{X}$ & $\mathrm{x}$ & & & & & & & \\
\hline \multirow[t]{2}{*}{$\begin{array}{l}\text { Educational } \\
\text { Agreements }\end{array}$} & $\begin{array}{l}\text { Educational Partnership } \\
\text { Agreements }\end{array}$ & & & $x$ & & & & & & & & \\
\hline & $\begin{array}{l}\text { Intramural Research Training } \\
\text { Award }\end{array}$ & & & & & & & & $x$ & & & \\
\hline \multirow{3}{*}{$\begin{array}{l}\text { Personnel } \\
\text { Exchange } \\
\text { Agreements }\end{array}$} & $\begin{array}{l}\text { Guest Researcher } \\
\text { Agreement }\end{array}$ & & $x$ & & & & & & & & & \\
\hline & $\begin{array}{l}\text { Industrial Staff Member, } \\
\text { Assignment, or Fellow } \\
\text { Agreement }\end{array}$ & & & & $x$ & & & & & & & \\
\hline & $\begin{array}{l}\text { Intergovernmental Personnel } \\
\text { Act }\end{array}$ & $x$ & $x$ & $x$ & $x$ & $x$ & $x$ & $x$ & $x$ & $x$ & $x$ & $X$ \\
\hline \multirow[t]{2}{*}{$\begin{array}{l}\text { Agreements with } \\
\text { Intermediaries }\end{array}$} & $\begin{array}{l}\text { Partnership Intermediary } \\
\text { Agreements }\end{array}$ & & & $x$ & & & & $x$ & & $x$ & & \\
\hline & $\begin{array}{l}\text { Other Types of Agreements } \\
\text { with Partnership } \\
\text { Intermediaries }\end{array}$ & & $x$ & $x$ & & & & & $x$ & & & \\
\hline
\end{tabular}

${ }^{*}$ Represents a partial capacity limited to certain parts of an agency or fairly restricted areas of use.

Original Source: Hughes, Mary E., Susannah V. Howieson, Gina Walejko, Nayanee Gupta, Seth Jonas et al. 2011. Technology Transfer and Commercialization Landscape of Federal Laboratories, Washington, DC: IDA Science and Technology Policy Institute. Updated based on more current information. 
Appendix 2. Comparison of SPP, CRADA, and ACT Attributes

\begin{tabular}{|c|c|c|c|}
\hline Attribute & Non-Federal SPP & CRADA & ACT \\
\hline Parties & $\begin{array}{l}\text { Laboratory* and } \\
\text { sponsor** }^{* *}\end{array}$ & $\begin{array}{l}\text { Laboratory* and } \\
\text { sponsor }^{* *}\end{array}$ & M\&O contractor* and sponsor \\
\hline Approval & $\begin{array}{l}\text { DOE approves each } \\
\text { SPP agreement, } \\
\text { including SOW and } \\
\text { contract terms }\end{array}$ & $\begin{array}{l}\text { DOE approves each } \\
\text { CRADA, including SOW } \\
\text { and contract terms }\end{array}$ & $\begin{array}{l}\text { DOE approves each statement of work, } \\
\text { plan to mitigate organizational conflicts } \\
\text { of interest, if applicable, and SPP-like } \\
\text { "checklist" but does not approve ACT } \\
\text { agreement with sponsor }\end{array}$ \\
\hline $\begin{array}{l}\text { Performance } \\
\text { guarantee }\end{array}$ & None & None & $\begin{array}{l}\text { M\&O contractor can commit to } \\
\text { negotiated schedule or performance } \\
\text { guarantee. Removes uncertainty for } \\
\text { sponsor and adds risk for } M \& O \\
\text { contractor. }\end{array}$ \\
\hline $\begin{array}{l}\text { Advance } \\
\text { payment }\end{array}$ & $\begin{array}{l}\text { Sponsor provides 6o- } \\
\text { day advance payment, } \\
\text { with some DOE- } \\
\text { approved } \\
\text { exceptions }\end{array}$ & $\begin{array}{l}\text { Sponsor provides 6o-day } \\
\text { advance payment, with } \\
\text { some DOE-approved } \\
\text { exceptions }\end{array}$ & $\begin{array}{l}\text { Negotiable; M\&O contractor ensures } \\
\text { funds are available before work is } \\
\text { performed, can begin work before } \\
\text { company transfers funds. }\end{array}$ \\
\hline Indemnification & $\begin{array}{l}\text { Sponsor indemnifies } \\
\text { both M\&O contractor } \\
\text { and government }\end{array}$ & $\begin{array}{l}\text { Sponsor indemnifies both } \\
\text { M\&O contractor and } \\
\text { government }\end{array}$ & $\begin{array}{l}\text { M\&O contractor indemnifies } \\
\text { government; sponsor indemnification is } \\
\text { negotiable. Reduces government risk, } \\
\text { enables sponsor risk sharing. }\end{array}$ \\
\hline $\begin{array}{l}\text { Intellectual } \\
\text { property }\end{array}$ & $\begin{array}{l}\text { Sponsor may elect title } \\
\text { to inventions with } \\
\text { certain restrictions }\end{array}$ & $\begin{array}{l}\text { Sponsor owns its } \\
\text { inventions; laboratory } \\
\text { owns its inventions } \\
\text { Undivided rights in joint } \\
\text { patents; sponsor has } \\
\text { option to license } \\
\text { laboratory rights }\end{array}$ & $\begin{array}{l}\text { Rights waived to "IP lead" designated in } \\
\text { deal negotiation (either sponsor or M\&O } \\
\text { contractor); in some cases, M\&O } \\
\text { contractor can retain rights to some or } \\
\text { all IP on M\&O contract termination }\end{array}$ \\
\hline $\begin{array}{l}\text { Government use } \\
\text { license }\end{array}$ & $\begin{array}{l}\text { Negotiable; } \\
\text { government may } \\
\text { retain only a research } \\
\text { license to intellectual } \\
\text { property }\end{array}$ & $\begin{array}{l}\text { Government always } \\
\text { retains a use license to } \\
\text { intellectual property }\end{array}$ & $\begin{array}{l}\text { Negotiable; government may retain only } \\
\text { a research license to intellectual } \\
\text { property }\end{array}$ \\
\hline $\begin{array}{l}\text { 3-Percent } \\
\text { Federal } \\
\text { Administrative } \\
\text { Fee }\end{array}$ & $\begin{array}{l}\text { Waived for state and } \\
\text { local governments, } \\
\text { nonprofit } \\
\text { organizations, and } \\
\text { small businesses }\end{array}$ & $\begin{array}{l}\text { Waived for state and local } \\
\text { governments, nonprofit } \\
\text { organizations, and small } \\
\text { businesses }\end{array}$ & Never waived \\
\hline
\end{tabular}

Source: Adapted from K. Edmonds, "Energy Department Answering President's Call on Commercialization,"

Energy.Gov News, October 28, 2011, http://energy.gov/articles/energy-department-answering-presidents-callcommericalization, and M. Paulus "Agreement to Commercialize Technology (ACT): A New Technology Transfer Mechanism," Oak Ridge, Tennessee: Oak Ridge National Laboratory, 2011.

* Laboratory refers to the organization that DOE shares an interest and risk with; M\&O contractor is the organization that operates the laboratory.

** Sponsor funds work performed by the laboratory; also referred to as partner.

*** DOE sometimes pre-approves certain model terms, which than allows the submission of a statement of work (SOW) without repeating an approval of the terms.

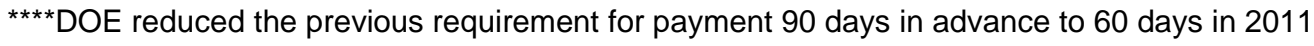

